\begin{abstract}
A CASE STUDY OF
THE IMPACT OF PROFESSIONAL HIGH SCHOOL INTERNSHPS ON COLLEGE AND CAREER READINESS
\end{abstract}

\author{
A Dissertation \\ presented to \\ the Faculty of the Graduate School \\ at the University of Missouri-Columbia \\ In Partial Fulfillment \\ of the Requirements for the Degree \\ Doctor of Education \\ by \\ STEPHANIE L. MOCZYGEMBA-AMAYA \\ Carole Edmonds, Dissertation Supervisor
}

MAY 2018 
(C) Copyright by Stephanie L. Moczygemba-Amaya

All Rights Reserved 
The undersigned, appointed by the dean of the Graduate School, have examined the dissertation entitled

\section{A CASE STUDY OF THE IMPACT OF PROFESSIONAL HIGH SCHOOL INTERNSHIPS ON COLLEGE AND CAREER READINESS}

Presented by Stephanie L. Moczygemba-Amaya

a candidate for the degree of Doctor of

Education and hereby certify that, in their

opinion, it is worthy of acceptance.

Dr. Carole Edmonds, Dissertation Supervisor

Dr. Timothy Wall

Dr. Julie Moore

Dr. Gregory Rich 


\section{DEDICATION}

To my family, my husband Damon, and my sons Cole, Jake, and Dillon, for their amazing support and encouragement! 


\section{ACKNOWLEDGEMENTS}

This has been an awesome, enduring, exciting, and difficult process. This experience is one I am proud of, as I am the first generation in my family to complete a doctorate degree. Lifelong learning is a passion in my life, and I am blessed to have had the privilege to make this educational journey. My family has always encouraged me to pursue my education. Their love, support, and encouragement have propelled me to continue this process when I have struggled. They inspired me to complete this dream. As this dream comes to fruition, I owe my success and motivation to each of them.

Thank you to Dr. Carole Edmonds for the continued and relentless expectations for me to finish this project. Your leadership and mentorship has been a valuable part of this experience. Thank you to my Jones Center staff, who encouraged me when I was working as a principal and completing this program. Thank you, Tara Kalis, my friend and my accountability partner. Thank you Sarah Haferkamp, my friend and colleague, for sharing my vision in public education. To all those who supported and encouraged me (Jeanette, Susan, Chris, and Jeff), thank you, thank you, thank you. I am truly blessed. 


\section{CONTENTS}

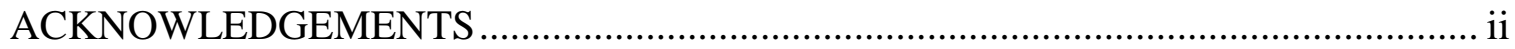

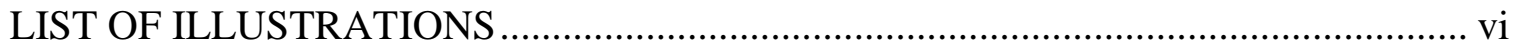

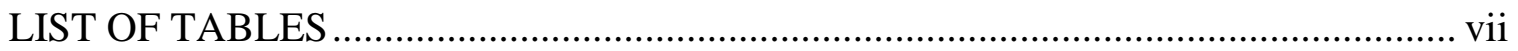

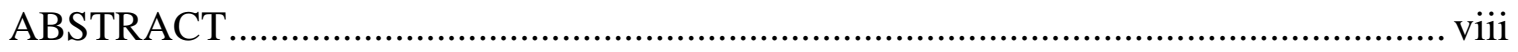

Chapter

1. INTRODUCTION TO THE STUDY .........................................................

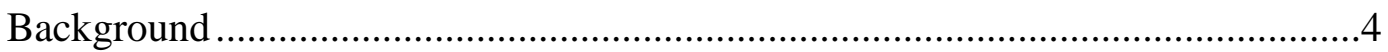

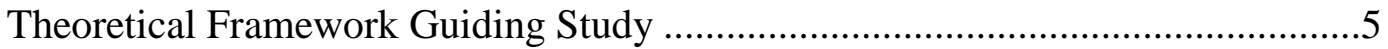

Problem Statement ................................................................................. 13

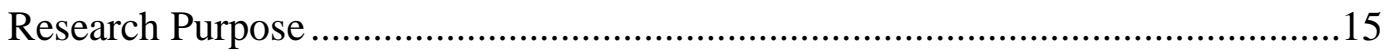

Research Question ................................................................................... 16

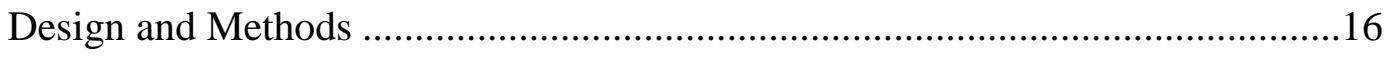

Delimitations, Limitations, and Assumptions..................................................19

Definition of Key Terms .......................................................................21

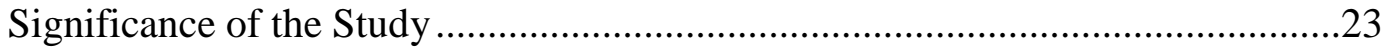

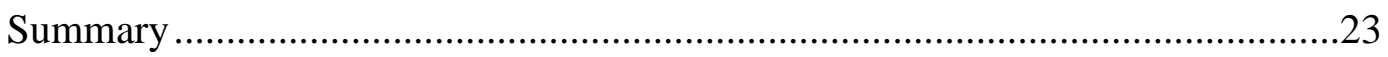

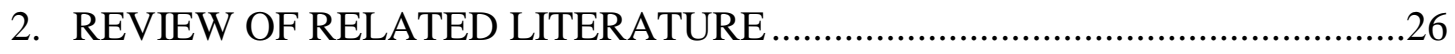

The Historical Development of the Comprehensive High School........................26

College and Career Readiness ................................................................42

The Continued Search for College and Career Readiness

in Public Education ..................................................................................44

High School Professional Internships .........................................................44 


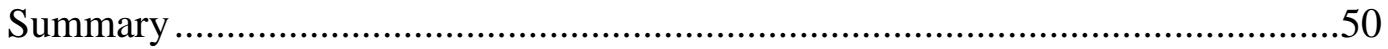

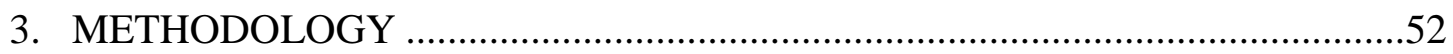

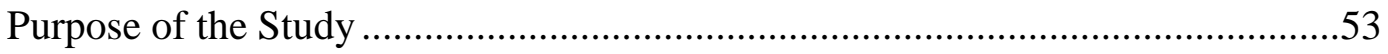

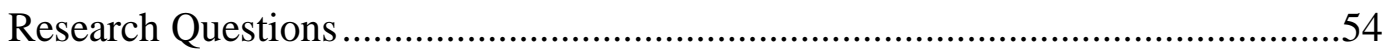

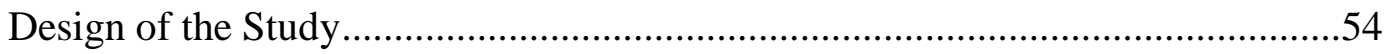

Delimitations, Limitations, and Assumptions......................................................64

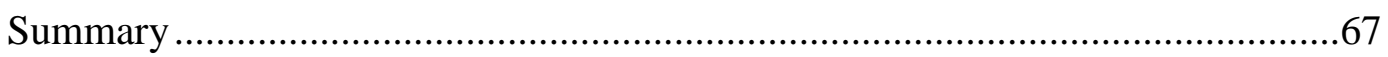

4. RESEARCH FINDINGS ……………........................................................

Setting of the Case Study ..................................................................................72

Relationship of Researcher to Research ..............................................................75

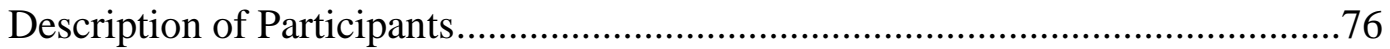

Interview and Focus Group Settings ................................................................78

Interviews and Focus Group ............................................................................79

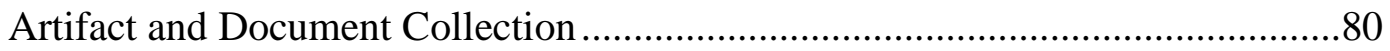

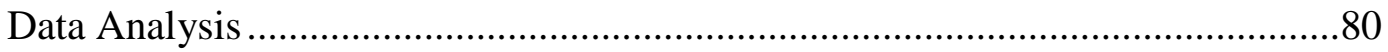

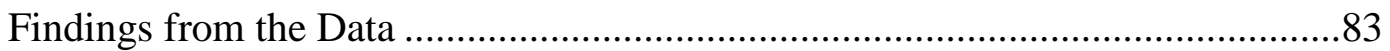

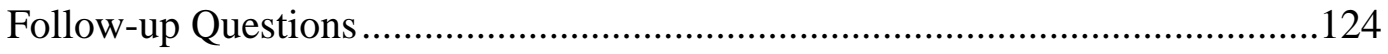

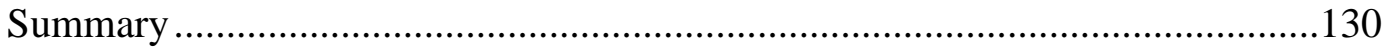

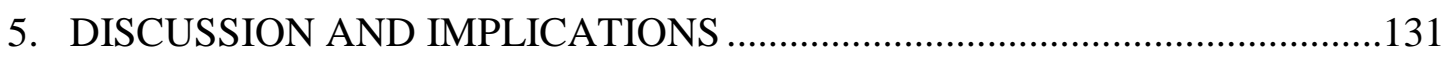

Discussion of Findings.................................................................................133

Michael Fullan’s Change Theory..................................................................134

Transformational Learning ...........................................................................137 
Professional (Soft) Skills

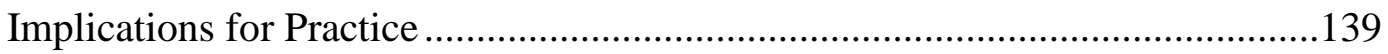

Implications for Future Research...................................................................149

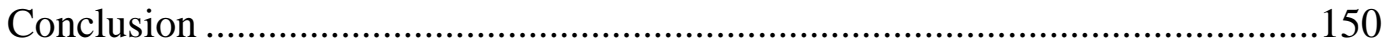

\section{APPENDIX}

1. Park Hill Approval Letter ...........................................................................152

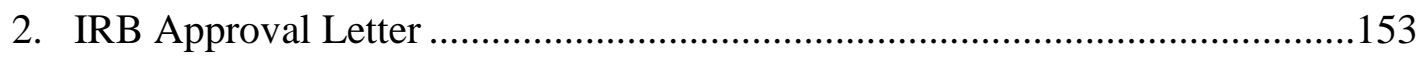

3. Letter from the Executive Director of Quality and Evaluation..........................154

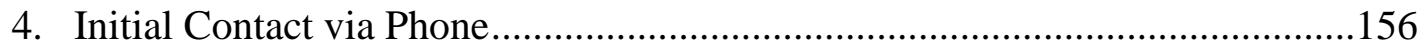

5. Informed Letter of Consent...............................................................................157

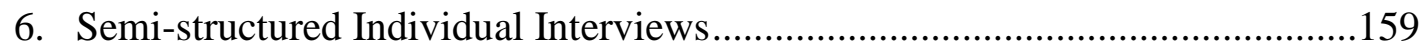

7. Focus Group Interview Questions ……………………................................160

8. Follow-up Phone Call Protocol.............................................................................161

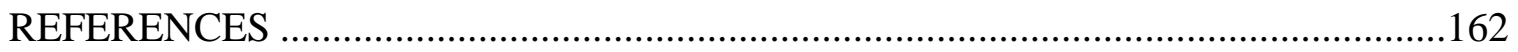

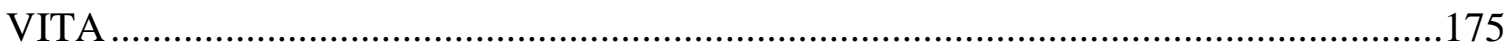




\section{LIST OF ILLUSTRATIONS}

Figure $\quad$ Page

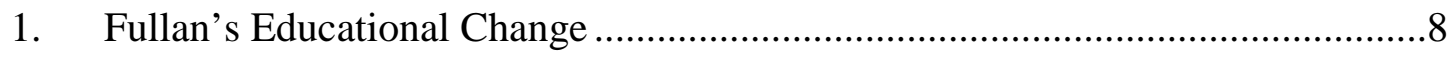

2. Characteristics of Change, Local Factors, and External Factors .......................10

3. Flow Chart Illustrating Fullan's Six Secrets of Change .................................13

4. Concept Map of the Impact of High School Internships on College and Career Readiness ........................................................................... 17

5. The Cardinal Principles of Secondary Education .........................................28

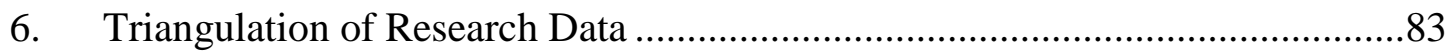

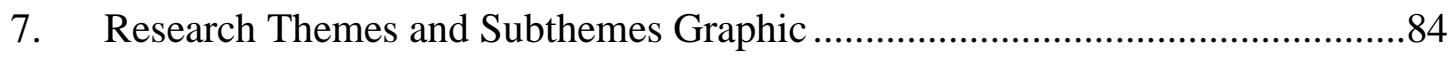

8. Transformational Learning Subthemes ......................................................91

9. Professional Experience Subthemes …...................................................100

10. Professional (Soft) Skills Learning Subthemes .........................................114

11. Post-secondary Learning Subthemes .........................................................124 


\section{LIST OF TABLES}

Table Page

1. Description of Student Participants .......................................................... 77

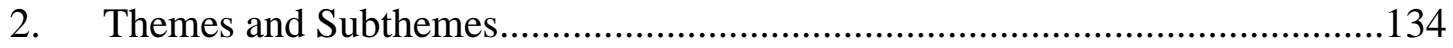




\title{
A CASE STUDY OF THE IMPACT OF PROFESSIONAL HIGH SCHOOL INTERNSHPS ON COLLEGE AND CAREER READINESS
}

\author{
Stephanie L. Moczygemba-Amaya \\ Dr. Carole Edmonds, Dissertation Supervisor
}

\begin{abstract}
The purpose of this qualitative case study was to explore the impact that professional high school internships have on college and career readiness. Educational systems, both public and private, continue to search for ways to improve postsecondary achievement. Research on this topic is limited; thus, this study aims to strengthen the body of literature and provide educational systems with insight and understanding of how high school internships impact postsecondary readiness. This study is significant, acting as a catalyst to encourage further research in educational systems where high school internships are used to cultivate professional skill building as a tool for successful skill retention in postsecondary experiences.
\end{abstract}




\section{CHAPTER 1}

\section{INTRODUCTION TO THE STUDY}

Increasing college and career readiness among graduates is a continued focus in public education. Understanding college and career readiness (CCR) and its implied impact on student achievement has become an ever more urgent issue as the job skills within the U.S. work force rapidly change (Owens, 2013). College readiness refers to a student's ability to complete education courses and standardized tests (Conley, 2012). Current research indicates graduating students, more now than ever, will require a postsecondary degree. Credentialing from a two- or four-year college/university will be essential to successfully obtain employment in the future.

In response to the increasing need for students to be college and career ready, many school districts have created initiatives to address postsecondary skills needed upon graduation. Undeniably, research shows college and career readiness is the key to successful outcomes for graduating students (ICF International, 2012). In theory, college and career readiness can be divided into three broad categories: academic preparedness, expected attitudes and behaviors (soft skills), and college and career knowledge. Academic preparedness focuses on K-12 alignment with standards, curricula, and assessments deemed college-ready. Districts must develop curricula that meet the college-ready standards while ensuring students fulfill the curriculum requirements prior to high school graduation. Assessment data must be used to track student progress and ensure early academic interventions are offered to students not making progress. Throughout the high school experience, students need guidance towards expected 
attitudes and behaviors. These soft skills focus on the attitude and behaviors students needs to be successful beyond high school. Optimally, schools create a college-going culture where students have opportunities to interact with adults and peers who build their college and career aspirations. This school culture supports college and career knowledge by assisting students in college planning and ensures students complete the critical steps for college entry. In order to ensure students receive the optimum support in the college application process, successful educational systems include families in a postsecondary planning partnership. Parents are given information to help them guide their child through the college enrollment process to provide a successful transition between high school and the postsecondary experience. The school acts as a resource to teach families about the financial aspects of college and how to help their child with college enrollment. Finally, schools provide students opportunities to explore different careers and assist them in aligning postsecondary plans with these interests (Samboldt \& Balestreri, 2013).

Despite the college and career readiness research available to school districts, many struggle to offer students opportunities to explore career interests outside the four walls of the classroom due to financial constraints (Stern, Dayton, \& Raby, 2010). Often, districts rely on college and career indicators that are easily implemented in the current school system: grade point average (GAP), attendance, ACT/SAT scores, advanced placement (AP) classes taken, and state standardized test scores (Junior Achievement, 2010). School districts are free to prioritize these indicators and develop action plans based on the needs of the students within each district (Mueller \& Gozali-Lee, 2013). 
College readiness refers to a student's ability to complete education courses and standardized tests. College readiness illuminates a student's ability to perform within the academic setting, completing a wide range of general education courses. Students participate in AP coursework, take the ACT or SAT exam, and collect a GPA as they complete mandatory classes for graduation (Conley, Drummond, de Gonzalez, Rooseboom, \& Stout, 2011). Career readiness implies students are able to complete courses specific to an occupational or certificate area. Students also participate in career pathway development, enabling students to enter a career with technical skills needed to adequately complete job expectations (Conley, 2012).

A great deal of research has been done on college and career readiness indicators, with the exception of high school professional internships. High school professional internships serve as part of a student's career pathway development. This experience allows students to participate authentically within the career pathway of their choice (Sullivan \& Baruch, 2009). Professional internships typically take place in a student’s junior or senior year. The length of time spent and high school credit earned varies, but overall students' academic and career learning is taking place in a community business where students earn school credit for their work contribution (Mourshed, Farrell, \& Barton, 2013). Offering experiences for students outside the comprehensive high school can be expensive, and often these programs are the first to be cut. High financial requirements, coupled with the lack of research on the effectiveness of internships, often leave students without optimal experiences to explore their career choices in the community (Mourshed et al., 2013). 


\section{Background}

In 2010 President Obama’s administration set goals for education reform. These goals stated all high school students would be college and career ready when they graduate from high school (U.S. Department of Education, 2010). The Obama administration created a blueprint for a re-envisioned federal role in education through the reauthorization of the Elementary and Secondary Education Act (ESEA). This revision created college and career ready standards and assessments to be used as a benchmark for all American students. Obama’s ambitious goal was by 2020 all graduating students would be on track to graduate from high school both college and career ready. Within the revision of the ESEA, common core standards in English and math would be created, national and state funding would be tied to student achievement, and national assessments would be created to measure student growth. This organizational shift at the national level, to equalize college with career readiness, was new dynamic in education. For the first time in history, school districts would be held accountable for achievement and career development (U.S. Department of Education, 2010).

Career exploration and planning was not a new concept to the comprehensive high school model. What was new was the idea that students would need opportunities to participate in real-world or authentic learning experiences to build transferrable skills after high school. There are not clear standards and benchmarks created in this area. Each school district interprets the standards and benchmarks in their own way. Most commonly, educational systems rely on Career and Technical Education facilities (both 
in and outside of school districts) to provide students with the essential technical, professional, and soft skills required for postsecondary work. Students can often earn college credit when participating in these classes. In some cases, these programs also include opportunities for job shadowing, professional mentorship, and internship experiences. For districts who rely on outsourcing these courses for students, this can be a very expensive endeavor with little state and federal aid (Bridgeland, Dilulio, \& Morison, 2006). High school internships in the community are free of charge, yet there is little research on the impact these internships have on the overall college and career readiness for students.

The term high school internship is not new in education. Historically, students have participated in job shadowing and work-based learning experiences. The term workbased learning encompasses any experience a student has outside the school setting while exploring a career path (Raelin, 2008). Work-based learning originated around 1906. During this time, vocational education was introduced, and learning both on and off school campus was a substantial component of the education system. Education embraced the vocational concept, and many different work-based programs have come and gone within the comprehensive high school (Maphosa, 2014).

\section{Theoretical Framework Guiding Study}

A theoretical framework is the theory used to guide the researcher and the research project (Asher, 1984). This framework is a set of ideas that helps to organize the research. This framework includes the following components: research question, a literature review, the methods, data collection, and analysis (Creswell, 2009). Within 
these frameworks, a social constructivist research paradigm was applied within a phenomenological study. The theoretical underpinning guiding this study was researcher Michael Fullan's Change Theory, which promotes an innovative approach to sustainable change in public education.

\section{Research Paradigm}

This phenomenological study used the social constructivists' worldview "to make sense of (or interpret) the meanings others have about the world” (Creswell, 2009, p. 8). The goal of this study was to "rely as much as possible on the participants' view of the situation being studied" (Creswell, 2009, p. 8). Therefore, the researcher will use an interviewing protocol with open-ended questions engaging participants to share their perception of the situation (Creswell, 2009). The researcher anticipates and expects complexity related to participants' views. The researcher understands participants have subjective views, producing varied meanings of what they experience (Creswell, 2009).

\section{Change Theory}

Change Theory was the theoretical framework guiding this case study. What is a theory of Change? Weiss (Connell, Kubisch, Schorr \& Weiss, 1995) defines a change theory as a way to identify if an initiative works. Connell and colleagues (1995) state change theory has several key elements that define the purpose, plan and the overall all progress of the initiative.

Educators often become theorists of change. They engage in mindful processes to research educational problems, create or develop ideas for fixing these problems, and implement change based on desired outcomes (Haslam, Reicher, \& Reynolds, 2012). A 
change theory offers a framework or structure that allows initiatives or reform actions to be predictable and measurable (Connolly \& Seymour, 2010). “A theory of change is a predicative assumption about the relationships between desired changes and the actions that may produce those changes,” (Connolly \& Seymour, p. 1). Simply put, Change Theory allows the prediction, "If $x$ happens, they I expect $y$ to occur." Change Theory brings into light what "cannot be seen" and guides and structures the implementation of the initiative (Fullan \& Boyle, 2013).

\section{Fullan's Change Theory}

Researcher Michael Fullan has spent the past 30 years focusing on educational change. Fullan's model focuses on the stakeholders who actively participate in the change process (Fullan, 2010). Ellsworth (2001) states in his findings that Fullan and Stiegelbauer's The New Meaning of Education creates a solid framework for leading educational change. This framework encourages change efforts ranging from students to national government. Fullan's work focuses on specific roles and strategies needed for various types of change agents (Fitzpatrick, n.d.).

According to Sturges and Rogers (1996), a change agent is someone who can influence other members of an organization to go in the direction of the values and mission of the organization. Rogers's research, recorded in his book Diffusion of Innovation (1962) makes a clear distinction between the change agent and the organization. These separate entities create a relationship through overlapping interactions between the two. Fullan's stance is very different, viewing every stakeholder participating in the change process is acting as a change agent. According to Ellsworth 
(2001), Fullan and Stiegelbauer assure change agents that "there is enormous potential for true, meaningful change simply in building a coalition with other change agents, both within one's own group and across all groups.”

\section{Fullan's Phases of Change}

Fullan (1993) states change is a constant journey and not a blueprint. Within change are uncertainties coupled with positive and negative forces of change. Change agents maneuver within these uncertainties, carrying the core of the change forward. Fullan comments that "effective change agents neither embrace nor ignore mandates. They use them as catalysts to reexamine what they are doing” (p. 24). Fullan’s (1999) theory provides a mental model for change agents capturing the conceptualization and multidimensional parts of educational change.

Fullan proposed four broad phases of change process, as shown in Figure 1: initiation, implementation, continuation, and outcome.

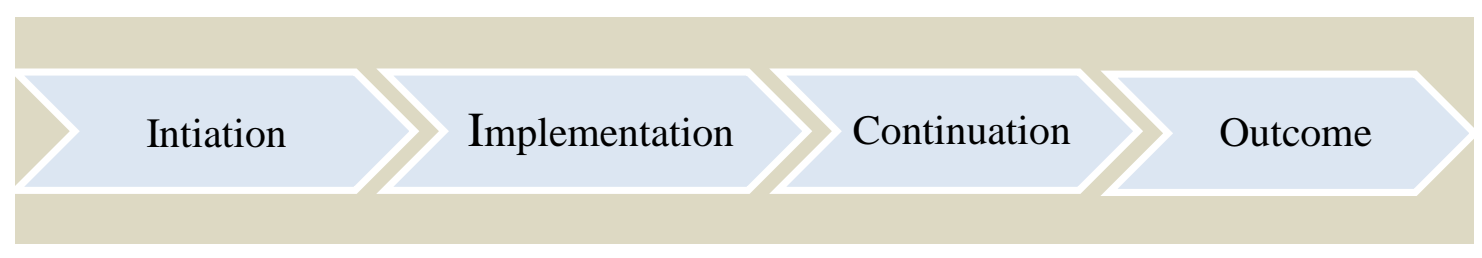

Figure 1. Fullan's Educational Change (Fitzpatrick, n.d.).

Initiation. Several factors impact the initiation phase. Four key elements are considered during this phase of a project. These influential factors include: existence and quality of innovations, access to innovations, advocacy from central administration, teacher advocacy, and external change agents. Fullan emphasizes the need for students, teachers and parents (users) to have input into the innovation process—existence and 
quality of innovations. These innovative process must be research-based, and the users must have access to quality innovations when action planning (Fullan, 1999).

For any educational change, advocacy from district/central administration is a key component in the initial stages of change. District or central office personnel must clearly communicate their support of the initiative-advocacy from central administration. District/central office personnel must be cognizant of including teachers in the initiation planning process — teacher advocacy. Teachers are more likely to accept a change when they have been part of the planning process and are able to interact with other professionals when learning about the change (Fullan, 1991).

Change agents who are external to the district, such as regional, state, and national roles are important in the initiation phase of a project-external change agents. These roles often stimulate change within local, state, and national political structures while connecting the educational system to local business partners. Much of the widespread reform is dependent upon the support and interactions between the educational system and the external change agents (Fullan, 2010).

Implementation. Fullan and Stiegelbauer (1991) identified three major factors affecting the implementation stage: characteristics of change, local characteristics, and external factors (government and other agencies). It is important to identify the different stakeholders at local, state, and federal government levels needed for buy-in. Communicating the components of change to each stakeholder is imperative. This communication should capture the details of the change and specific information each 
stakeholder should consider before committing to or rejecting the change effort (Fullan, 2012) (see Figure 2).

\section{Characteristics of Change}

Need for change

\section{Local Factors of Change}

The School District Board of Education

Principa

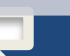

\section{External Factors of Change}

Other Agencies

Figure 2. Characteristics of Change, Local Factors, and External Factors (Fitzpatrick, n.d.).

Continuation. Continuation is vital to the survival of change. During this stage, a decision about the institutionalization of an innovation is decided based upon positive or negative reactions to the change. For the innovation to continue, these factors must be present: the change must be embedded into the structure of the educational system (through policy and a budget timetable). The change must have generated a critical mass of administrators or teachers who are skilled in the change, and the change must have established procedures for continuing the change with support and assistance (Fullan \& Smith, 1999). 
Outcome. Several perspectives must be present to support the achievement of a positive or successful change outcome. Change development does not end within the active initiation and participation phase. To the contrary, change continues to evolve as the innovation gains capacity through the interactions between the participants and the environmental change the innovation brings forth (ten Brummelhuis, 1995). The outcome of the innovation is present or evidenced by the skills, thinking, and committed actions of the participants. As participants cultivate ownership of the innovation, problems are overridden by new skills, thinking, and committed actions to the change (Fullan, 1993).

A significant amount of research has gone into understanding how to implement educational initiatives and sustain those initiatives through change theories. Many researchers have developed change models to help guide leaders through the change journey (Fullan \& Langworthy, 2014). Leadership is the key to planning, implementing, and successfully sustaining change in organizations.

\section{A Change Model for Leaders}

Fullan's book entitled The Six Secrets of Change is a change model for leaders. Fullan's book describes the essential lessons leaders must understand in order to survive and thrive when implementing change in today's complex educational system. Fullan's book reveals leadership traps and misconceptions of what is needed to bring about systemic change in organizations. Fullan emphasizes lasting change does not happen by chance, but instead relies on strategic planning and purposeful leadership (Fullan, 2011).

Fullan’s six secrets are based upon and embedded within Fullan’s change theory.

“There are five assumptions and criteria that underpin the set” (Fullan, 2011, p. 10). First, 
change theory is to be used to apply large-scale reform. The goal within Fullan's change theory is to change whole organizations and/or whole systems. Second, the six secrets have to be used synergistically. Each of the six builds upon the other five. Third, the set is heavily nuanced—meaning it takes a lot of personal energy, time, thought, and reflection to appreciate their significance and use. Fourth, they are emotionally embedded, building upon individuals' passion and positive energy to create motivation towards change. Fifth, "each of the six represents a tension or dilemma, which means you can err in one direction or another-the sophisticated leader holds them in dynamic tension” (Fullan, 2011, p. 11).

Every secret requires leaders to use integrative thinking (the ability to synthesize ideas) (Fullan, 2011). Leaders learn to think about thinking in a conceptual mental realm of understanding how to "hold two conflicting ideas in constructive tension" (Martin, 2007, p. 26). Martin (2007) conducted interviews with effective leaders from a diverse range of organizations and found a common cognitive trait. These leaders could hold two opposing ideas within their cognitive thinking without panic, anxiety, or picking one or the other idea. The leaders were able to "produce a synthesis that is superior to either opposing idea” (Martin, 2007, p. 52). Martin called this capacity “integrative thinking” and defined it as "the ability to face constructively the tension of opposing ideas and, instead of choosing one at the expense of the other, generate a creative resolution of the tension in the form of a new idea that contains elements of the opposing ideas but is superior to each” (Martin, 2007, p. 75). Each of the six secrets relies on this form of integrative thinking. Through the use of the set, leaders learn to take a "broader view of 
salient issues, try to figure out complex causality, visualize the whole while working on the individual parts and eventually arrive at a creative resolution of the tensions” (Fullan, 20011, p. 120). Fullan's change theory, coupled with his change model, creates a roadmap for leaders to follow when implementing systemic change. These ideas act as a guide for concrete planning, reflective implementation, and the development of essential leadership skills needed to sustain complex change within an educational system (Fullan, 2010) (see Figure 3).

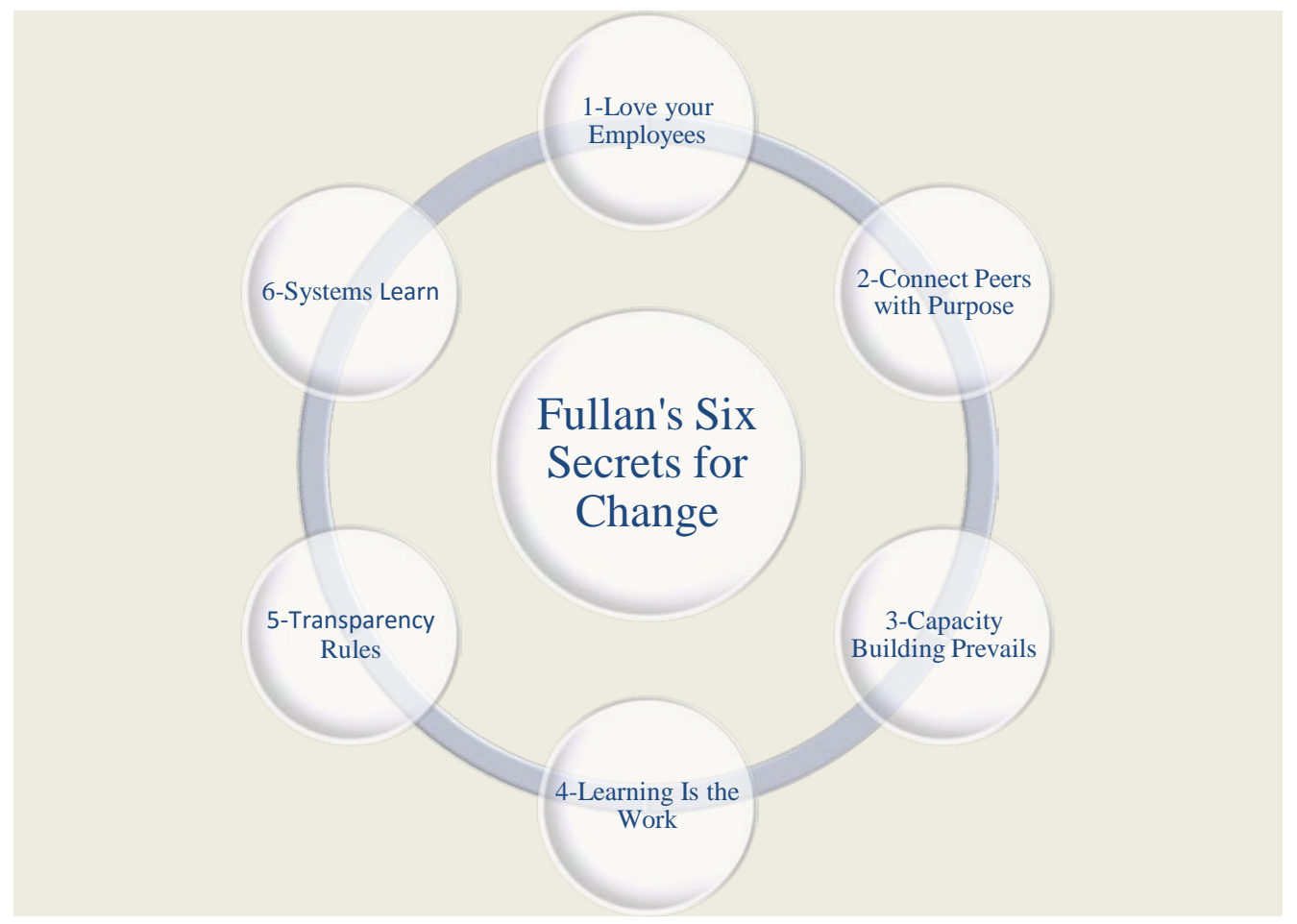

Figure 3. Flow chart illustrating Fullan’s Six Secrets.

\section{Problem Statement}

A cornerstone of U.S. education is to afford students free and public education for grades K-12. Students within this system are encouraged to pursue education and career 
paths according to individual strengths, interests, and personal passions. This autonomy and flexibility is the trademark of the U.S. education system. Within this system many students experience success, yet others struggle with a multitude of disadvantages (Hughes, Moore, \& Bailey, 1999). Many students experience the complexity of maneuvering within the public education system without career knowledge and workforce experience (Alfeld, Johnson, \& Watts, 2013). Many obstacles and academic challenges can derail their progress. Some students do not graduate from high school and others who do are not prepared for the transition from high school to the next life phases (Bentley University, 2014).

While national core academic standards are necessary, the Common Core Readiness Standards (CCRS) do not sufficiently prepare students for the transition from high school to postsecondary and the workforce (Bohrnstedt, Birman, Phillips, Osher, \& O’Day, 2013). Employers report students lack professional skills for entry-level jobs necessary to communicate and navigate current workforce expectations. Conclusions from the 2013 Oganisation for Economic Co-operation and Development (OECD, 2013) study showed:

by international standards, despite a relatively high level of education qualifications, the basic skills of adults in the United States are relatively weak. Unlike many other countries, there has been little sign of improvement in recent decades. The skills of youth people are little different from those of their parents. (p. 3)

With these deficits in preparation, many districts are left to design and implement programs that support professional skill building. U. S. employers define professional skills as important as academic skills (Bentley University, 2014.). Specifically, 
professional skills mentioned by employers as most valuable are oral communication, work ethic, collaboration, and critical thinking. Often professional skills were more valued by employers than the "knowledge of writing in English, the English language, mathematics, and science” (Casner-Lotto \& Barring, 2006, p. 12).

Many districts are in the process of initiating programs to address the need for professional skill building. Action plans for program initiatives are often deployed with limited research. Because the development of CCRS is recent, current research exploring these types of programs related to student postsecondary success is scarce. This study aims to explore the implementation of high school internships as a way to build students' professional skills. Schools have used various school-to-work programs over the past 25 years. How high school internships have impacted students' ability to be college and career ready (CCR) is still uncertain. Understanding the impact of these internships on CCR is imperative as districts prioritize their funds and resources to sustain programs created to build skills beyond the classroom (Northland Center for Advanced Professional Studies, 2015).

\section{Research Purpose}

The researcher's purpose is to explore the impact high school internships have on college and career readiness. School districts continue to search for ways to improve postsecondary student achievement. This study aims to determine whether internships serve as a valuable part of the high school experience that directly impacts college and career readiness through professional skill development. Additionally, this study will add and strengthen the body of literature to provide school districts with insight and 
understanding of how high school internships impact postsecondary readiness. This study is significant, acting as a catalyst to encourage further research within school districts where high school internships are used to cultivate professional skill building. Figure 4 shows a concept map of the impact of high school internships on college and career readiness created to guide the organization and work flow within this study.

\section{Research Question}

The guiding question for this research was: What impact do high school internships have on college and career readiness? After a review of the literature, other questions emerged based on the quality of the internship: level of immersion in the business, types of professional skills acquired, and number of transferrable postsecondary skills.

\section{Design and Methods}

A qualitative methodology was used to construct this study. A social constructivist view guided the study, coupled with a phenomenological approach to research utilizing a concurrent embedded approach. Social Constructivists use a qualitative methodology as a way to construct reality through the interpretation of complex ideas (Hatch,2002). They use the perceptions of others as a way to collect data that is translated into common themes, allowing the researcher to make "interpretations 


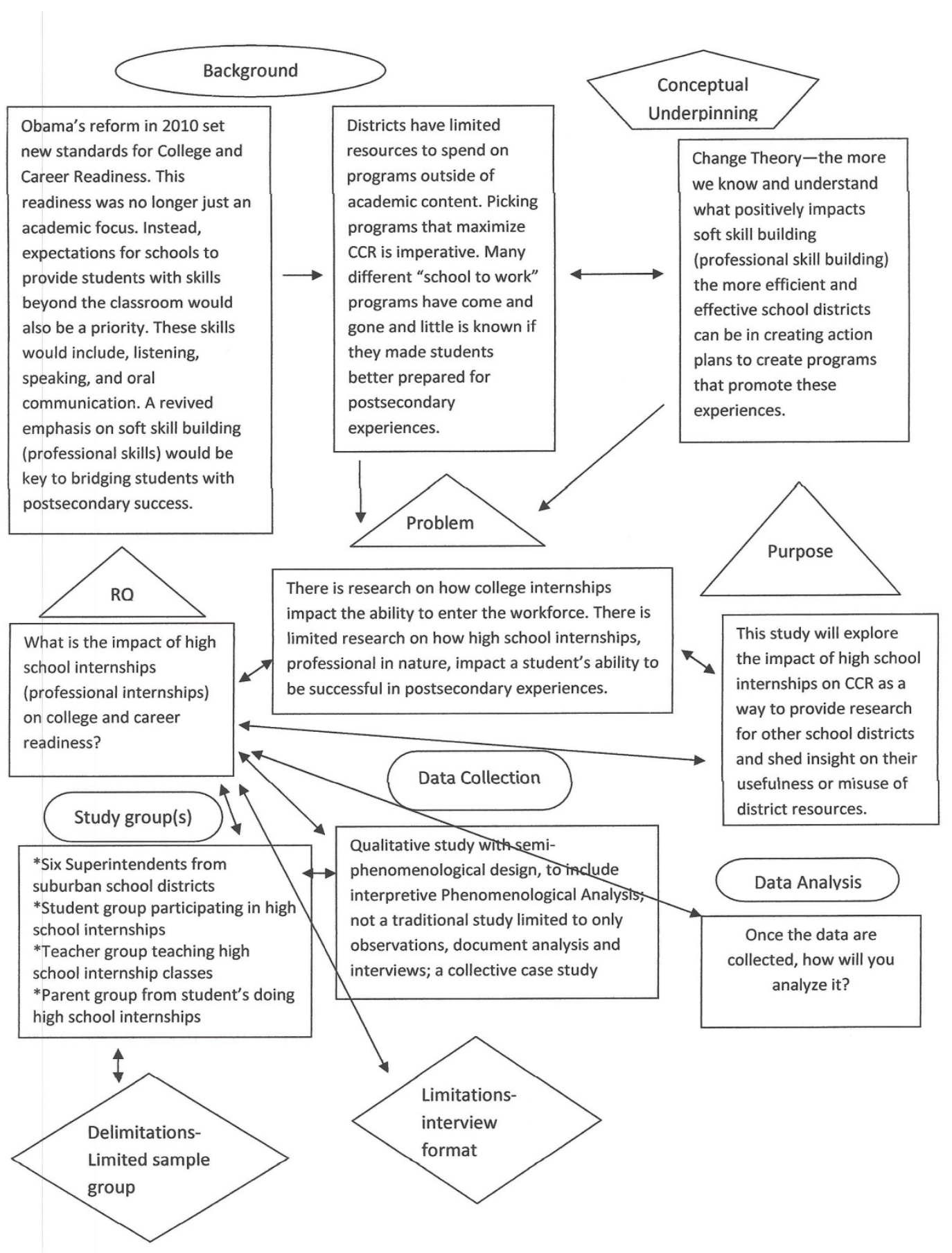

Figure 4. Concept map of the impact of high school internships on college and career readiness. 
of the meaning of the data” (Creswell, 2009, p. 4). These interpretations are then applied to the outcomes of the qualitative case study. The phenomenological research method was selected because of the importance of identifying and understanding firsthand phenomena of students impacted by high school internships (Commonwealth Association for Public Administration and Management, 2010). The instrument used in this study was a semi-structured interview to provide the researcher with a clear set of questions that provide reliable and comparable qualitative data (Smith, Flowers, \& Larkin, 2009). Other forms of qualitative data collection were used, such as observation and informal and unstructured interviewing, as an additional way to develop keen understanding of the research question.

Participants in the interviews were comprised of four groups: students, teachers, administrators, and parents. Participants were contacted by the researcher and asked to share their perceptions of how high school internships impacted college and career readiness for students. Data collection included a face-to-face interviews with openended questions. Data collection took place within the participants’ typical setting (Creswell, 2009). Follow-up interviews with each group took place as needed to allow for clarification from the original interviews (Stake, 2005). The researcher collected artifacts of the students' experiences in the internships that relate to the relevancy of the study. The interviews and artifacts were triangulated using open and axial coding to identify emergent themes, which will be analyzed to determine the impact high school internships have on a student's ability to be college and career ready (Hatch, 2002). 


\section{Delimitations, Limitations, and Assumptions}

This study's delimitations, limitations and assumptions are addressed in this section. The assumptions of this study are justified and explained throughout the study. The delimitations of the study are within the researcher's control in the study and narrow the focus of the study. The limitations of the study are the weaknesses of the study and provide explanation for future research (Creswell, 2009).

\section{Delimitations}

A delimitation of this study was the decision to create interview groups from six school districts that had current internship courses. Each school district participated in a consortium that provided internships for students or provided these internships within the district's current curriculum. The interview groups were purposely comprised of students, parents, teachers, and administrators - each representing a stakeholder group that had personally experienced a program providing high school professional internships

\section{Limitations}

A limitation of the study was the sample size. There was a small group of individuals representing each stakeholder group of students, parents, teachers, and administrators. Due to the small sample size, the researcher was cognizant that the results would be unique to this study. The researcher was aware the honesty and accuracy of the participant responses would be relative to each participant's personal perceptions of the experience. Results of this study would not be generalized to all students participating in high school internships (Commonwealth Association for Public Administration and Management, 2010). 


\section{Assumptions}

Qualitative research is designed to explain how individuals see and experience the world. “Qualitative approaches are typically used to explore new phenomena and to capture individuals’ thoughts, feelings, or interpretations of meaning and process” (Given, 2008, p. 10). As the researcher began this case study, the first assumption made was that all participants would be honest when discussing their perceptions of internships. The researcher anticipated an emergent qualitative design where the research changes based on the emerging themes and responses of the participants (Creswell, 2009). The participants would have both positive and negative aspects of their experiences to report, and the research outcomes cannot be predicted prior to entering the field and prior to data collection.

The second assumption hinged on the researcher's interpretive lens relating to the researcher's personal background in education. This background in education makes assumptions or predispositions that might bias the researcher. It was critical that the researcher created and conducted surveys that provided multiple opportunities for others to have input into the research question. This input allowed for multiple forms of “interpretive lenses” in the data interpretation (Creswell, 2009).

The finally assumption was that artifacts would exist at the internship sites and could be used to help determine the impact of high school internships on college and career readiness. These artifacts would be in the form of projects, written reflections, personal narratives, and business performance reviews. The artifacts would be identified once the researcher was in the field and had access to the internship sites: "the initial plan 
for research cannot be tightly prescribed, and all phases of the process may change or shift after the researcher enters the field and begins to collect data” (Creswell, 2009, p. 176).

\section{Definition of Key Terms}

To better understand the findings of the research, the following section is included to clearly define the key terms in direct relation to this study.

- Academic achievement - Academic achievement refers to a student's success in meeting both long and short term goals in their educational process. In the context of this paper, it refers to the successful completion of the requirements for earning a high school diploma (Reference, 2016a).

- Career exploration - Career exploration is the process of a student learning about personal interests and passions and how these traits relate to the world of work. Students often explore careers of interest throughout the K-12 educational process. High school students explore career paths in order to prepare for postsecondary planning. Postsecondary planning in high school typically includes college and/or career goal setting (Berkeley: University of California Career Center, 2016).

- Career and Technical Education (CTE) - Career and Technical Education provides students of all ages with coursework and/or programming that primarily focuses on technical skills, coupled with the knowledge and training needed to be successful in future career. There are currently approximately 12.5 million high 
school and college aged student enrolled in CTE courses or programs across the nation (U.S. Department of Education, 2016).

- College and career readiness (CCR) - College and career readiness is a set of skills a student acquires during high school determining the student is ready for college and/or a career upon high school graduation. CCR students are able to obtain a baccalaureate or certificate or participate in career pathway training programs successfully. Success is measured by the graduated student's ability to participate in entry-level jobs and/or college credit-bearing courses without the need for remediation or developmental coursework (Conley, 2012).

- Common Core standards - Common Core standards is a set of national standards created in English language arts/literacy (ELA) and mathematics. These high-quality standards provide learning goals for what a student showed know at each grade level (Common Core State Standards Initiative, 2016).

- Comprehensive high school - Comprehensive high schools are the most common form of public high schools in the U.S. These high schools serve all students as compared to other nations, where students are assessed and sorted into different high schools for different populations (Copa \& Pease, 1992).

- Educational systems - Educational systems typically refer to public education grades kindergarten through high school age. Schools or school districts are referred to as the smallest part of the larger, national, educational system (Mondal, 2016). 
- Postsecondary - Postsecondary refers to any education or training beyond high school. For example, postsecondary skills, postsecondary outcomes, or postsecondary planning (Reference, 2016b).

- Professional high school internships - Professional high school internships refers to an off-campus professional experience a high school student participates in that relates to a career path. These are unpaid positions, and students earn school credit and sometimes college credit during the internship. The organization provides continual mentorship and feedback to the student who is pursuing professional skill building (McLachlan, 2015),

- Soft skills - Soft skills are referred to as interpersonal skills and character traits that distinguish a person's ability to make relationships with other people ("Soft Skills,” 2016).

\section{Significance of the Study}

This study may be significant because it adds to the body of research helping to clarify if there is an impact made by high school internships on college career readiness. Although there are many different types of internship programs nationally, very few students have been invited to share their stories. This study will open up avenues for further research for programs seeking to improve individualized educational programming for students as a way to increase postsecondary success.

\section{Summary}

College and Career Readiness is a set of strategies created by the federal government to help close the achievement gap in public education. Many states have 
woven accountability measures around these College and Career Readiness Standards with expectations and accountability measures (Brand, 2009). National Common Core initiatives brought a new wave of accountability for academic expectations coupled with the College and Career Readiness Standards. These increased expectations for academic programming and postsecondary planning, with decreased revenue reimbursement, often leave districts with deflated innovative aspirations. This case study focused on a personalized form of education known as a high school internship. This kind of programming costs relatively little money; the main requirement is to acquire business and community partnerships within the school community. While many studies have looked at school to work programs and these programs’ outcomes, little research has been done to determine if personalized internship programs have impacted a student's college and career readiness. This study aimed to close this research gap by providing firsthand personal perceptions and artifacts from stakeholders fully immersed in a high school internship program.

A qualitative methodology was used to construct the design and methodology of this study. A social constructivist view guided the study, coupled with a phenomenological approach to research utilizing a concurrent embedded approach. Social Constructivists use a qualitative methodology as a way to construct reality through the interpretation of complex ideas. Participants in the interviews were comprised of four groups: students, teachers, administrators, and parents. Data collection included a face-toface interview with open-ended questions. Data collection took place in the participants' typical setting (Creswell, 2009). Follow-up interviews with each group took place as 
needed to allow for clarification from the original interviews (Stake, 2005). The researcher collected artifacts of the students' experiences in the internships that related to the relevancy of the study. The interviews and artifacts were triangulated using open and axial coding to identify emergent themes in order to understand if high school internships have an impact on students' college and career readiness (Hatch, 2002). Delimitation, limitations, and assumptions of this research study were identified. Suggestions were made for additional research in areas where personalized educational programs were developed to aid high school students in college and career readiness.

Chapter 1 covers the background of the issue under investigation, the stated problem, purpose of the study, and the research questions. Chapter 2 explores the literature in three main themes: (a) understanding the comprehensive high school and the evolution of curricular expectations; (b) defining the role of high school professional internships in industry settings; and (c) exploring the impact professional internships have on college and career readiness. The literature review uses the theoretical framework of change process. Three underlying concepts are explored in this case study: the historical perspective of the organization and growth of the comprehensive high school, the historical evolution of vocational education related to high school internships, and the key performance indicators mandated by the federal government for students to be college and career ready. The underlying concepts provide a lens for understanding and interpreting the literature reviewed. Chapter 3 presents a comprehensive discussion of the methodology and procedures of the study. Chapters 4 and 5 give the results and recommendations for further practice and research. 


\section{CHAPTER 2}

\section{REVIEW OF RELATED LITERATURE}

The purpose of this descriptive case study is to add to the body of knowledge about how high school professional internships impact college and career readiness. In order to understand the impact of these internships, it is important to review the historical perspective related to the evolution of the comprehensive high school, the development of high school internships, and the various perspectives related to college and career readiness. In addition, it is imperative to review the literature for themes that directly relate to the research question. Therefore, the literature is explored in three main themes: (a) understanding the historical development of the comprehensive high school and the evolution of curricular expectations; (b) understanding the evolution of high school professional internships in school/industry settings; and (c) defining college and career readiness indicators. This review of literature uses the theoretical framework of change theory as a lens to interpret the three main themes related to the research question. The examination of these themes provides an understanding and interpretation of the literature reviewed.

\section{The Historical Development of the Comprehensive High School}

The "comprehensive high school” is a term typically used in the United States to describe the most common form of secondary education (Keller, 1955). "Comprehensive high school” can also be defined as a school that serves the needs of all high school students. When compared to schools outside the U.S., the comprehensive high school was rare. Schools outside the U.S. typically sorted students into different high schools based 
on intelligence and/or social status (Tanner, 1982). The current comprehensive high school most commonly offers college preparatory courses, remedial instruction/interventions, and some type of vocational program(s) (Sherington \& Campbell, 2006).

\section{Early 1900s}

Historically, the first mention of the term "comprehensive high school” was in the early 1900s. In 1906, the Commission on the Reorganization of Secondary Education was appointed to create a new framework for secondary education. In creating this framework, the commission also created a new name to describe public high schools. Thus the term "comprehensive high school” evolved (Copa \& Pease, 1992). During this time (1918) in education reform, the commission proposed the Seven Cardinal Principles, which would serve as a guide to outline the purpose of secondary education. These principles included "health, command of fundamental processes, worthy home membership, vocation, citizenship, worthy use of leisure and ethical character” (Scherer, 2015, p. 1). The Cardinal Principles of Secondary Education were to serve as objectives for secondary education. Because creating clearer content was desperately needed due to a rapid increase in the number of students enrolling in secondary schools (Hammack, 2004), the commission decided that these objectives would segment subjects and the subject matter as a way to support the individual needs of all students. These changes created a new focus in education. For the first time, students' individual “differences, goals, attitudes, and abilities” were the key drivers when setting goals in the comprehensive high school (Scherer, 2015, p. 1) Although written more than 75 years 
ago, these fundamental principles still exist today in the current construct of secondary education (see Figure 5).

\begin{tabular}{|c|c|c|c|c|c|c|}
\hline Health & $\begin{array}{l}\text { Command of } \\
\text { Fundamental } \\
\text { Process }\end{array}$ & $\begin{array}{l}\text { Worthy Home } \\
\text { Membership }\end{array}$ & Vocation & $\begin{array}{l}\text { Civic } \\
\text { Education }\end{array}$ & $\begin{array}{l}\text { Worthy } \\
\text { Use of } \\
\text { Leisure }\end{array}$ & $\begin{array}{l}\text { Ethical } \\
\text { Character }\end{array}$ \\
\hline $\begin{array}{l}\text { Health } \\
\text { habits, } \\
\text { health } \\
\text { instructio } \\
\text { n and } \\
\text { physical } \\
\text { activities. }\end{array}$ & $\begin{array}{l}\text { Fundamental } \\
\text { processes in } \\
\text { writing, } \\
\text { reading, oral } \\
\text { and written } \\
\text { expression } \\
\text { and math. }\end{array}$ & $\begin{array}{l}\text { Development of } \\
\text { qualities that } \\
\text { make an } \\
\text { individual a } \\
\text { worthy member } \\
\text { of a family. } \\
\text { Taught through } \\
\text { literature, } \\
\text { music, social } \\
\text { studies and art. }\end{array}$ & $\begin{array}{l}\text { Student gets } \\
\text { to knows self } \\
\text { and a variety } \\
\text { of careers } \\
\text { allowing the } \\
\text { student to } \\
\text { pick a } \\
\text { suitable } \\
\text { career. }\end{array}$ & $\begin{array}{l}\text { Students } \\
\text { develop } \\
\text { awareness } \\
\text { and concern } \\
\text { for one’s own } \\
\text { community. } \\
\text { Students } \\
\text { should gain } \\
\text { knowledge of } \\
\text { social } \\
\text { organizations } \\
\text { and learn a } \\
\text { commitment } \\
\text { to civic } \\
\text { morality. }\end{array}$ & $\begin{array}{l}\text { Skills to } \\
\text { enrich } \\
\text { body, mind } \\
\text { and spirit. } \\
\text { Taught } \\
\text { through } \\
\text { music, art, } \\
\text { literature, } \\
\text { drama, } \\
\text { social } \\
\text { issues and } \\
\text { science. }\end{array}$ & $\begin{array}{l}\text { Students learn } \\
\text { personal } \\
\text { responsibility } \\
\text { and initiative. } \\
\text { The student } \\
\text { learns that these } \\
\text { seven principles } \\
\text { are not divided } \\
\text { into separate } \\
\text { categories; } \\
\text { instead, they are } \\
\text { interrelated. }\end{array}$ \\
\hline
\end{tabular}

Figure 5. The Cardinal Principles of Secondary Education (Scherer, 2015).

The Cardinal Principles provided curricular diversification to meet the growing needs of students. This was also the first document to address the integration of vocational education goals within the secondary education concept. This notion is validated in the Committee's statement, "it is only as the pupil sees his vocation in relation to his citizenship and his citizenship in the light of his vocation that he will be prepared for effective membership in an industrial democracy” (Wraga, 1994, p. 112). The committee's approach gave purpose to future attempts to integrate professional experiences in the secondary curriculum. The Cardinal Principles served as a guide for the next 75 years of education reform in America. 


\section{0 to 1940s}

The early 1900s created socioeconomic upheaval that spanned from the end of World War I through the beginning of World War II. During this time, the comprehensive high school began to take root. High schools were faced with large numbers of illiterate youths attempting to access America’s public school system. For example, in 1930, secondary enrollment of those aged 14 to 17 was 4.8 million, and by 1940, enrollment soared to 7.1 million (Copa \& Pease, 1992). The staggering number of illiterate students enrolling in the public school system prompted the need to rethink curricula nationwide. Thus, the beginnings of the "triad differentiation of curriculum into academic, vocational, and other [general curriculums]” appeared (Copa \& Pease, 1992, p. 12). This curricular differentiation allowed for student choice and personal insight and focused on individualized growth and achievement through coursework. These themes became so prominent in the framework of secondary education that they remain present in today’s comprehensive high schools.

\section{0 to $1960 s$}

During the 1940s and 1950s, larger societal contexts negatively impacted the comprehensive high school. After World War II, service men and women returned home, creating the baby boom that significantly increased school enrollments in 1950. Propaganda during the Cold War escalated fears. All these factors, as well as increased suburbanization, created a need for people to see themselves as individuals living in a larger society. Throughout the middle of the 1900s, these societal issues continued to mold the systematic framework and curriculum of comprehensive high schools. For 
example, in 1954 the Supreme Court ruled "separate but equal has no place in public education,” triggering the desegregation movement (Keller, 1955, p. 6). Although societal tensions grew, the comprehensive high school continued to focus primarily on educating youth.

Several studies during this time challenged the democracy of the comprehensive high school. The fundamental principle of a comprehensive high school is the notion of student democracy. Democratic education sees students as active participants in their education. Students are not merely passive participants taking in knowledge, but students who express their thoughts, act out their interests, and pursue their passions (Koliba, 2000).

Democracy begins with the philosophy that each student is unique, and these unique qualities cause each student to learn in different ways. Democratic education supports the individual development of each person. Democratic learning environments focus on caring communities that allow young people to learn about themselves, engage in activities that help them learn about the world in which they will someday work and live, and provide classroom curricula that engages them in becoming positive contributors to society. The idea of bringing democratic values to the comprehensive high school is not new. In fact, democracy in education has been talked about for more than 120 years by authors such as John Dewey, Marian Wright Edelman, and Margaret Mead. Each author built upon the notion that education should be a shared decision making process employing democratic processes such as self-directed learning, individualized project work, and student-chosen internships in the community. During the 1950s, 
vocational programs began to develop both inside and outside the comprehensive high school.

Author Franklin J. Keller (1955) raised the question related to vocational education, "What kind of education organization will give our children the kind of education they ought to have?” (Keller, 1955, pp. xiv-xv). Throughout his writing, Keller points out that "different students do have different (occupational) aspirations and there is no reason to evade recognition of this fact and ultimately there is nothing undemocratic about this diversity” (Copa \& Pease, 1992, p. 25). Keller challenged the democratic "status quo" in the comprehensive high school. Ultimately, Keller encouraged schools to move from "uniformity and sameness" to schools of choice and exploration for students (p. 25).

Joining in the effort to expand the comprehensive high school, James B. Conant, President of Harvard University from 1933-1953, conducted several studies on the comprehensive high school concept (Proefriedt, 2005). Conant’s definition, originally proposed by the President of Carnegie Corporation, reads:

[the comprehensive high school is] a particularly American phenomenon. It is called comprehensive because it offers, under one administration and under one roof (or series of roofs), secondary education for almost all the high school age children of one town or neighborhood. It is responsible for educating the boy who will be an atomic scientist and the girl who will marry at eighteen; the prospective captain of a ship and the future captain of industry. It is responsible for educating the bright and not so bright children with different vocational and professional ambitions and with various motivations. It is responsible in sum, for providing good and appropriate education, both academic and vocational, for all young people within a democratic environment which the American people believe serves the principles they cherish. (Klink Thomas, 2008, p. ix) 
Conant challenged high schools to create a well-rounded education that supported the notion of democracy in secondary schools. Conant insisted that comprehensive high schools would not only include academics, but should emphasize a focus on career exploration and development of those professional skills needed in that occupation (Copa \& Pease, 1992).

Following this definition, Conant created three main objectives to guide the continued development of the comprehensive high school:

[1], to provide a general education for all future citizens; [2], to provide good elective programs for those who wish to use their acquired skills immediately on graduation; [3], to provide satisfactory program for those whose vocation will depend on their subsequent education in a college or university. (Conant, 1959, cited in Wraga, 1994, p. 37)

Conant's study strove to answer the question: "Would it be possible to fill these three objectives within the same high school?” His study posed questions about the feasibility of the comprehensive high school concept. Conant also asked, "Is there a need for new specialized schools to provide separate vocational and college preparatory schools?”

Constant's study, encompassing 55 high schools in 18 states, concluded that no radical alteration of the structure of the American high school was necessary (Copa \& Pease, 1992), although he made 21 specific recommendations to improve the comprehensive high school model. Key suggestions covered the organization of the school day, which required programs for all students; developing the counseling system; requiring English composition for all students; creating individualized programs, programs for low learners and gifted learners and diversified programs for the 
development of marketable skills. Although Conant's work suggested making changes towards an even more comprehensive high school, he recognized the diversity of American schools. He urged schools to use the "bootstrap method of adapting the best from that which has been well tried and tested"-meaning schools needed to consider the local situation in order to make appropriate changes (cited in Copa \& Pease, 1992, p. 28). Conant's work served as a framework for the academic and vocational expansion of the comprehensive high school.

\section{0 to 1980s}

The 1960s and 1970s ushered in a concern for equal opportunity and equal access for all students in America (Tanner, 1982). President Johnson's war on poverty created a major focus on alleviating poverty in America's schools. Schools were expected to “attack problems of poverty and racial and ethnic discrimination” (Copa \& Pease, 1992, p. 30). With a heightened awareness of poverty came a heightened awareness of inequality. Gaps relating to inequality between urban and suburban schools began to be recognized during this time.

The "curriculum revisions and intellectual focus" during the early 1960s intensified the concern for equal opportunity (Copa \& Pease, p. 31). These revisions were not implemented evenly and typically benefited large suburban areas. The implementations of these revisions were criticized for "producing an irrelevant curriculum for the average and below average student” (p. 32). Research indicated that during this time period a considerable gap widened in the educational reform process. Hammond noted, for instance, "a considerable sized group of people were being 
bypassed from the benefits of educational reform” (p. 32). Despite great efforts to eliminate poverty from schools, research indicates that education did not help to change the socioeconomic status of each generation. Instead, poverty was being passed from "grandparent to parent to child” and a "rather stable culture of poverty existed” (p. 32). Social leaders began to refer to some low income urban areas as "social dynamite." This conclusion played out during the massive riots in Harlem (1964), Watts (1965), and in Detroit in 1967 (Hammack, 2004).

Faced with enormous socioeconomic and equity issues, education for students began to shift from the "subject matter to the learner and their learning problems as opposed to the discipline oriented subject matter specialists who had advocated and worked on the earlier curriculum revisions” (Copa \& Pease, 1994, p. 32). An emphasis began to be placed on teaching marketable skills to students who were not likely to go to college. This new focus on "marketable skills" caused a shift in the comprehensive high school. In conjunction with this shift, federal legislation was created to support students choosing not to attend college. In 1963 the Vocation Rehabilitation Act was passed, which would later have amendments in 1968 and 1976 providing "equality of opportunity” (Wraga, 1994, p. 80) for targeted populations of students who were identified as special needs learners. Similar legislative acts were passed to provide comprehensive high schools with guidance for improving educational opportunities for disadvantaged students (Wraga, 1994).

After public disenchantment due to the comprehensive high school's inability to meet the needs of all students over time, the National Commission passed the Reform of 
Secondary Education in 1973. The act would open new pathways for students to earn a diploma. Historically, passing this legislation would be the first time vocational interests were included in pathways to graduation. These pathways would include personal interests such as job apprenticeship programs as well as 32 recommendations for significant reform in the comprehensive high school. These recommendations would serve as a guide to engage more students in personal learning, which would be centered on personal interests helping to address "the mix of young people from inconsistent social backgrounds” (Copa \& Pease, 1992, p. 35). Opposition to this type of reform shifted the high school from a "comprehensive model” to a more "specialized" school model.

In 1976, the National Panel on High Schools and Adolescent Education issued a report entitled The Education of Adolescents. The introduction states:

An essential feature of the report...is the conviction that the high school has become over burdened and should share its responsibilities for youth with other agencies in the community, so that instruction and educational experiences can be provided both in the school and outside the school in the community itself. (Copa \& Pease, p. 37)

The report concluded that comprehensive high schools were no longer equipped to provide universal schooling for all youth. The panel found the complexity of student needs to be more than the comprehensive schools could handle. These complex needs included: (a) the younger age of puberty onset, (b) the distinct need for the separation between teenagers and adults in the school setting, (c) the lack of education for citizenship, and (d) a greater need for vocational education and experiences outside the classroom. Responsibility was placed upon the high school to fix society's ills, and there 
was a growing need for leaders of change in the governance of schools. The panel's suggestions to help elevate the comprehensive high school's burdens and create a more practical comprehensive education for students included eleven major reform recommendations, including “inaugurate participatory education for joint participation of adolescents and interested qualified adults, especially in the areas of education in the arts, vocational education,” and the establishment of small, flexible, short-term part-time schools (Copa \& Pease, p. 38). Shortly after these recommendations were made, many full-time and part-time specialized schools begin to evolve.

Between the late 1970s and the 1980s, many “school to work programs” begin to develop in the comprehensive high school and specialized schools. For example, education-related work service programs were created to allow students the opportunity to attend school part-time and work part-time. Typically students focused on core academic content in school, and their elective coursework took place in the community in a work setting. Other similar programs included: work/service opportunities through the facilities of the high school; curriculum created in schools to include basic vocational skills; emphasis on creating opportunities for students to learn about job opportunities and college entrance requirements through in-job placement centers or high school guidance counselors. During this time, critics say, the stratification of students in the public education system continued. In essence, this stratification created two paths-one towards college and one towards work (Hammack, 2004).

Shifting from the comprehensive high school model and creating specialized programs such as vocational education had consequences. From a historical perspective, 
Robert Hutchins stated, "the best education for the best is the best education for all" (Hutchins as cited in Noddings, 2013, p. 135). Hutchins implied that the best education is an education that is truly accessible and where every student receives the same quality education. The research on vocational education programs indicates educators turned to these programs for the "portion of the school population which they incorrectly and unjustly appraise[d] as being uneducable—only trainable” (p. 19). Research in this area also confirmed that a skills gap existed between students seeking vocational interests after high school and those planning to attend college. The need to close this identified skills gap has continued to drive educational reform efforts from the early 1980s to the present day (Wimberly \& Noeth, 2005).

\section{0s to Present}

In 1983, the National Commission on Excellence in Education issued their report entitled A Nation at Risk: The Imperative for Educational Reform. The report largely focused on schools setting high expectations and providing a "strong commitment to the equitable treatment of diverse populations” (p. 3). In the commission's report, allegations were made that a mediocre educational system was at risk of falling behind other countries in areas of science, math, and technology. As a result of fear that students were falling behind their foreign counterparts, reform efforts reestablished mandatory credits in English, mathematics, science, social studies, and computer science as a requirement for graduation (Copa \& Pease, 1992).

School curriculums have become homogenized, diluted, and diffuse to the point that they no longer have a central purpose. In effect, we have a cafeteria style curriculum in which the appetizers and desserts can easily be mistaken for the 
main courses. Students have migrated from vocational and college preparatory programs to "general track" courses in large number. (p. 42)

The commission's report was pointing towards a more focused curriculum that ensured all students were, in fact, receiving the core components of education. The comprehensive high school was to ensure all students were receiving common core content, thus retracting previous models present in the early 1970s and 1980s. Within days of the commission's report, the Task Force on Federal Elementary and Secondary Education Policy released their findings. Their report expressed concerns about students leaving school without the essential learning skills and self-discipline needed to be successful beyond high school (National Commission on Excellence in Education, 1983, p. 43). The report exposed the skills gap between vocational and college-bound students. This exposure pressed the issue of raising expectations for all students in order to appropriately compete with advancing skills needed in the industry. "In essence, the skills that were once possessed by only a few must now be held by the many if the United States is to remain competitive in an advancing technological world...equality and excellence are not mutually exclusive objectives" (National Commission on Excellence in Education, 1983, p. 43).

The skills gap continued to grow between students seeking employment and those preparing for college and primarily impacted minority students. The largest concentration of students resided in urban communities. Therefore, urban schools were the most impacted by the skills gap. The federal government mandated that states define and provide equitable access to education through the comprehensive high school in order to close this achievement gap. This is reflected in the summary statements in the task force 
report: "What is needed is a fresh approach by the federal government, which reflects the national concern for a better educated America and that strikes a reasonable and effective balance between quality and equality" (National Commission on Excellence in Education, 1983, p. 43).

Since A Nation at Risk, written more than thirty years ago, the comprehensive high school has been bombarded with a host of curriculum revisions and assessment expectations. Pieces of this educational reform are still impacting the comprehensive high school today (Bohrnstedt et al., 2013). This reform set into motion standards for learning in curriculum, higher rigor in coursework, and identification and planned interventions for the reduction of the achievement gap. It also created the preliminary standards for college and career readiness. Several movements of reform have transpired since 1983: Effective Schools, Accelerated Schools, and Schools within Schools; and nationally, the Education Goals movement. Each movement propelled reform towards the standards moment (Copa \& Pease, 1992). The 1990s standards movement later morphed into the 2001 reauthorization of the Elementary and Secondary Education Act, more commonly referred to as No Child Left Behind. Shortly after the No Child Left Behind (NCLB) revision, Race to the Top emerged, and the Common Core Standard Initiative followed shortly thereafter. Since the passage of these initiatives, the comprehensive high school has seen a drastic shift in the impact of federal mandates on education. With the passage of No Child Left Behind in 1994, the federal government moved from being a passive partner in educational reform to the primary decision maker in educational initiatives. 
By 1994, NCLB was revised to assess “adequate yearly progress” (AYP), requiring schools to meet proficiency targets on annual assessments. The outcome of these assessments would ultimately determine if schools were "meeting adequate yearly progress." Comprehensive high schools, for the first time in history, were deemed successful based on standardized assessment. Despite the identified historical achievement gaps, the federal government pursued a high stakes accountability process as the key measure for successful schools (Guilfoyle, 2006). As substantial problems began to surface concerning the accountability of NCLB's structure, another initiative surfaced to reward states for "creating conditions for education and innovation and reform” (U.S. Department of Education, 2009b). The Race to the Top Program (2009b) provided federal funds to states that demonstrated reform in four core areas: (a) adopting standards and assessments that prepare students for success in college and the workplace; (b) collecting data that can measure student growth and success; (c) recruiting and retaining highly qualified staff; and (d) turning around low-achieving schools. The program was promoted as an effort to ensure every student was "college and career ready." The law allocated $\$ 4.35$ billion in funds to help promote "educational equity” by “turning around the lowest-performing schools" (U.S. Department of Education, 2009b, p. 1). Race to the Top funds have continued to be reallocated since 2009 and were recently repurposed in the President's 2015 budget for education. Race to the Top provided another layer in the top-down effect of government reform in education. Although Race to the Top mentioned “college and career ready" standards, these standards were not clearly defined. Local districts were left to interpret what college and 
career ready actually entailed, and inconsistencies between local schools, districts, and states continued (Cawelti, 2006).

As Race to the Top began and NCLB continued to have unintended consequences in improving student achievement, Congress called on President Obama to "fix” NCLB. Congress charged the President with offering up concrete solutions in education that would adequately prepare all students for college and career readiness ("Reforming No Child Left Behind,” 2013). In March of 2010, the Obama Administration sent revisions to the Elementary and Secondary Act (ESEA) that addressed the issues created by NCLB (U.S. Department of Education, n.d). Under the new revisions, state accountability would be set higher for all students graduating from high school, including an expectation that all students would be college and/or career ready. The new ESEA act would raise standards for students in English language arts and mathematics, would develop assessments that align with college and career standards, and would ensure that educational programs are implemented through professional development and evidencebased instructional models (U.S. Department of Education, n.d.). This new legislation would create a national common focus on the equality of education. This legislation in equality would provide equal access in public education to all students. Students’ race, ethnicity, or college and career readiness would not limit their access to public education.

The ESEA would require all students, regardless of their postsecondary plans, to participate in the same curricular rigor and expectations. Comprehensive high schools are in the process of revising curriculum and ensuring both on and off campus programs meet the ESEA requirements. Clear expectations have been cited in this reform, including 
definitions for college and career ready. Many of the initiatives in high schools today exist to ensure that students achieve college and career ready standards.

\section{College and Career Readiness}

Education matters to Americans. Recent research indicates that education provides economic value for both working individuals and America as a whole (Carnevale, Rose, \& Cheah, 2011). Jobs created by 2020 are projecting to require highly technical skills, and in most cases, will require a minimum of a two-year degree. Unfortunately, college enrollment projections show there will not be enough college students graduating to fill these positions (Junior Achievement, 2016).

Even if the United States could produce more college graduates, studies show that these students would still be unprepared for the workforce. Large international studies and research by ACT in the United States revealed college graduates are not prepared and lack adequate skills to perform entry level positions (Mattern et al., 2014). This lack of preparedness is evident in both the PreK-12 public education and higher educational systems. The lack of readiness is evident in the number of remedial college classes and low graduation rates for college students. This data suggest that many students do not learn college and career readiness skills prior to graduating from high school (U.S. Department of Education, 2009b). Although national data show improved high school graduation rates, low college completion rates suggest too many students complete high school yet lack college and career preparedness (U.S. Department of Education, 2009b).

CCR indicators have traditionally been appraised at the high school level through core academics, such as high school grade point average, ACT/SAT scores, class rank, 
and the number of classes taken that are regarded as "rigorous coursework." This type of ranking has been challenged in the research. Current research suggests CCR should encompass a unique set of indicators that include both cognitive and non-cognitive abilities. These non-cognitive skills or soft skills (professional skills) provide opportunities for students to learn about his/her personality, explore career interests, and acquire intrapersonal skills needed to be successful in the workforce. The research regards soft skill/professional skill development as an integral part of preparing students for postsecondary success (Mattern et al., 2014).

States have struggled to define CCR. Districts have been left to define and develop their own CCR indicators. College and career readiness indicators have been defined on a long continuum ranging from narrow to broad, from one-dimensional to multidimensional. It is clear not all students need the same set of knowledge and skills to be successful in postsecondary experiences. Research has proven a more expansive multidimensional definition creates challenges to measure, but produces more accurate data at the state level and more actionable information for the student (Junior Achievement, 2016). The key to a more expansive definition is the overlapping of cognitive skills (content knowledge) with soft skill/professional skill development and career exploration opportunities (Conley, 2011).

\section{The Continued Search for College and Career Readiness in Public Education}

With the growing complexity of the world and the increasing demands of the 21st century workforce, there is little question that schools nationwide agree students should graduate from high school fully prepared for college and careers. From an academic 
perspective, college and career readiness means that a high school graduate has the academic knowledge and skills to qualify for and succeed in entry-level, credit-bearing postsecondary coursework without the need for remediation—or a high school graduate has the academic knowledge and skills needed to qualify for and succeed in the postsecondary job training or technical skill training necessary for their chosen career (e.g., community college, university, technical/vocational program, apprenticeship or significant on-the-job training) (ConnectEd, 2012).

To be college and career ready, high school graduates must have studied a rigorous and broad curriculum grounded in the core academic disciplines, and including other subjects that are part of a well-rounded education. Academic preparation alone is not enough to ensure postsecondary readiness, but it is clear that it is an essential part of readiness for college, careers, and life in the 21st century (Conley, 2011).

College and career readiness is the umbrella under which many public education and workforce policies continue to evolve. From high quality early education and strong, foundational standards in elementary school to rigorous career and technical education programs and college completion goals, college and career readiness is a unifying agenda to better define and establish expectations for postsecondary student outcomes (Achieve, 2016).

\section{High School Professional Internships}

Today's schools are faced with enormous challenges. These challenges require comprehensive high schools to adequately prepare students for postsecondary success. Postsecondary skills are increasingly complex as our technology-based economy and 
rapidly changing job market continue to evolve. Comprehensive high schools are asked to educate the largest and most diverse student body in history while meeting the increased academic achievement standards. The postsecondary college and career readiness target keeps moving as student and job market needs continue to diversify. Schools must sort through complex management systems, testing mandates, and everchanging curriculum standards.

Faced with complex challenges, schools continue to create innovative ways to meet the diverse needs of their students. Programs such as work-based learning opportunities have evolved over the last century as a way to close the gap between graduation and postsecondary experiences.

Work-based learning flourished through historical legislation dating back to the Smith-Hughes Act of 1917, which primarily targeted vocational reform in education and provided schools with funding to create vocational programs. This act grew out of political claims that urgent social and educational needs required vocational training in public schools. The act outlined skill-based training programs and claimed to respond to the labor force needs identified by industry (Hyslop-Margison, 2000). Proponents of this legislation believed this type of reform would provide structure for "non-academic "students into "required labor force roles for which they were most suited" (HyslopMargison, 2000, p. 2). David Snedden (cited in Hyslop-Margison, 2000), referring to the social-efficiency framework, believed educators should simply accept "the industrial social system and its accompanying class structure as an inevitable fact of life.” He later added, "the primary purpose of vocational education is to meet the labor force needs and 
prepare students with assumed limited intellectual capabilities for immediate employment in the industry" (Snedden, cited in Hyslop-Margison, 2000, p. 23). Others believed this type of legislation would only continue to stratify and widen the gap between the achieving and non-achieving students. John Dewey, the most vocal opponent of Snedden's stance, warned this type of educational reform "would validate class stratification by accepting an educational philosophy of social predestination” (Dewey, 1916/2015, p. 18). Dewey believed vocational education should be part of the comprehensive curriculum to provide students with opportunities to explore and develop a wide range of personal competencies. He argued students should be able to use their personal capabilities to enhance versus limit their future occupational choices (Hyland, 1993).

Vocational programs continued to develop without any major legislative mandates through the 1940s. Vocational education debates and reforms began to occur after the numerous social and economic problems brought about by World War II. In 1943, the National Education Association (NEA) featured a vocational topic in their 42nd yearbook. The NEA called on legislators to focus on vocational reform stating, "Vocational education was the greatest importance in American schooling” (Henry, 1943, cited in Hyslop-Margison, 2000, p. 9 ). NEA's report encouraged vocational programs to continue the employability skills programs and to add a supervised work experience component to facilitate the transitions between school and work.

The following year, NEA's Education and Policies Commission presented Education for ALL American Youth. This program supported the employability skills 
programs but strategically added the need for vocational education curriculum to remain broad-based and integrated into all content areas to "ensure school sensitivity to local labor markets.” The NEA's plan challenged Snedden's earlier beliefs that separate vocational programming needed to exist outside the comprehensive high school. In contrast, NEA's plan proposed that students would not be tracked into academic and vocational categories; they would remain in flexible, interrelated academic paths (Tanner \& Tanner, 1980).

Despite NEA's efforts to integrate vocational programs into existing curricula, political opposition subdued this attempt. A.E. Bestor, Jr. (1956, cited in Tanner \& Tanner, 1980), a critic of Progressive education, condemned any attempt to integrate vocational programming with academic content. Bestor pursued a derisive attack on vocational education reform, arguing that students should not be granted academic credits for vocational courses. He emphasized vocational courses should not be made available for students under the age of 17 . Bestor believed vocational education was heavily influenced by corporate power and politics. He saw vocational schooling as a catalyst in paralyzing "sound educational philosophy."

In any vocational school, including a school that provides training in pedagogy, students are rarely called upon to think of knowledge as the fruit of original inquiry. Knowledge is simply a fact, a body of established data, stubborn, inert, and unquestioned. (Bestor, 1956, cited in Tanner \& Tanner, 1980, p. 78)

Bestor continued to press on vocational programs, stating they would intellectually cripple students in the education system and "generate the belief in students that he/she cannot deal with any matter until he/she has taken a course in it” (p. 79). 
Vocational education philosophies continued to clash throughout the 1940s and 1960s. During this time, two clearly opposing arguments emerged. One group assumed all education is in fact vocational. In other words, traditional academic study prepares students for postsecondary experiences for occupations outside of trades (Tanner \& Tanner, 1980). Opponents argued vocational programming embedded within the curriculum diminished rigor in areas of critical thinking, inquiry, and problem solving (Hyslop-Margison, 2000). During this time, vocational programs continued to grow without any major federal mandates. Schools had autonomy in the creation of vocational programs. Schools would not experience any Congressional action until the early 1960s. Social and economic anxieties that sparked the Smith-Hughes Act of 1917 were once again looming in the 1960s. This period marked growing concerns in the area of "youth unemployment, urban decay, and Soviet success in space" (Gordon, 1999, cited in Hyslop-Margison, 2000, p. 4). Social and economic pressures, regardless of their validity in the classroom, had a major impact in American public education. Growing pressure to solve these societal problems created a since of urgency and perceived need for vocational reform, thus prompting President Lyndon Johnson to sign The Vocational Education Act of 1963. This legislation expanded the scope of vocational programming and influenced job training in schools. A much broader definition of vocational education programming was introduced, and federal funds were allocated to support the growth of vocational programs in schools. This act authorized federal funds to support residential vocational schools, work-study programs, research, training, and the development of other programs focusing on vocational and/or business education. This legislation would 
prove to be the most influential legislative action in vocational education (Tanner \& Tanner, 1980).

The concept of internships evolved from work-based learning opportunities provided in vocational education programs. "Internships provide students the opportunities to experience real world application. Students are able to interact within the workforce using classroom content while gaining professional and technical skills needed to successfully enter the workforce” (Linked Learning, 2012, p. 1). These work-based programs provide students opportunities to learn employability skills while working in a real world environment. Although these work-based programs have been in practice for centuries, their evolution and continued growth as an integral part of the education system began to take root in with the passing of the Vocational Education Act of 1963. It was not until the early 1990s, with the passage of the School to Work Opportunities Act, that traditional high schools received federal funding to support work-based programming in the educational system (Alfeld, Charner, Johnson, \& Watts, 2013). After passing this legislation to broaden student access to work-based programs in high schools, the effort "fell far short of its goal of extending work-based learning opportunities to a significant fraction of high school students” (Symonds et al., 2011, cited in Alfeld et al., 2013, p. 31). Continued federal investment in school-to-work programs declined during the No Child Left Behind era, but later resurfaced during the high unemployment rates from 2008 to 2012. Currently, there is a new focus on creating opportunities for students to experience work-based programs through internships 
experiences as schools search for ways to helps students better prepare for college and careers (Scott \& Sarkees-Wircenski, 2004).

\section{Summary}

This case study examined three underlying concepts explored in the research: the historical perspective of the organization and growth of the comprehensive high school, the historical evolution of vocational education related to high school internships, and the key performance indicators for students to be college and career ready mandated by the federal government. Research in each of these areas clearly demonstrated the need for a clear understanding in how to plan, cultivate, and implement change in educational systems.

Michael Fullan's work in Change Theory refers to change as a constant journey, not a blueprint. Within change are uncertainties coupled with positive and negative forces of change. Leaders learn to maneuver within these uncertainties, carrying the core of the change forward. Fullan's book entitled The Six Secrets of Change (2011) describes essential lessons for leaders to survive and thrive when implementing change in today's complex educational systems. Leaders provoking change must master the concept of Change Theory and possess Change Theory skills to successfully apply large-scale reform. Without these skills, leaders are lost to rigid, chaotic systems, unable to navigate a road map to sustainable change. Fullan's work creates a mental model for leaders capturing the conceptualization and multidimensional parts of educational change. Within this model, leaders learn the phases of change as a tool to implementing educational initiatives. As educators evaluate historical perspectives in order to apply new 
innovations, Change Theory tools are essential to the success of long-term, sustainable change. 


\section{CHAPTER 3}

\section{METHODOLOGY}

Increasing college and career readiness among graduates is a continued focus in public education (Mueller \& Gozali-Lee, 2013). Understanding college and career readiness (CCR) and the implied impact on student achievement has become an ever more important issue as the job skills within the U.S. job industry rapidly change (Wenger \& Owens, 2013). New research on the skills needed to be successful in the ever changing workforce will require, more now than ever, a postsecondary degree or credentialing from a two- or four-year college or university to successfully obtain employment (Meister \& Willyerd, 2010). In response to the increasing need for students to be college and career ready, many school districts have created initiatives to address postsecondary academic skills needed upon graduation. Undeniably, research has shown college and career readiness is the key to successful outcomes for graduating students (ICF International, 2012). Often, key performance indicators for college and career academic standards include GPA, attendance, ACT scores, AP classes taken, and standardized tests (Junior Achievement, 2010).

Little is known about the impact high school professional internships have on college and career readiness. Therefore this research study will strengthen the body of literature to provide school districts with insight and a better understanding of how high school internships impact postsecondary readiness. This study is significant in acting as a catalyst to encourage further research within school districts where high school internships are used to cultivate professional skill building. 


\section{Purpose of the Study}

In order to close the achievement gap in public education, national college and career readiness indicators were created by the federal government to ensure all students would have the skills needs to enter postsecondary colleges/universities or pursue a career without the need for skill remediation upon graduation (Conley \& McGaughy, 2012). For several years, public school systems have struggled to adequately identify college and career readiness indicators that adequately balance both academic and soft skill development (“Making Career Readiness Count,” 2014). Often, CCR indicators focus on only academic achievement and fail to offer soft skill development. Current workforce data reveal a highly unskilled workforce in the area of soft skill development lacking in the areas of team collaboration, agility, problem-solving, communication, and leadership skills (“A Guide to Career Readiness \& Employability Skills Lesson Plans”, 2015). As school districts strive to creatively and innovatively develop programs that emphasize soft skill development, more data is needed to adequately measure the impact these programs have on CCR indicators. For years, high school students have participated in various forms of professional internships with local businesses, experiencing hands-on, real world projects and experiences. Many students use internships to meet graduation requirements and are having to make decisions, in some cases, between taking AP/BP courses or internships. Often academic and career exploration programs become competitive in a comprehensive high school. In some cases, a significant amount of time can be allotted to these internship experiences. Understanding the impact of these professional internships and how these experiences impact college and career readiness 
will strengthen the overall body of knowledge. How impactful these internships are in providing students with professional experiences that are directly transferrable to college and/or career opportunities is the significance of this study. Therefore, the purpose of this study is to explore the impact high school internships have on college and career readiness. As school districts continue to search for ways to improve postsecondary preparedness, this study aims to determine whether internships serve as a valuable part of the high school experience that directly impacts college and career readiness through professional skill development.

\section{Research Questions}

The following overarching question was used to guide the research and address the purpose of this study:

What impact do high school internships have on college and career readiness? The overarching research question was designed to act as a general question to adequately explain the ideas and experiences of the participants in the study. The research questions directly relates to the central phenomenon of this study (Creswell, 2009).

\section{Design of the Study}

The design of this study was a social constructivist paradigm using a qualitative methodology. The study used a phenomenological approach to research using concurrent embedded triangulation. Social Constructivism was used in this study to understand how student participants interacted in their internship experiences. This was appropriate in this study, as the main philosophical assumption of social constructivists is to seek interpretation from interactions from others in the world (Creswell, 2009). Social 
constructivists often view the world from their own vantage point, making meaning from their own reality and experiences (Hatch, 2002).

Working from a social constructivist theory, the researcher strategically chose the qualitative methodology for two reasons. First, it allowed the study to focus on the perceptions of the participants being studied. In the study, participants were able to express their personal experiences and how those experiences directly impacted their thoughts, feelings, and actions within the context of their day-to-day lives. Creswell mentions in his text (2009) how important it is to rely as much as possible "on the participants' view of the situation being studied” when defining a person's personal experience. It is within the context of the participants’ personal view that the social constructivist can begin to create a social interaction that linguistically begins to define a person’s social story (Hatch, 2002).

Secondly, the researcher believes social constructivism allows for participants to gain meaning and understanding of "how individuals make sense of their everyday lives" (Hatch, 2002, pp. 6-7). It is in this understanding that individuals glean clarity and motivation to transform behaviors within the context of high school internships. If this type of behavior is present in the qualitative methodology, the researcher will inductively build "from particulars to general themes" allowing the researcher to validate or invalidate "interpretation of the meaning of the data" (Creswell, 2009, p. 4).

The case method was selected in this study because the focus on understanding how the perceptions of high school internships impact of college and career readiness is the key component of this study. The definition of a case study is to investigate "a 
contextualized contemporary phenomenon within specific boundaries” (Hatch, 2002, p. 30). In combination with a social constructivist theory, a phenomenology research method was applied to this study as an additional approach to seek understanding as to how "the essence of human experiences about a phenomenon as described by participants” impacts the experiences of the participants in this study (Creswell, 2009, p. 13).

Furthermore, the researcher used a concurrent embedded approach to triangulate the research data. In this study, the primary method of data collection included interviews, focus groups, and the review of collect artifacts. In order to adequately ensure a variety of methods were used to collect the data for this study, a variety of population samples were collected. As a way to further validity, the researcher used the embedded approach along with data triangulation (Creswell, 2009).

\section{Participants and Sampling Procedures}

The study's population was high school seniors over the age of 18, teachers, administrators, and a parent focus group. Reflective qualitative research suggests a small sample size with varies groups; therefore this follows the research guidelines (Creswell, 2009). Choosing the small sample size allowed the researcher to spend ample time "in the natural setting gathering information” with each of the various groups (Creswell, 2009, p. 178). The districts are all in close proximity in the Northland. These Northland school districts were specifically chosen because they all participate in the Northland Center for Professional Studies Program and have students participating in internships each year. This type of qualitative nonprobability-sampling method is purposely designed and used 
to gain insight and understanding into what is happening with something (Merriam, 1998). Therefore, the researcher selected a sample population where the most information, insight, and understanding about the phenomenon studied, "the impact of high school internships on college and career readiness” could be examined.

\section{Data Collection}

The focus of this study was the interpretation of a phenomenon. This section includes the following: data collection process, rationale for the data collection method, and how the method aligned with the research questions. Procedures for the interviews were addressed in these sections and included the following: potential risks, trustworthiness, protection of participants, and ethical considerations. The protocols used to collect artifacts were explained and the data were analyzed using an inductive process to thoroughly identify the phenomenon.

Data collection procedures. The researcher was required to request permission from the district's Executive Director for Quality and Evaluation to conduct research in several school districts where students were participating in professional high school internships (Creswell, 2009). The researcher received a written letter from the Director for Quality and Evaluation in order to fulfill the requirements of the Institutional Review Board (IRB) (see Appendix 1). Upon approval from the school district to complete the study and conclusion of the proposal defense, IRB approval was received (see Appendix 2).

The researcher sent an email to parents, students, teachers, and administrators on behalf of the Executive Director for Quality and Evaluation introducing the researcher 
and the study, and inviting them to participate in an interview (see Appendix 3). A follow-up phone call was made five business days after the letter as a courtesy to answer any questions about the context of the study and to confirm participant participation (see Appendix 4). During the informational phone call, the informed consent was discussed and then mailed to all participants (see Appendix 5). The informed consent outlined the details of the interview session. Participants would participate in an initial interview for approximately one hour, allowing for the collection of additional artifacts, then participate in a short follow-up interview. In the consent form, the participants' rights were addressed, highlights of the significance of the study were given, and the researcher explained the assurances and measures in place to protect confidentiality. Participants were informed that all data collected during interviews would remain confidential and they could refuse to answer any questions at any time. All participation was voluntary, and participants could withdraw from participating in the interview at any time. The informed consent had two signatory lines: one for consent to be audio-recorded and one for general consent for participation. All participants were asked to provide artifacts that related to the high school internship experience, as qualitative research provides the opportunity to collect data from the participants’ setting (Creswell, 2009). Artifacts enhanced the understanding of the social phenomenon under investigation, providing the researcher with additional opportunities to reflect and analyze external constructs influencing these participants’ experiences (Hatch, 2002).

Interviews and focus group. The informal interviews in this study, lasting no more than one hour, provided the primary method of data collection in this qualitative 
study with a phenomenological design (see Appendix 6). In conjunction with this study's interviews, the researcher held a formal, semi-structured focus group that included parents of students who had participated in a professional high school internship (see Appendix 7). The data collection in both the interviews and focus group answered the main research question, "What is the impact of high school internships on college and career readiness?”

As the researcher worked from a constructivist point of view, informal interviews and focus groups served as a connecting point between the researcher and participants. Through these interactions, social constructs were discovered and explored as a way to make meaning and discover influences within the context of high school internships (Hatch, 2002). A semi-structured interview method was followed during the interview sessions and the focus group (Smith, Flowers \& Larkin, 2009). Questions followed an open-ended format in order to gain a deeper understanding of the participants experiences, allowing each participant their own scope and pace of reporting (Seidman, 2006). Finally, each interview and the focus group were audio-recorded and the researcher took notes as a cross reference for accuracy when working with transcriptions.

The researcher provided each participant in the individual interviews with a half hour follow-up, as well as with the focus group members, to ensure trustworthiness within the interview process (see Appendix 8). Participants were provided an opportunity to check for accuracy in the researcher’s reflected transcript and artifacts. Furthermore, participants were provided additional follow-up questions relating to themes emerging 
from initial data coding and analysis to ensure interviews had reached proper saturation in answering the research question (Fusch \& Ness, 2015).

Documents. Artifact documents and records were used to further strengthen the study. These items were provided by participants and were used to clarify perceptions of participants in the study. Creswell (2009) explains this type of data provides a different type of vocabulary or words for the environment in which the participants are interacting. Creswell also says this type of data brings validity to a study, as it "represents data which are thoughtful in that participants have given attention to compiling them” (2009, p. 180).

Human subjects protection and other ethical considerations. The Institutional Review Board (IRB) exists to provide "protection against human rights violations" (Creswell, 2009, p. 89). The IRB assessed the risk to participants in this study. Prior to data collection for this study, the researcher presented a proposal to the IRB with information that contained specific information about the procedures and participants to the campus IRB for review and approval. After deciding the degree of risk and providing the required documentation for interviewing students, IRB permission was granted. As per IRB protocol, the Informed Consent Letter included the following components: an explanation of the study and the risks (if any) to the participants, guarantee of confidentiality to participants, and the right to refuse any questions and/or withdraw from participation (Creswell, 2009). The researcher assured both the signing off for the audiorecording and the Informed Consent Letter took place prior to any initial interviewing began. Confidentiality was ensured throughout the study. IRB provides clear guidelines in protecting participants' confidentiality. IRB states researchers can increase participant 
confidentiality by providing the use of pseudonyms and by archiving data by type (interview, survey, artifact) and not by participant. Each of these strategies were used throughout the study. Only the researcher had access the data collected during the study. The researcher would discard the data seven years after the completion of the study (Creswell, 2009). The interviews took place at the school district's main office; artifacts were provided at the discretion of each participant. Finally, a follow-up interview was provided to each participant to review the initial interview transcripts and to provide any feedback or clarifying comments as necessary.

\section{Data Analysis}

Inductive data processing takes place during phenomenological research. It is within this inductive data processing that the researcher begins to envision the general sense of the phenomenon described by the participants. These perceptions are both described and shown through artifacts. Each participant conveyed his/her perceptions of how internships impact high school college and career readiness. Two stages occurred during the data analysis phase. First, raw data were created through interviews. These interviews were transcribed and analyzed independently of each other. The researcher reviewed the transcriptions for identifiable patterns, repeating or reoccurring patterns for possible themes. This activity provides an inductive analysis of the data in which "findings emerge out of the data, through the analyst's interactions with the data" (Patton, 2002, p. 453). Using emerging themes is appropriate for a qualitative study using a phenomenological design. This type of systematic process provides an understanding of the research participants' experience. All transcripts were coded and analyzed together 
during this stage using an iterative codebook designed around the following: if a code persisted through each transcript, the code was kept; if it appeared in one transcript but not in all the others, it was eliminated but kept as a possible outlier (Creswell, 2009). Research participants were asked to reflect on the completed transcript that reflected the impact of internships on high school college and career readiness and make any clarifications as needed in their 30-minute follow-up interview.

\section{Role of the Researcher (Positionality)}

Increasing college and career readiness among graduates is a continued focus in public education. In response to the increasing need for students to be college and career ready, many school districts have created initiatives to address postsecondary skills needed upon graduation. Often those skills are academic focused and do not include professional skill building (soft skills). Professional skills focus on the attitude and behaviors students need in order to be successful beyond high school. Despite the college and career readiness research available to school districts, many struggle to offer students opportunities to authentically explore career interests outside the four walls of the classroom (Stern, Dayton \& Raby, 2010). A great deal of research has been done on college and career readiness indicators, with the exception of high school professional internships. High school internships serve as an experience that has the potential to shape the avenue a student will take past high school. Offering internship experiences for students outside the comprehensive high school can be time and labor intensive, and in some cases expensive. The researcher believes it is important to know the impact of these experiences on students and their college and career readiness. 


\section{Trustworthiness}

Shenton (2004) discusses strategies for ensuring trustworthiness in qualitative research. Shenton encourages researchers to considered these measures when pursuing trustworthiness in a qualitative study. Shenton refers to Guba's work, who proposes four criteria to aid in trustworthy data collection: “credibility (in preference to internal validity); transferability (in preference to external validity/generalizability), dependability (in preference to reliability), and confirmability (in preference to objectivity)” (Shenton, 2004, p. 64).

Credibility. Credibility is internal validity, confidence in the data findings. Credibility is achieved through a consistent adoption of an established research method as mentioned in this chapter. Secondly, the researcher should become familiar with the culture of the participants prior to the data collection. This can take place through observations, research, or informal interactions. Third, the researcher must triangulate the data. This happens through taking into account findings from all the data collection methods. All data are combined and consistencies throughout the resources are generated. Results from these consistencies are evaluated in conjunction with the comprehensive account of the phenomenon. Credibility is ensured when characteristics of the research question are identified and then focused on through observation (Lincoln \& Guba, 1985, cited in Robert Wood Johnson Foundation, 2008).

Dependability. Dependability addresses the issue of reliability within the study. Dependability allows the study to be repeatable. This was accomplished through the use of an inquiry auditor. The person functioned to "provided an objective assessment of the 
project” and had no connection to the researcher or familiarity with the project (Creswell, 2009, p. 192). The role of the research auditor was to check the connections between the research questions and the data collection and analysis.

Transferability. Trustworthiness is demonstrated through transferability. This happens through shared data analysis that is applied to the context by accurately detailing and describing what is happening within the phenomenon (Lincoln \& Guba, 1985, cited in Robert Wood Johnson Foundation, 2008). This type of detailed analysis comes from the researcher's ability to accurately identify and report patterns of cultural and social relationships from a field experience into context.

Confirmability. Confirmability increases trustworthiness through the triangulation of data. This data triangulation reduces the effects of the researcher's bias in the study. The researcher used an audit trail to assure transparency throughout the research steps. Steps were taken to ensure all areas of the research project were clearly described in the following categories: note taking protocols, process notes, instruments for observation, raw data, and data reduction and analysis products.

\section{Delimitations, Limitations, and Assumptions}

All studies have limitations and assumptions. These factors are appropriate to every research topic and methodology. Limitations are weaknesses within the study and these are out of the researcher's control. Assumptions are those factors outside the researcher's control, but without these assumptions, the study would not have relevance (Hatch, 2002). 


\section{Delimitations}

There were several delimitations related to this study. First, the small sample size of the interviews and focus groups. The small sample size may not have adequately represented all the different perceptions of how high school internships impact college

and career readiness. The sample included only students, parents, and administrators from one geographical location and did not represent a stratified representation from the entire city. Secondly, this study was limited by setting. Observations took place in only five internship locations. The lack of sample size and lack of setting locations during observations could cause the researcher to misinterpret the phenomenon. Often phenomenological research does not comprise large sample groups. The lack of large sampling makes it difficult to generalize data information from that sample group. Finally, the subjectivity of the data collection made it difficult to suspend judgment or predispositions about the interactions and observations in the context of the phenomenon (Shenton, 2004).

\section{Limitations}

The research in this study was naturally limited by the design of the study. Participants provided detailed accounts of their experiences, yet these experiences were “filtered” through their personal views (Creswell, 2009). The researcher provided observations in the study. These observations may have been limited in their effectiveness by the researcher in these areas: (a) the intrusive nature of observations, the researcher engaging within the participant's environment (b) the researcher's skill level of conducting interviews in the field and (c) the researcher's personal biases during 
observations (Creswell, 2009). Unobtrusive data provided limitations as this data collection was not originally collected with the goals of this study in mind, and therefore may have misrepresented the phenomenon (Creswell, 2009).

\section{Assumptions}

There are several underlying assumptions in the methodology of qualitative studies. The fundamental philosophical assumption of qualitative research is that individuals make meaning or construct reality as they interact with the social constructs of the world in which they live (Merriam, 1998). This reality, when inserted into a qualitative study, is now subject to the personal filters and perceptions of the researcher. The researcher must be aware of their own perceptions during data collection. Researchers must strive to make meaning from the participants’ perceptions safeguarding the use of their own perceptions (Merriam, 1998). Additionally, qualitative research requires the researcher to be immediately responsive to the data collected. This responsiveness includes appropriate data analysis including deducting meaning from emerging themes. Qualitative research assumes the data collected were the participants' own thoughts, ideas, and words. In this research process, it is assumed the researcher worked toward a theory using an inductive progression building on information collected in the field (Merriam, 1998).

Although the risk potential was low in this study, there were potential risks present. Participants were able to opt out of any interview, focus group, or observation voluntarily at any time. Participants were able to opt out of any questions that might cause them discomfort or remove themselves from a focus group at any time. The 
researcher used pseudonyms for participants to help secure confidentiality. Although the research study was filled with rich, specific, and detailed information about the perceptions of high school internships on college and career readiness, information about the actual participants of the study was purposely limited and protected. Participant information (consent forms, demographic information, and raw data) was not stored by personal information, and instead was stored by type and held in a locked and secured file cabinet.

The researcher made several assumptions in this study. The first assumption was that participants in high school internships, parents, and administrators would be willing to participate in this study and have rich thoughts, ideas, and perceptions related to the research questions. The second assumption was within the researcher's own experience. The researcher works in a program that provides students with an internship experience and was exposed to both positive and negative outcomes from these internships. The researcher was biased in believing internships have the ability to be transformational in helping students in postsecondary planning.

\section{Summary}

The research process for this study was clarified to include the purpose of the study and to clearly define the research questions. The different parts of the methodology were described to include a universal paradigm. A clear explanation and justification for sample size and selected participants was discussed. The data collection process and analysis stages were described from beginning to end. This included how the data would be collected, stored, analyzed and reported. Key limitations, assumptions, and researcher 
positionality were discussed to ensure trustworthiness in the study. The results of the study will be explained in detail in the next chapter of the study. These results will include the identification of macro themes in the study.

As this study progressed and the researcher conducted the literature review, Michael Fullan's change theory model was applied to better identify the historical milestones of change, or lack thereof, in relation to the impact of high school professional internships on college and career readiness. The initiation and implementation of high school professional internships has developed over the past 50 years. Federal funding allotted for work-based programs in public education has continued the progression of professional-based internships over the past 20 years.

Fullan's (1999) change theory provided a mental model for change, capturing the conceptualization and multidimensional parts of educational change.

Two factors play a role in explaining the evolution of high school professional internships. These factors are the historical development of the comprehensive high school and the current advancement of the college and career readiness indicators. The historical review of the comprehensive high school revealed a long-standing system with very little sustainable change. Over the past 75 years, many educational reform movements were implemented in hopes of improved academic achievement for all students. However, often these reforms fell short of meeting the needs of all students, and school districts retreated to institutional norms that had been present for decades. Lastly, the CCR concept is currently in the implementation phase. Current research suggests lack of clarity and inequities in schools across the nation has posed a barrier for the 
institutionalization of this concept in public education. This study aims to understand how professional high school internships impact postsecondary success despite the challenges in measuring and ensuring academic achievement for all students. 


\section{CHAPTER FOUR}

\section{RESEARCH FINDINGS}

Improving college and career readiness continues to be a focus in public education. Understanding college and career readiness (CCR) and its implied impact on student achievement has become an urgent issue as the gap between high school learning and real-world application widens (Owens, 2013). In response to the increasing need for students to be college and career ready, many school districts create initiatives that encourage post-secondary skill building in the world of work prior to graduation. Part of this skill building provides students a focus on attitudes, behaviors, and mastery of "soft skills.” These soft skills are transferable skills needed to help students relate to a culture of work and interact successfully with others beyond high school.

A great deal of research has gone into understanding how soft skill building positively impacts college and career readiness (Achieve, 2016). As an avenue to provide students with opportunities to learn and develop soft skills, many districts are creating opportunities for students to engage in professional internships at the high school level. The term high school internship is not new in education. Historically, students have participated in job shadowing, internships, and work-based learning programs. Often students earn college credit when participating in these classes. For districts who rely on outsourcing these courses, this can be an expensive endeavor with little state and federal aid (Bridgeland, Dilulio, \& Morison, 2006).

Within the realm of high school internships, there is currently minimal research on how these internships impact college and career readiness. Professional internships 
typically take place during a student's junior or senior year. The length of time spent and high school credit earned varies, but generally students' academic and career learning takes place in a community business where students earn credit for their work contribution (Mourshed, Farrell, \& Barton, 2013). Offering these experiences for students can be a financial burden for school districts and often are the first programs to be cut. High financial requirements, coupled with the lack of research on the effectiveness on these internships, often leave students without optimal experiences to explore their career interests prior to a career or college experience (Mourshed et al., 2013). This researcher conducted a case study to determine the impact of professional high school internships on college and career readiness.

This chapter provides results from data analysis collected from ten student interviews, one administrator interview, four building principal interviews, one parent focus group, and a review of pertinent documents. The data from these sources were coded, organized, and analyzed to glean insight and address the research questions (Creswell, 2009). The following research questions were used to guide the study:

1. What experiences do internships provide in fulfilling graduation requirements and how have they helped you grow personally?

2. What soft skills (professional skills) do internships provide that cannot be provided in the traditional high school?

3. How do internships provide professional skills (soft skills) that can be used in post-secondary opportunities? 
4. Did your internship provide you with experiences that helped you decide on college or career plans or change your thoughts on what you wanted to do? If so, how?

5. What was the best part of your internship and would you recommend this experience to other students and why?

This chapter begins with a description of the setting/structure of student participants' high school professional internships and introduces the participants who were involved in the study. The findings in this chapter include patterns, commonalities, discrepancies found in the study, as well as any patterns/themes that emerged during the coding process. The findings from the data analysis are present in relation to the conceptual framework and the research questions. Themes from the data transcriptions are identified and discussed. An overview is given on how the data coding procedures were used to discover emerging themes, ending with a generalization that summarizes the case study findings. Examples of the data findings are woven throughout the chapter, including excerpts from individual interviews, the focus group, and any review of formal documents.

\section{Setting of the Case Study}

Students participating in these high school internships attended District A, a Midwestern suburban school district with approximately 12,000 students. Approximately 23\% of students qualify for free and reduced lunch. In 2015 the median family income in this area was around $\$ 68,000$ with approximately $7.6 \%$ of families living in poverty. There are 18 school buildings, a central office, and an underground facilities location. 
The buildings consist of ten elementary schools (K-5), three middle schools (6-8), three high schools (9-12), one day treatment facility (K-12), and one early childhood program (pre-Kindergarten). There were approximately 3,650 high school students in 2017, and 122 junior and/or senior high school students were participating in off-campus professional internships. These internships were offered off-campus in the business community. Most internships were within 15-20 minutes of the student's high school campus; however, eight students were traveling 25-30 minutes. Students were provided early release from their last block of the day (1:05 p.m.) and participated in 8-10 hours of internship time per week. This was a one-semester course, and students had the option to take the course all year (two semesters). Students earned a practical art elective from the high school and were eligible to receive up to three hours of a general elective college credit. Students were encouraged to provide their own transportation; however, the school district provided cab services for any student needing transportation. Students were expected to dress professionally within their internships, mirroring the attire of each internship site. The school district provided clothing assistance to students if needed.

Students filled out an application to participate in the internship program. This application was reviewed and students were matched with an internship experience that aligned with the personal career interest of each student. Only students who were on track for graduation were eligible for this program. Students were matched with a professional mentor in each of the internship sites. These mentors served as professional guides for students, helping to navigate students' questions, experiences, and ongoing reflection throughout the semester and providing professional networking beyond the high school 
experience. Internships were typically offered for one or two semesters during the student's junior or senior year. All programs allowed students to take an internship in both of their junior and senior year. Some programs offered internships for half the school day, and others offered internships during a 90-minute period (one block of the student's day). All internships provided students with six to eight hours of onsite internship for a period of 10 to 12 weeks. All programs provided mentorship and supervision to the students from a classroom teacher. Students met with their classroom teacher once a week on their school campus as "check ins," and teachers were required to visit the student's internship site on average twice a semester.

Students were provided anywhere from a four-week to sixteen-week "boot camp" as a professional skill-building course prior to beginning their internship experience. These courses provided students with soft skills such as professional dress, communication skills, teamwork, collaboration, and course work designed to help them make plans for the transition from high school to a career or college. Each student was provided a professional internship instructor who monitored, observed, and provided feedback, in conjunction with their onsite mentor, to the student throughout the semester. Students huddled with the instructor once per week to debrief, reflect, and participate in ongoing professional skill building. In all programs, students were expected to complete online coursework throughout the semester in addition to meeting the six- to eight-hour internship requirement. The coursework was designed to enhance the internship experience. Part of this coursework was an end of semester capstone project. This project was presented to the business partner and the community as an authentic demonstration 
of the student's mastery of professional skills. Student grades were based on a combination of professional skill mastery during internship, online coursework, and the culminating capstone project.

\section{Relationship of Researcher to Research}

The researcher is an employee in District A and is currently working in a program that provides high school professional internships. The researcher has been employed by District A for the past eight years and has worked in this district as a building principal and currently at the district office level. The researcher has been in public education for the past 24 years serving as a school social worker (6 years), school counselor (6 years), social studies teacher (4 years), building principal (4 years) and a district administrator (4 years). At the time of this study, the researcher was leading a high school internship program. Due to this professional role, it is assumed all parties involved in this study worked contentedly together to determine the impact professional high school internships were having on college and career readiness for students in District A.

Due to the researcher's current role in securing internship opportunities for students in District A, the researcher held the assumption that professional high school internships are important in building professional skills (soft skills) needed to ensure student success in post-secondary experiences. In helping to secure the researcher's neutrality in this study, the researcher continually reflected on the study's process and the researcher's reactions to sustain a clear focus on the purpose of the study. 


\section{Description of Participants}

The researcher's goal was to have input from students, parents, and administrators who have experienced being part of a professional high school internship. The researcher interviewed students who had participated in an internship within the past two years. These students were 18 years and older and had successfully completed a semester of internship during their senior year. The parent focus group was comprised of members who had a child who participated in an internship within the past two years. The administrators included one administrator and two other district principals. The administrator currently leads District A and has a vested interest in college and career readiness for all students. Administrator A requests feedback on the internship program in District A on a yearly basis to determine the impact on student achievement and postsecondary readiness. The two other administrators have similar internship programs in their districts. They collaborate with other administrators within their districts to assess the overall success of the internships programs in their district.

\section{Students}

All students were given permission by their parent to participate in the study. Each parent of the student received a letter from the Executive Director of Research and Assessment in District A, inviting the student to participate in the interviews. Along with this letter, they received notification that the study was voluntary and a detailed explanation of the confidentiality associated with this study. Of the 12 students whose parents agreed to the interview, 10 were interviewed. By the time the 10 students were interviewed, there was adequate saturation within the data collection to ensure accuracy 
in the data analysis within the sample group (Creswell, 2009). Table 1 indicates students interviewed, their age, career interest, gender, number of semesters in an internship and type of internship.

Table 1

Description of Student Participants

\begin{tabular}{|c|c|c|c|c|c|}
\hline $\begin{array}{l}\text { Student } \\
\text { Number }\end{array}$ & Age & Career Interest & Gender & $\begin{array}{l}\text { No. semesters in } \\
\text { internship program }\end{array}$ & Type of Internship \\
\hline 1 & 18 & Teaching & $\mathrm{F}$ & 2 Fall \& Spring & $\begin{array}{l}\text { Middle School } \\
\text { Teaching, Student } \\
\text { Teaching }\end{array}$ \\
\hline 2 & 18 & Physical Therapy & $\mathrm{F}$ & 1-Spring & $\begin{array}{l}\text { Chiropractic Care } \\
\text { Physical Therapy } \\
\text { Acupuncture }\end{array}$ \\
\hline 3 & 18 & $\begin{array}{l}\text { Diabetic } \\
\text { Counseling }\end{array}$ & $\mathrm{F}$ & 2 Fall \& Spring & $\begin{array}{l}\text { Diabetic Counseling } \\
\text { Nursing }\end{array}$ \\
\hline 4 & 18 & $\begin{array}{l}\text { International } \\
\text { Affairs }\end{array}$ & $\mathrm{F}$ & 1 Spring & Business \\
\hline 5 & 18 & Medicine & M & 1 Spring & Medical \\
\hline 6 & 19 & Technology & M & 2 Fall \& Spring & $\begin{array}{l}\text { Telemedicine } \\
\text { Technology } \\
\text { Diagnostics }\end{array}$ \\
\hline 7 & 18 & Teaching & $\mathrm{F}$ & 2 Fall \& Spring & $\begin{array}{l}\text { Elementary } \\
\text { Teaching, Student } \\
\text { Teaching }\end{array}$ \\
\hline 8 & 19 & Veterinarian & $\mathrm{F}$ & 1 Spring & $\begin{array}{l}\text { Veterinarian } \\
\text { Specialty }\end{array}$ \\
\hline 9 & 19 & Pharmacology & M & 1 Spring & Pharmacology \\
\hline 10 & 19 & $\begin{array}{l}\text { Social Work/ } \\
\text { Psychology }\end{array}$ & $\mathrm{F}$ & 1 Fall & Social Work \\
\hline
\end{tabular}




\section{Parents}

All parents received a letter from the Executive Director of Research and Assessment. This letter included logistical details regarding the focus group, the understanding of voluntary participation, and the confidentiality information. Twenty parents were requested to participate in the focus group, and six parents volunteered. All the parents had a child who participated in an internship program.

\section{Administrators}

All administrators received an email letter from the Executive Director of Research and Assessment in District A. This letter requested their voluntary participation in interviews. Each email included an attached letter with confidentiality details. Requests were sent to ten administrators, and three volunteered to be interviewed. The administrators interviewed had involvement in District A’s internship program.

\section{Interview and Focus Group Settings}

Student and administrator interviews were held at District A's central office at a convenient time for each participant. All participants seemed to find this a comfortable setting, allowing each member to effectively participate in the interview. The parent focus group was held in a conference room at the central office, and all participants seemed comfortable, allowing for a natural flow of data collection from each member. The interviews of the student and administrator participants ranged from twenty to thirty minutes in length. The parent focus group was just under one hour.

Upon entering each interview setting, the researcher allowed time for some informal conversation. This helped to build rapport with the interviewee and allow time 
for questions. Before each interview and the focus group began, the researcher reviewed the confidentiality details and reminded participants they could withdraw from the study at any time. Audiotaping the interviews was also explained, as well as how the data collected would be used in the study. Each of these activities helped to build trust between the researcher and the interviewees, encouraging participants to share openly.

\section{Interviews and Focus Group}

The researcher prepared a set of open-ended questions for the interviews and focus groups based on the research questions and knowledge of the internship programs. The questions focused on eliciting responses from the participants to help analyze the impact of these internships on college and career readiness.

As the interviews progressed, the researcher began to include specific questions that emerged from the responses of the participants. This enabled the researcher to probe more deeply into understanding the phenomena in the context of the internships (Onwuegbuzie \& Leech, 2007). Part of the interview process is to ensure credibility and trustworthiness with participants to make sure the interviews accurately reflected what was said. A participant checking process was carried out with each member in person or via phone conference (Casey \& Krueger, 2015). The researcher went over the contents of the transcription with each participant to review for accuracy and to ensure the transcript was an accurate reflection of their thoughts and perceptions. There were no changes to the transcripts, which allowed verification of trustworthiness and accuracy of the interview process. This allowed the researcher to begin the process of open and axial coding of the data (Creswell, 2009). 


\section{Artifact and Document Collection}

During the interview process, the researcher collected artifacts and reviewed documents that might clarify the student experiences in the professional high school internship programs. Among the artifacts reviewed were internship program fliers, the internship handbooks, partner/mentor program touch points, and District A's website.

\section{Data Analysis}

Upon completion of the interviews and focus group, the conversations were transcribed. The researcher read the transcriptions and examined the unobtrusive documents, seeking to identify categories, themes, confirmations and negations (Creswell, 2009). During the reviewing of these documents, special attention was given to the importance of viewing the data in light of the information gathered during the literature review process. Several steps were followed during the review of the transcriptions. The researcher first made corrections in grammar, punctuation, and vocabulary. Transcriptions were read multiple times, and recordings were listened to alone and with the transcriptions to ensure accuracy. This was a vital part of the data collection, as understanding the participants' voice inflections and tone was essential to accurately knowing the content (Corbin \& Strauss, 2006). Transcripts were reread numerous times in an attempt to define importance, frequency, differences, and similarities. This information began to shape a system of coding and categorizing in the transcripts. Items relevant to the research questions were acknowledged, coded, and categorized using open and axial coding to properly identify emerging patterns in the data 
(Creswell, 2009). This was a continual process until reaching "saturation” and no new data appeared.

Creswell (2009) described open coding as the process of analyzing textual content into smaller segments prior to determining the meaning within the text. Axial coding disaggregates the core themes within the text. Both open and axial coding provided a process for the researcher to group common and relevant key phrases and statements relevant to the research questions in the interviews and focus group. Participants' descriptive words and phrases were copied and pasted into a Microsoft document, an organizational tool used to provide structure to the data collection process. This process was replicated for each interview and for the focus group. Categories were added as the data collection process progressed. An identical process was utilized for the reviewing of artifacts. The categories that emerged were the following:

1. Transformational Learning

2. Professional Experiences

3. Hands-on, Real World Experiences

4. Mentorship

5. Professional Skills (Soft Skills)

6. Post-secondary Planning

7. Career Exploration

8. Planning for College/Career

9. Confidence Building

10. Personal Growth through Reflection 
11. Failing Forward - Mistakes

12. Life Perspective

13. Connections between the Classroom and Real World

Upon completion of transcripts and review of the document data, the data were categorized and axial coding was used to identify themes from the initial categories. This data collection included descriptive statements from across all transcripts and documents collected. The work by Strauss and Corbin (1990) describes axial coding as a process used to examine subcategories and relate them to a single category. Statements emerging from the data were re-categorized under themes. The themes were created from the research questions and information gleaned from the literature review.

The following themes emerged: (a) Transformational Learning; (b) Professional Experiences; (c) Professional (Soft) Skills; and (d) Post-secondary Planning. The researcher identified significant statements from each of the interviews and focus group conversations to provide support for these themes. Evidence supporting these themes is presented in the following sections in support of the research findings. Figure 6 displays the triangulation between the research data. 


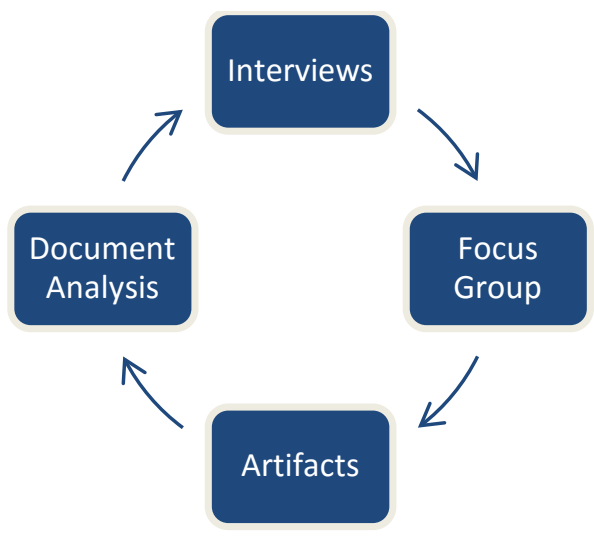

Figure 6. Triangulation of research data.

\section{Findings from the Data}

After triangulating and coding the data, four themes were revealed: (a)

Transformational Learning; (b) Professional Experiences; (c) Professional (Soft) Skills; and (d) Post-secondary Planning. Subthemes were identified within each of the four themes (see Figure 7). These themes and subthemes emerged during the data analysis upon the completion of participant interviews, a parent focus group, administrator interviews, and artifacts collected from three websites. Data analysis provided insight into the impact of high school professional internships on college and career readiness. 

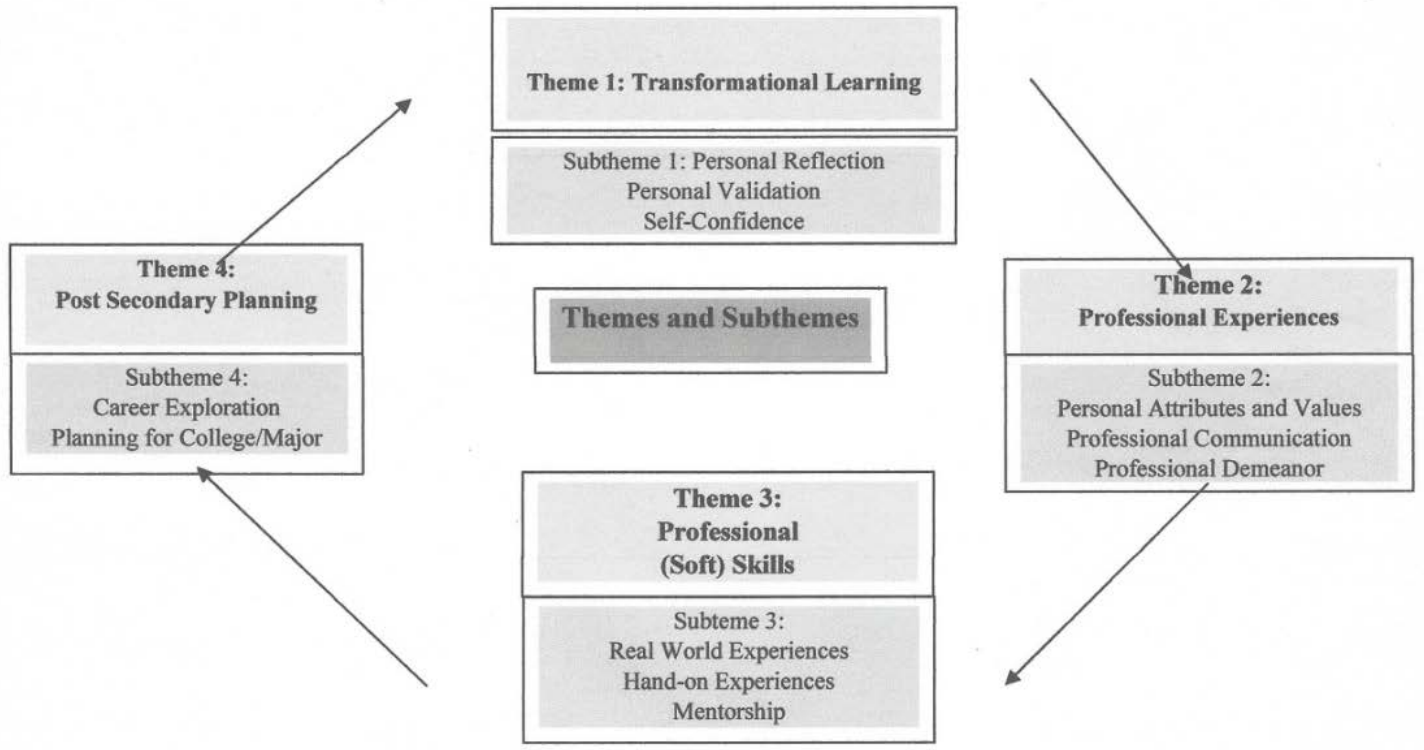

Figure 7. Research themes and subthemes graphic.

\section{Theme 1: Transformational Learning}

This first theme emerged from the student participant interviews, parent focus group, and administrator interviews. This theme was evident as student participants, parents, and administrators revealed how students' personal growth and insight was significant from the beginning to the end of these high school professional internships. Continued examination of this data revealed these additional subthemes: (a) self confidence; (b) personal validation; and (c) learning through reflection. Transformational learning was described by Mezirow (1991) as a constructivist way of learning. The learner makes meaning from their "sense of the experience," making meaning from that experience, "hence learning." Student participants in this case study identified feelings of personal growth and insight throughout the internship experiences. Student participants 
traveled beyond the four walls of their high school classrooms and were integrated into the world of work. Participant two described her off-campus experience:

This experience really showed me how much work it takes to be an engineer, and how much patience you have to have with every client. I think this is something that most classrooms, most schools don't provide you with. I think it was an experience that every student should have.

The goal of the internships was full immersion for the student participants into career exploration in a professional setting. These internships included adult mentorship, real-world projects, exploration of personal passions, and the application of knowledge gleaned from the student participants’ past high school coursework. One participant described this experience as, “I can’t really explain how good the atmosphere was - you actually get to feel what it's like being in the real world.” Student participants who had these internship experiences stated they felt more confident and ready to take the next step in their life after high school. “Personally, I think if I didn’t have this experience, I would be scared, or timid to go into this degree just because I didn’t know exactly what it was. This has given me full confidence” (Participant seven).

Subtheme: Learning through reflection. Artifact data collected from three internship programs showed internship student participants were required to do weekly reflections. These reflections focused on the student participants articulating what he/she learned during the internship, how that applied to their personal and professional development, and opportunities he/she had for improvement. Embedded in this reflection, one program also included a place for documenting "ah-ha" moments for student participants to capture ideas, concepts, feelings of accomplishment and/or feelings of validation. Student participants during the interview process described these reflections 
as a tool for reviewing, thinking about, and processing cognitively what he/she learned.

These reflections provided the student participants with personal insight into professional growth, opportunities to explore his/her feelings around an experience, and time to give meaning to what they learned.

I think the internship was very beneficial to me and made me realize who I want to be. Taking time to do the reflection writing was a pain sometimes, however, it really did help me understand what I wanted to do with my life. (Participant one)

The reflection process was coupled with feedback from an instructor. Weekly feedback was given electronically in all three programs, and students were expected to complete some type of paper or project summarizing the reflection process. Participant five stated, “Those reflection papers really allowed me to realize how you have to step up to the plate when you want to be at the professional side of things in the internship." These reflections purposely embedded into the curriculum also generated discussions with student participants about personal thoughts, values, and goals. Program instructors posed questions, asked for clarification, or assigned tasks through this learning modality with the goal of personal learning and validation of post-secondary goals. Participant six explained, “I didn’t always like doing them, but they helped me figure things out. It was like a light bulb went off in my head. It helped me see what I was doing and how it changed my life.” Student participants spoke of not wanting to complete the reflections in the beginning of the semester, but understanding their importance as they progressed in the internship. In addition to these comments, parents and administrators spoke about reflection during the focus group and interviews. 
Although questions about reflection were not presented in the research questions, this subtheme continued to resonate throughout the parent focus group and administrator interviews. Parents voiced improved conversations with their child about their future plans, personal growth, and dreams for the future.

- "He was given time to reflect on things. I think this changed things for him. He always wanted to go into the medical part, but now he knows why and understands more of what is expected" (Parent four).

- “I believe these experiences were invaluable, I don’t remember having these even in college. She was able to learn and then they asked her to reflect on it and then they conferenced with students on it. It prepared the students in whatever field they wanted. It (the reflections) helped their professional side and taught them how to write from the professional aspect of it" (Parent eight).

- "It was a hands-on, heartfelt experience. They wrote about it, talked about it and had time to think about what they were learning" (Parent three).

- "There was great questioning because we talked about it at home. I was able to ask my child, “And what's next?” It definitely impacted some of her plans for college” (Parent two).

- "My child talked about herself more, what she wanted to do with her life. We really never talked like that before. She realized to do something like that, you know, she's going to have to give up her, you know, social life in some ways" (Parent five).

In accord with the parent focus group, the administrators touched on how reflection allowed students to gain insight and validation for their life beyond high

school. Administrator one stated,

I definitely recommend it. I've recommended it to even family members that don't have this opportunity with their schools, that they do this, during the summer, or after school hours. I really do believe these students learn to reflect on themselves, their experiences. It is that piece that gives them validation, how they can do these things at 17 and 18-years-old. They are able to answer questions like, how is that going to impact my future? And once they start making those connections, it means so much to them and they grow personally. 
Administrator three went on to explain,

They are literally getting a clean slate and an opportunity to figure out who they are. They get to reflect on who they are. And I think we've all had that in our lives where you have a new job or new experience and you walk in and go, "Okay, this is kind of a new slate for me, it is my time to define me. And I think it's the same thing for our kids.

Administrator two believed, "I think internships provide them with reflective thinking, it really verifies for them and validates their choices, and their desires as they move to the future.” This subtheme provided the student participants opportunities for insight and personal growth. The next subtheme emerged as student participants, parents, and administrators expressed how the reflection opportunities provided personal validation for the student participants.

Sub-theme: Personal validation. The phenomenon of validation occurs when a person considers a statement or an experience as having personal meaning or significance for them (Onwuegbuzie \& Leech, 2007). This theme of personal validation was present in all research groups. For the student participants, the theme of validation occurred when the student participant was able to reflect on "where he/she is now" (high school) and confirm where the participant "wants to be” (post-secondary expectations). This subtheme emerged as student participants expressed having a sense of personal validation through the internship experience.

- $\quad$ "This gave me real-life experiences and scenarios to help me problem-solve where I want to be in my life” (Participant six).

- “This experience gave me different experiences that I wouldn’t have otherwise to focus on what I want to do with my life. I learned from them and it validated what I want to do" (Participant one). 
- "The comments from my project manager made me feel like this is what I want to do, I'm confident in this. This is what I want to do with my life" (Participant ten).

Student participants used words such as validated, validation, solidified, and confirmed to describe how the internship provided personal meaning in helping to narrow or choose future plans beyond high school.

Sub-theme: Self-confidence. Student participants, parents, and administrators in this study consistently described increased self-confidence as being one of the benefits acquired from these internship experiences. Student participant three stated, “I feel like I know who I am now. I know how to talk with people in real life now. I'm not scared to talk to people and I just feel more confident in myself altogether.” Two key experiences were described by student participants as reasons for increased self confidence: (a) being allowed to make mistakes, and (b) being treated as an adult. Student participants described their internship experiences as opportunities for the student participants to “make mistakes” and learn from them. "I have already made mistakes in my internship, I've processed and gone through them and I know how to correct my mistakes now" (Participant ten). The internship environments provided opportunities for the participants to have professional experiences with "less risk" of performing poorly on a job evaluation or losing a job. Participant six conveyed,

I've definitely learned how to focus more on what I want to do with my life and how I can look at my mistakes that I have made in high school, whether that was in internship or just in my personal life, and how I can turn those mistakes into bettering my life.

Although the risk level was lower from the performance standpoint, student participants still viewed their experiences as “adult like” and articulated other positive 
feelings as though they were "real” employees in the businesses/organizations. Student participants viewed being treated "as an adult" as a positive experience, providing motivation for their engagement and productivity in these internships. Participant five described the internship experience in this way: "I think it just helped me build myself as a person.”

- "It helped me interact with adults in ways I normally would not do by just sitting in the classroom” (Participant two).

- "I think the internship helped me come out of my shell. I'm not afraid to talk to adults anymore, it showed me how to talk to adults, the proper way to address them and ask questions, and just have a conversation with all types of people" (Participant one).

The opportunities to make mistakes and learn from them, coupled with full immersion into an adult environment seemed to be a common influencer on the student participants' feelings of self-confidence after completing an internship. Parents had additional views on what was influencing this increase in self-confidence. Parents often articulated the student participants grew in self-confidence from understanding the "unknown" and acquiring knowledge of the real world, thus becoming less anxious or fearful of what the future holds beyond high school. Parent two stated, "Just learning how to communicate with adults and the professional experiences increased my child's confidence. For example, she learned to think on-the-spot and really benefited from that.”

- "My child has learned to listen to adults; the people working in our community are contributing to the professional development of my child. She had learned she can do this, and she is not afraid to make mistakes and make changes" (Parent six).

- "My child has confidence; I think she's much more secure and self-assured. I think it built her confidence for speaking to adults professionally, she had to branch out and put herself in leadership roles” (Parent four). 
- "She needed these opportunities, they asked her to stretch her wings a little bit more” (Parent nine).

Administrator interviews similarly noted that internship experiences provided the student participants with an overarching sense of accomplishment, motivation, and selfconfidence.

I think the exposure these students are given in the real world is crucial. We are able to push them a little out of their comfort zone in a supportive way and they grow so much confidence - they can do it! I think this is such a critical piece for them as we move forward. (Administrator one)

Administrator two added,

I personally like the fact that we trust our students with their learning and their education. I'm validating they are important and these experiences are important. I am telling our students they have value past high school and our students grow personally and gain confidence.

“These experiences are opening doors for their future and they have confidence that they can do it” (Administrator three).

Transformational learning through reflection, personal validation, and selfconfidence, were all noted by the student participants during their interviews (see Figure 8).
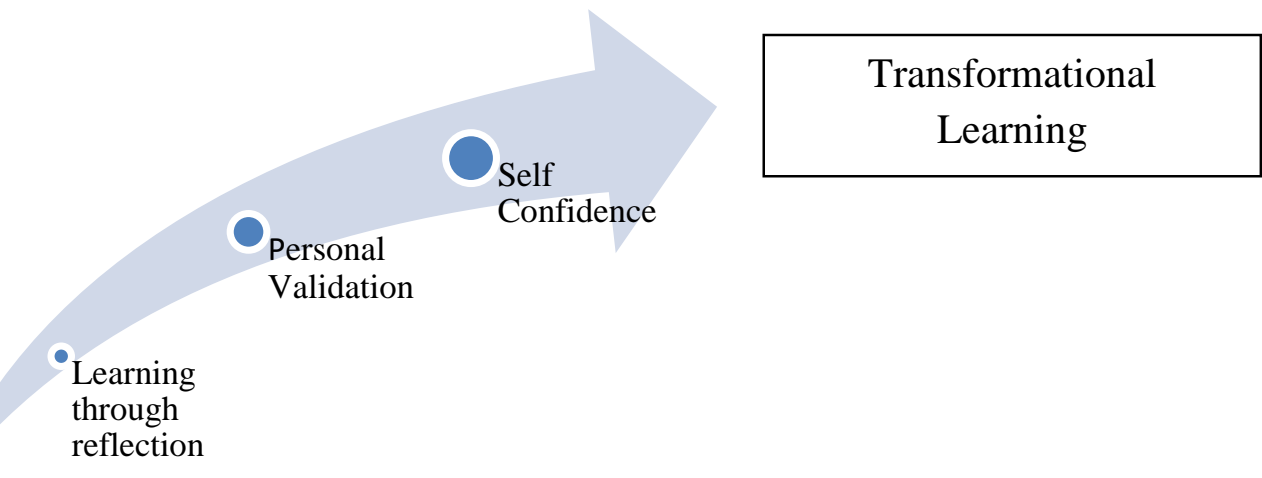

Figure 8. Transformational learning subthemes. 


\section{Theme 2: Professional Experiences}

Professional experiences was the second theme that emerged from the student participant interviews, parent focus group, and administrator interviews. This theme was created to group subthemes in a meaningful way. When defining professional experiences, student participants described authentic learning experiences that promoted professionalism, increased professional skills (soft skills) and promoted personal/professional growth and insight. Continued examination of this data revealed these additional subthemes: (a) personal attributes and values; (b) professional communication; and (c) professional demeanor. The term professional experience describes how student participants viewed their learning. This type of learning provided students with adult-like experiences that were outside of the traditional classroom. These off-campus experiences provided students an opportunity to understand workplace social norms. Social norms can be explained as behaviors that are accepted in a particular group, community, or culture. Hidden rules or norms can be difficult for students to distinguish or understand (Raelin, 2008). High school internships provide professional experiences that allow students to explore their personal attributes and values in order to create a sense of professionalism. This sense of professionalism can be applied to any place of employment as a way to ensure appropriate responses to social norms within the world of work. "Having professional experiences was so important, yeah, professionalism in general. You can use professionalism in your work or in your college experience” (Participant one). 
Subtheme 1: Personal attributes and values. Student participants described the internship experience as providing personal insight into their personal attributes and values. Student two explained,

I learned a bunch of skills that are about me, personally. I'm going to know how to act. I know how to use them now to help me when I go to college and do that stuff. I'll feel like I know what is important to me and I'll be, yeah, more confident in myself and what I'm choosing to do.

Student participants expressed the process of learning about their personal attributes and values as a conduit for personal understanding and growth.

I think learning these professional skills just helped me build myself as a person. I want to be honest and have integrity every single day and, um, I know to be this I have to act like this when I'm out there. (Participant five)

Student participants explained they spent time in class learning about what values they will take into the workforce, what type of work environment they would thrive in, and what type of work will motivate them and bring out their personal passions.

- Learning about myself and my own values gave me perspective of different type of things. I don't get a lot of opportunities to learn this in a classroom. (Participant three)

- I want to back up and do this again; it helped me clarify things about myself that I didn't always know were there. I can be motivated and passionate and know that is important to me. They ask a lot of you, ya know, questions about you in a different way, it makes you think anyway. (Participant eight)

- It helped me solidify what I want to do in my life, what is important to me and what kind of place I want to work in. (Participant seven)

Often student participants reflected on personal growth through the understanding of one's self and personal values.

These connections I made about myself, um, they helped me know what type of job I need in the future. They help me determine, for example, where I will be 
happy working - big town, small town, city or um, maybe back at my home town. (Participant three)

We learned a lot about professionalism, more about us too. More about what makes us a great leader or a great team member or how we go out there and be honest, trustworthy, kind, considerate. These are just as important as your work, for me anyway. (Participant nine)

Participant two expressed this personal understanding:

I have two younger sisters and my parents discuss values and what is important in life with us all my life. I've learned many ways of dealing with different things. And I think personally, this was good for me. I am able to understand myself and what I believe about myself a lot better.

Student participants conveyed that understanding one's self through exploration of personal values and attributes was important. Utilizing this insight became beneficial as the student participants began thinking about moving beyond high school to a postsecondary setting. Participant feedback mirrored the parent and administrator feedback related to the importance of building personal knowledge around these professional (soft) skills.

Parents described this exploration of personal values and attributes as a professional skill set needed for their child to feel confident about his/her future postsecondary decisions. In general, parents believed this exploration was a key component for their children's personal development. Parents expressed that these experiences, both in the classroom and in the internship experience, helped their children better identify college and career choices. Parent one explained her child's experience with this type of growth:

Through this experience she realized she was not about healthcare. She liked the business side of it, but did not like the patient side of things. She had to look at her personal skill set, what drives her, what excites her and she was able to land 
on something different. She needed time to explore herself and what she believed inside was a good fit for her. And I think this will give her or afford her more opportunities, that, you know, lead her in a path that I think is more, you know, her.

Other parents agreed with this idea of knowing one's self (personal values and

attributes) as an important part of driving decisions around career choices.

I think, for my child, it helped her figure out that she needs to pursue something that gives her lots of avenues to be creative. Her major part of her is creativity. She also learned she needs to be around other people. She's like her mom, in that she I very energized by people. The internship helped her understand that about herself and helped her in that direction. (Parent six)

Parent two described her child's growth and insight in this way:

My child had never had these types of professional experiences where she was asked these type of things. For her, she had ideas of things that she felt and believed with different situations, things she liked and did not like. This experience helped her put together her way of thinking, or the things she wants to do to make sure she is happy in her life. That was huge for her and me.

Parents stated their children had benefited from the continued focus on the student participants' knowledge of self (personal values and attributes) allowing the student participants the ability to change their thoughts and feelings prior to post-secondary planning.

I know that has never been a thought on her mind until passing through these internship programs. She knows what she wants to work with, maybe what she wants to do in her adult years. It solidified her desire to work with others and not just individually like a programmer or something. Understanding herself and what she thinks is important, and um, changed what she wanted to do. (Parent four)

Administrators revealed similar thoughts as the parents related to this subtheme.

As our students decide what they want to do in the areas they have interest in, what a wonderful opportunity for them to explore who they are and what values they bring to the table. They get to determine if this is really their passion as they look into the future. (Administrator two) 
Another administrator explained, “And so, watching their personal growth, I think the other piece we miss sometimes is also their - how they change what they think about themselves and how they begin to understand the relevancy of these professional experiences.” All student participants, parents, and administrators expressed the benefits of student participants learning about their personal values and attributes. Each group emphasized how these professional high school internships provided experiences, helping student participants to become better equipped in answering unresolved questions about post-secondary planning. As student participants progressed through these experiences and built self-knowledge, other skills emerged in areas of professional communication and demeanor.

Subtheme 2: Professional communication. Professional communication encompasses many types of communication. Student participants, parents, and administrators defined this type of communication as professional writing and oral communication skills. Student participants described how they naturally improved these professional communication skills while participating in their professional high school internships. Each student participant touched on this subtheme in some way, explaining how they learned to be more prepared in a presentations, how to handle receiving critical feedback during an evaluation, or how to articulate their thoughts, ideas, and questions. Student participants were given an assignment at the beginning of their internship to complete a capstone project. This project required some type of presentation that accurately represented the student participants’ experiences throughout the semester. Several student participants talked about how they improved their use of PowerPoint, 
Prezi, and other online presentation tools. Many student participants conveyed they learned more ways of communicating in presentations and how to speak in a professional manner. "I learned that I wrote too much on my PowerPoint, I needed to cut down and say less. I learned to add visuals and tell a story rather than have bullet points, and yeah I'm better at that" (Participant five). Participant seven explained,

It's not like your traditional, like I said, classroom where you are sitting there with students, if you mess up in a presentation it's no big deal, everyone will laugh together. Where it's a bigger deal when you mess up professionally because you were not prepared - everyone notices it; so you want to practice more. I think that's one of the things that I really gained from it was my professional speaking skills.

Another participant relayed, “I have to say truthfully, I didn’t know there was a different way of speaking during a presentation - yeah, it was helpful for me to see that and learn that.” Improved oral communication skills were also mention by the student participants as a way to connect confidently with adults.

I was told I needed to take initiative and ask for help or let adults know when I needed something. This, yeah, um seemed strange at first, but we learn how to conduct ourselves. We learn to start conversations and just be involved in them. (Participant five)

Participant two put it this way: "As I got better with understanding how to speak professionally, I think I am, uh confident and not afraid to talk to adults, new people and talk to the customers, and that kind of thing."

Parents in the focus group touched on some of the same feedback as that provided by the student participants. In general, parents were impressed with how their children became immersed in professional jargon, participated in corresponding professionally through emails, created presentations and produced written documents in a professional 
way. Parent two described her daughter's experience of improving her written and oral professional skills in this way:

This solidified her desire to work with special education students. Her growth professionally, how she learned to speak professionally to them, how she learned to talk to parents. It all helped her make herself more marketable when she applies for a job as a teacher. I know that was never a thought in her mind before - how am I speaking to adults and to a child, how is my communication and writing. After all she wants to be a teacher, it should be right.

Often parents stated their children learned a degree of professionalism, including oral and written skills that could not be taught alone in the classroom.

This internship helped him to see the importance of professionalism and that your peers, your boss, they all watch what you do, say, write and um, this is a real thing. It can make or break a person in a job. (Parent six)

The administrator feedback was similar to that of the parents, focusing on the importance of the student participants having appropriate communication and written skills in the work place. One administrator explained,

We teach them English and public speaking in the classroom, but we don't give them authentic ways of getting feedback on this. The internships provide that authentic feedback from employers, customers and mentors. That feedback that is so important to their work later in life, to them personally as a professional.

As the professional oral and written communication developed, it was joined by comments about professional demeanor. This professional demeanor was defined by student participants, parents, and administrators as how to professionally connect and interact with others, how to receive critical feedback, and how to stay focused in times of stress or anger.

Subtheme 3: Professional demeanor. In many cases, the student participants used the word professionalism to describe professional demeanor. Often student participants 
described professionalism as a way of acting or presenting oneself. Several student participants gave examples of situations occurring during the internship in which he/she used professionalism to solve a problem, connect with a client, or receive critical feedback on his/her performance. Parents added to this definition of professional demeanor. The parent and administrator group surmised professionalism was obtained when their child learned to use his/her professional (soft) skills. In general, parents agreed that the appropriate use of professional (soft) skills led to an understanding of professionalism. Participant seven conveyed this idea of professionalism:

We learned a lot about professionalism, which you don't learn a lot about in high school. In the real world you have to be professional and we learned how to send emails, talk with others and things like that, the stuff you need in life.

Professionalism was a common term used throughout the interviews and focus groups.

Often the word professionalism was noted as a way to describe the overall behavior or actions by the student internship participants. Professionalism was seen as an overarching expectation for the way students interacted and engaged with other professionals. Participant six described their experience in this way:

Overall, I learned to be professional at all times. It didn't matter what we were doing, I was expected to treat everyone respectfully. This was, um, easy because I was, you know, treated like an adult, not a child. I was treated like a professional.

Participant eight agreed. "I think my biggest take away was learning to be professional. Skills like cooperation, team work, responsibility. You don’t get this in a classroom, I felt it.”

Student participants often used the word professionalism as a behavior and professional/soft skills (such as flexibility, team work, collaborate, and so forth) as the 
characteristics of professionalism. The theme of professionalism surfaced as a "way of acting” accomplished only by the mastery of soft skills. Professionalism seemed to be a result of a culmination of professional/soft skills demonstrated while participating in the internship experience. Participant one explained,

I think both professionalism and being professional will help me in the workforce. I was able to get experience with both in my internship - it was an eye opener and like I said, it made me better and will help me when I am ready to work.

Administrator three summarized the concept of professionalism: "You know, it’s professionalism that helps them grow the most. Attendance expectations, making eye contact, being part of a professional team, clear communication, learning to articulate what they want - it's all those soft skills that help them move forward.” Professionalism provided an avenue for students to conduct themselves in a way that displayed appropriate professional/soft skills. The professional/soft skills learned while in the internships gave student participants the tools needed to interact within their environments effectively. Professional experiences were defined by student participants as personal attributes and values, professional communication, and professional demeanor (see Figure 9).

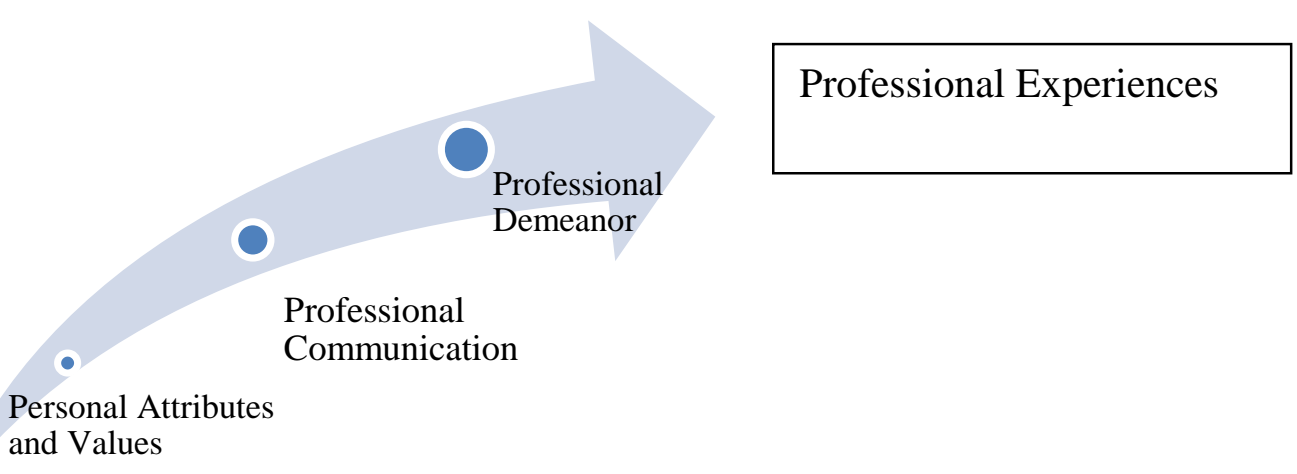

Figure 9. Professional experience subthemes. 


\section{Theme 3: Professional/Soft Skills}

Professional/soft skills are defined as non-cognitive skills. These non-cognitive skills or soft skills (professional skills) provide opportunities for students to learn about his/her personality, explore career interests, and acquire intrapersonal skills needed to be successful in the workforce. The research regards soft skill/professional skill development as an integral part of preparing students for post-secondary success (Mattern et al., 2014). While examining these data, additional subthemes emerged: (a) real-world experiences; (b) hands-on experiences; and (c) mentorship.

Soft skills are personal characteristics that allow employees to effectively relate to others. Soft skills are developed and learned throughout the life span and are often enhanced or developed over time (Studer, 2017). Employers have stated lack of soft skills inhibits a worker from being successful in the workforce. Soft skills serve as a way for employees to interact with other people in the work environment. A lack of these skills can impair a person's ability to socialize and build positive relationships with others (Studer, 2017). Having the technical skills and knowledge to successfully execute tasks is only one part of job success. Unlike hard skills/technical skills, soft skills are able to be applied across any job, organization, or industry. These skills allow employees to be more efficient, productive, and harmonious and to obtain greater personal satisfaction in the job. Soft skills encompass both personality traits (such as optimism) and abilities that can be learned and practiced (such as empathy).

There is great debate on which soft skills are the most important to learn and which skills are most effective. Regardless of how these are ranked or ordered in 
importance, current literature indicates the more soft skills a personal acquires, the more likely they are to be successful in a job (Studer, 2017).

The words professional skills were used synonymously for the words soft skills in this study. The words professional skills imply the learning of a behavior or personal attribute that is connected to professionalism and professional internship experiences. Student participants talked about the different types of professional skills learned throughout the internship. Common traits reported by student participants were team work, collaboration, flexibility, patience, integrity, responsibility, dressing professionally, hardworking and taking initiative. Participant seven explained how these skills were developed and enhanced during the internship experience:

Learning these skills was really important. The soft skills I learned were more like personal things, yeah, like being on time and dependable. You want adults to see you as responsible and trustworthy. When you talk to an adult, you want to be confident in yourself and know it is okay to voice your opinion, thought, um your ideas. Just do it respectfully.

Participant three added, “I didn’t understand how important soft skills were until this experience. All these people helped me learn about myself and how being professional, on time, reliable and courtesy is so important.”

Each of the student participants interviewed shared a new awareness of what professional/soft skills are and how they are important in the workforce and in life. All the participants interviewed in this study could articulate and name the professional/soft skills they learned while participating in their internship experience and conveyed the importance of using these skills. Participant two explained her experience:

I definitely learned how to properly dress, and talk in an interview. I learned how to ask questions and really listen. Uh, obviously in a normal classroom, like math, 
or science classroom, you don't really get that opportunity to go out and interview with a professional that could possibly her you in a job.

"You learn how to act, talk and be dependable. You might think you have

professional/soft skills, but you really don't know what that is until you do an internship.

At least I didn’t know, uh, I get it now,” stated Participant four. Participant three talked

about learning to work in a team:

In the SPED classroom, I also had teachers in there observing me. So, I had to connect with my students, but also the other teachers and I had to learn to have a relationship with them, that really helped me learn in my teaching class. I felt like I was part of the team and that's a really big deal. You want to make sure that everyone feels comfortable with each other and there's mutual respect.

Participant two related,

I think soft skills will help me when I go into the real world, and I need to collaborate with everyone. I've learned to collaborate, everyone needs input. So, it's not your way or the highway. You really have to collaborate, and make sure those ideas are getting in.

Participant ten summarized thoughts on professional/soft skills:

The internship taught us a lot of soft skills. Um, we learned these skills are in us, we just have to use them and understand what they mean. The internship gave us this chance to understand what patience or being trustworthy means, yeah, we learned we can do it. It is about understanding what makes us tick or what we are connected to as a person. I am kind, smart and I can be outgoing and I learned I am definitely responsible.

The parent focus group shared many similar thoughts about the student participants’ experiences in learning professional/soft skills. In general, parents agreed that professional/soft skills provided a platform for the student participants to successfully interact in a professional manner.

I think they learned to be professional and learned to be good listeners to other professionals. My child learned to dress appropriately, be a team player, and write appropriately. I don't think they often get this type of skills in the classroom. If 
they do, they feel fake because they are not naturally part of the classroom environment. She had to be professional every moment, she learned how to be flexible and responsible for her learning.

Parent one explained her child's experience in this way:

My child learned professional skills like time management, you know like making a list of all these things and I've got to get them all done. She also learned soft skills like how to be a team player. She had to look at her list and work with others sometimes to get things done. These skills went together in a way to help her interact and grow.

Administrators conveyed the need to integrate professional/soft skills into the classroom and curriculum. Administrators believed professional/soft skills could be taught in the classroom and would better prepare students for all of their classroom learning. Each administrator believed professional/soft skills were essential to postsecondary success.

We hear so much in the area of soft skills from the work industry. CEOs in the area talk about people needing these skills as fundamental basics to being a successful employee. They say they can teach them the technical skills but the person needs those other soft skills to be able to do the technical skills appropriately and successfully. (Administrator one)

Administrator three added, "Soft skills are the most essential work skills. Without these, our students will not compete in jobs. Students in internships learn to accept responsibility for their personal development and how to be responsible learners in the work environment.” The internship afforded student participants the opportunity to learn about themselves while enhancing their ability to successfully interact with others. As students learned how to interact professionally using professional/soft skills in their internships, they were also integrated into what student participants, parents, and administrators called "real-world experiences." 
Subtheme: Real-world experiences. Real world experiences are defined by the student participants, parents, and administrators in this study as internship experiences that take place in the work place or learning that can be applied directly to real life.

These internships really speak to real world experiences. They are learning skills that public schools can't teach them. These experiences are very different than a homework assignment being due, that just impact them. These experiences are real world, so if I don't get my part done or don't do it well, it impacts the whole system. (Administrator one)

"Students are used to grades and the internship teaches them what happens in the real world, they can see the direct impact they are making - all the value they are bringing to the table,” explained Administrator two. Real world experiences were described as a way to understand how the internship work was adding value to the internship sites. Student participants talked about how real world experience brought more engagement in their overall learning and a better understanding of what adult experiences would be like in a job. Participant two explained,

My favorite part of the internship was when the teacher really allowed me to get into action. She allowed me to be the teacher for two full hours I was there. And it was very changing - it was an experience I couldn't explain - you never know what's going to happen but you do it and learn you can.

Another student participant described real world like this, "This is like real life; this is what I'm going to be doing with my life, and I really enjoyed it.” Overall, student participants articulated they gleaned real world experience in their internships and this real world experience helped them better understand the dynamics and expectations of a job. These real world experiences were vital in influencing the student participant's choice of a career path. Participant five explained her real world experience: 
In my internship I knew I wanted to do something with sports. So, I got to work with a professional soccer team and work with the physical therapists. They allowed me to interact and help members of the team. I was able to be in the real world and see it there. So, that was very helpful for me.

Another student participant articulated the experience this way: "It helped me solidify what I wanted to do with my life. I was able to see it first hand and now I've kind of narrowed down what I want to do and where.” Participant six summarized the general thoughts of the student participants. "I think this gave me so many opportunities to see the real world. It gave me a chance to kind of pinpoint exactly what I wanted to do.”

The parent focus group viewed the internship in a similar way. Several parents expressed their excitement for their child to be in a real world experience where they could decide if this was a realistic career path prior to investing time and money into college. Parents believed these real world experiences could not be authentically simulated in a classroom. Three of the six parents expressed their child benefited from the internship as they discovered they were no longer interested in the same career after completing the internship. "How much more real world can you get. My child no longer wants to be an engineer. I think this is way valuable and sure helped him know before he went to college” (Parent five). "Although the internship was a very short period of time compared to all their other classes, this was real time, real world and they learned a lot about planning for their career in a short period of time” (Parent one). Parent four explained,

I don't think kids get to understand how the real world works in schools. And I don't think we often get that opportunity until our college years, my child has this great opportunity in her high school years. And that was just a wonderful benefit for her. 
Real world experiences in internships were described as providing the opportunity to explore, reflect, learn, and to aid in decision making for college and further career pathways. Student participants often coupled real world experiences with the term handson experiences. Student participants articulated that hands-on experiences provided more engagement and more learning by “doing” in their internship experiences.

Subtheme: Hands-on experiences. Hands-on learning is doing something that enables learning without listening to a lecture or reading something from a book. This type of learning requires the person to be actively involved in something at a personal level (Grandin, 2014). Often the student participants described their experiences using the term, hands-on learning. This type of learning, in the context of this study, was the “doing” within the real world experiences. Hands-on experiences seemed to provide deeper engagement for students in the work or projects during the internships. Student participants used words such as ownership, responsibility, accountability, and fidelity in conjunction with hands-on experiences to describe the type of behaviors they were exhibited during their internships. The majority of student participants viewed these hands-on experiences as a lens into their future adult experiences. This lens allowed students to view different aspects of a career without the high risk of possibly losing a job they were not qualified to perform. "For the things we have to learn before we can do them, we learn by doing them” (Aristotle, 1866). Participant six explained hands-on learning:

I was able to go out and do some learning. I was able to perform and use my skills that I had been wanting to use, rather than just sitting in a classroom, taking like, um, an exploratory class or something that would not help me learn about my career path. 
Another example was given by Participant five:

Um, I think this experience was great, it teaches you a lot, and um, it's very hands-on. So you're not just sitting in a classroom listening to a teacher project something on a screen. Um, I learned a lot by doing stuff in the workforce. And I think it will put me ahead of some other students because they're not going to know how to, um conduct themselves. And so, I think I am, uh, confident and not afraid of making plans for college and a job.

The internship provided me with hands-on stuff that help me learn patience, and how to be more understanding with other people. It was not like a traditional classroom. You were out there doing the job and other people, um, depended on you - it was the real deal. (Participant three)

Participant seven added,

The internship was helpful to me to get out there and do what I was thinking about doing in my life. And so, that was so helpful for me to be able to try out the things I wanted to do. In the classroom you are stuck learning, but you don't really get to do it. I was able to try all the different things I wanted to do.

Participant nine summarized the hands-on concept in this way:

I knew if I were to go into teaching, I needed to jump in there and do it. I'd have to be able to do all ages, and I looked forward to doing my student teaching. I looked forward to it because I was a real teacher, doing what teachers do. So, I think that helped me a lot in gaining perspective of the job.

The administrators also believed these hands-on experiences in the internship provided students with opportunities to retain more by doing. One administrator talked about how memory is formed by hands-on experiences. The administrator explained, "Students who have hands-on experiences retain more knowledge and build more memory mass” (Administrator two). Another administrator described hands-on learning:

As our students participate in internships, they get so much hands-on learning. As so, they have to own it and have personal responsibility for their learning. This learning, by engaging in projects and tasks in the workforce, now becomes theirs. It's not ours that we are pushing them to learn, but it's what they are experiencing 
that makes it theirs. And so, they are out there and immersed in the profession and this is so important because in their minds, that is where they are going.

Administrator three said,

I've seen this multiple times in the internships. They need to go out and participate in the learning to decide what they want on their own, without their parents or even teachers. And as they do their projects or as they learn about the career, they change sometimes and think, "Gosh, I really thought this is what I wanted, and now I don't like it.” In many, many cases I've heard students say, "My parents told me this is what I should do in the future. Sometimes they find it is a fit and other times they do not want to do that in the future.

Hands-on experiences provided the student participants with opportunities to understand career objectives and expectations. The professional internship encouraged students to explore and reflect on their experiences, giving the students time to change their career path prior to entering a post-secondary school. This type of exploration was described as helping students "really understand what they would be doing before they spend money on college and then change their mind” (Parent four).

Parents in the focus group shared the same ideas about hands-on learning. In general, they were pleased that student participants were given the freedom to experience a real job and the flexibility to change their career path prior to graduating from high school. Parent two shared the sentiments of several other parents.

I think it's absolutely invaluable just from my own perspective and not having these kind of opportunities. Um, I'm just as excited about her learning what she doesn't want to do through this internship as learning what she does want to do. I think doing these hands-on kind of things helped her really explore, you know, determine what the right fit is for her.

Parent five agreed. “It is equally important to me that she finds out what she doesn't want to do as if she finds out what she does want to do, really. This internship gave her the insight to the job as she did it, she learned what she liked and didn’t like.” Parent three 
added, "This experience was important because what they do in the internship cannot be learned in the classroom.” Parent two's comments seemed to sum up the group's thoughts:

By doing this internship my child learned so many things. The hands-on experiences every day helped her mature and think about the future. I think she has learned to connect with adults at a totally different level. There is no teacher holding her hand telling her what to do next, she is out there doing it on her own, um, she figured it out on her own. Um, she has definitively learned to be independent.

Real-world, hands-on experiences were a common theme described by students as providing personal insight and growth during their professional internships.

Conversations about these terms led to comments and explanations about the mentors who provided the personal support for these students on a day-to day basis during the professional internship experiences.

Subtheme: Mentorship. Mentorship is a formal relationship between two people in which one person has a professional kind of experience that the other person does not. The mentor shares this information in a personal way to support the professional and personal growth of the individual (Myers, 2016). Myers (2016) explained that mentorship focuses on one person providing their personal and professional ideas, resources, and insights to build soft skills in the mentee, enabling the mentee to be successful in his/her job. Mentorship provides an individual an opportunity to hear and learn about the mentor's experiences. This type of dialogue between professionals helps the mentee reduce unintended consequences on the job by having a neutral person share their personal knowledge, wisdom, and failures (Lukas, 2013). 
Professional internships provided student participants with mentorship, which was developed in several different ways. Some student participants described their project manager (the person they reported to on a daily basis at the internship) as their mentor. Others described their teacher or classroom instructor as a mentor. Although the types of mentors varied by location, all student participants voiced appreciation for having access to a mentor to help them navigate through the internship experience. Participant one stated, "My mentor was good at providing me critical feedback and um, nuggets that were good. They might have added days on my life!”

Participant five said,

My mentor helped me. I was able to learn from someone who had, yeah, seen a lot of things in their life. I was able to ask questions and bounce ideas off them. They, um, gave me direct and sometimes brutal feedback on what I was doing. Not in a bad way. Yeah, um, I sometimes got encouragement or just that I was doing things in the right way.

Student six thought of mentorship in this way:

I think this gave me a view of real-life, where oh, yeah, I had this person who helped me understand what to do every day and helped me walk through my job, and know like, okay, gave me professional time to talk and ask questions. They helped me talk about where I was going and what I wanted to be. They helped me a lot.

Participant five said,

Uh, I think the best part was, um, building the relationship with my mentor. Um she taught me lots of things, and she was just there to-um help me, and that kind of mapped what I should do for the way I wanted to go about college.

Participant two remembered mentorship as,

So, um, they were very personal to me, and um, were just good people to fall back on to. They said they will be there when I get back from college, and if I ever need anything to come back to them. 
Participant nine related,

I got really close to my mentor. And it's just - the teaching was so different. You get to talk about things at work and your life, professional stuff, and they take time to break it down, and then once you understand it, it's like - it means everything to you.

“My mentor I think helped me personally, it helped me understand the job, my project and what I was doing. It made the whole thing better” (Participant two). Participant one described her mentor ship experience:

Mentorship was number one in my book. I didn’t get that in the classroom necessarily, because there are so many students and there's really not time to talk one-on-one with the teacher. When you are with a mentor it is kind of more laid back and they help you learn the expectations and professionalism.

Several parents in the focus group commented on the benefits of mentorship: "I think it's an opportunity to meet people in the field, to ask questions, to build those mentorships early on. The mentor expected a lot from my child as a teenager and that's okay (Parent two). Parent three added,

I think all kids need a mentor. I think some kids aren’t ready for real life and the mentorship helps this challenge. It helps the child to be better at accepting responsibilities and the independence from others. My child kind of stepped back and didn't always take the constructive criticism lightly, and um, you know, maybe got his feelings hurt. You know, in the end it was a beneficial experience for him and the opportunity to be mentored at the time. I believe it was so beneficial for him.

Parent seven said,

My child had a great mentor who prepared her for whatever was coming in the job, talked to her about the career field that she wanted, um, talked about the professional side and the professional aspect, provided the law side of it, to the hands-on experience side.

Parent ten remembered her child conveying this about her mentor, "Her mentor told her to keep in touch and said she wanted to hear how she does. She was super excited to see 
how my child grew in the internship and really cared about growing her confidence.” Parent eight said, "The mentorship and the connecting with other professionals was priceless. She has network when she gets out of college. She could go back and connect with them.”

The administrator interviews provided similar feedback on mentorship; they said that students get mentorship in the classroom; however, in internships they get professional advice that makes the experience valuable. "The internships allow our students to see the career they are thinking about through the lens of another professional" (Administrator one). Mentorship was described as "the secret sauce to the program” by Administrator three. "Without the mentorship, I don't think students would grow as much personally and professionally. These relationships are vital in connecting our students from the classroom to the workforce. The networking and mentorship are just invaluable” (Administrator three). Overall, mentorship was described as a professional relationship where life lessons, both personal and professional, are shared with the mentee for the purpose of insight, reflection, and growth. Mentees seemed to benefit from these relationships, relating the personal connections in the internship made the internship experiences meaningful and connected the interns to professionals in their career paths well beyond high school and college. Furthermore, student participants felt they benefited from the mentorship, as often these professional relationships fostered conversations in relation to college and career plans upon graduation. Student participants noted that in order to master professional (soft) skills, real world experiences, hands-on experiences, and mentorship were all needed (see Figure 10). 


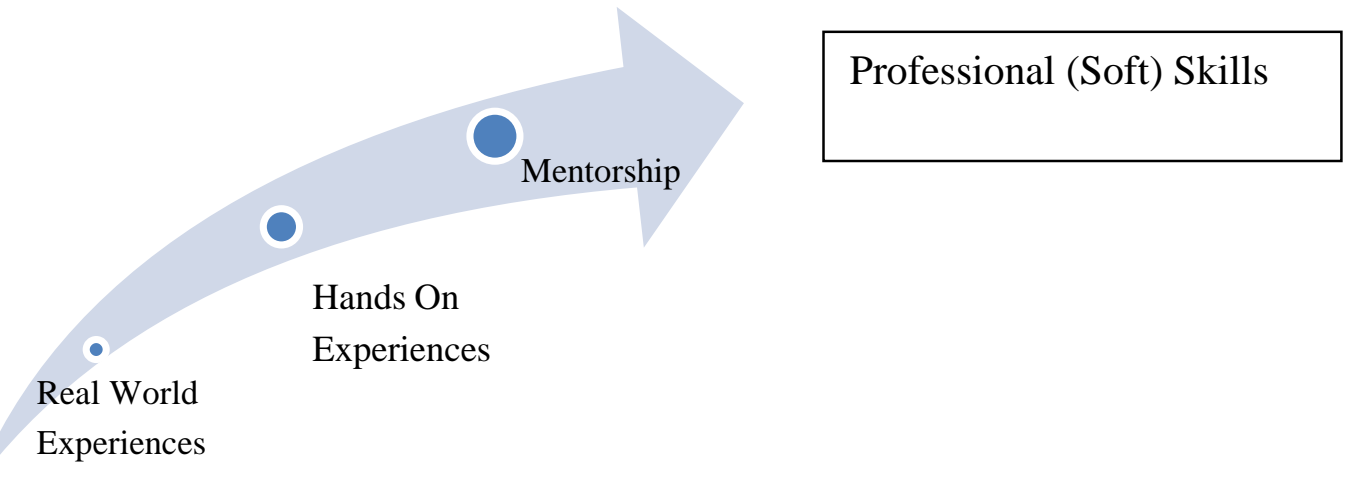

Figure 10. Professional (Soft) Skills learning subthemes.

\section{Theme 4: Post-secondary Planning}

Often, post-secondary planning is described as preparing students for college and/or career, both finically and academically. Post-secondary planning in schools can start as early as middle school, providing students with lessons and assistance on how to plan for course work in high school (Rosenbaum, Miller, \& Krei, 1996). This guidance continues into high school, with students creating personal plans of study that guide course work toward a career path based on their interests. School counselors provide lessons to students on how to access scholarships, financial aid, or technical skills prior to entering college or work (Rosenbaum et al., 1996). Post-secondary planning is a vital part of helping students plan for what they will do upon graduation. Student participants believed the internships were a key influencer by providing exploration and confirmation for their post-secondary planning. Often student participants described the internship experience as a way to validate or change their ideas, views, and plans for their college and career plans. 
We learned a lot on our careers - like people skills and just learning about your field and what you want to study. We were actually on the floor with nurses and doctors, and all different kinds of people that we learned things. So, we got to learn about all different types of jobs to help know what we want to do. (Participant seven)

Participant one added,

I liked being an employee, being professional, in the workforce, um learning what kind of jobs there are, personally that helped me. It was an eye-opener, and like I said, it helped me better understand what people do in engineering. It connected me to what I was doing and what I want to do in my life, my job.

Participant six stated,

So, when I went into it, I had the idea I wanted to become a teacher, and I liked working with children. But then after it, it really validated that I want to be a teacher. And it really made me love teaching even more, made me excited to go to college. I realized how much you impact children, and everything you do for them.

Participant three said, "Uh, originally, I just wanted to teach elementary, like regular education. But, then, when I did special education, I completely fell in love with it, and now that's what I'm going to get my degree in.” Student participants relayed their internships provided time for post-secondary planning, and parents and administrators voiced similar opinions.

Parents in the focus group expressed how important the internship was to their child's post-secondary planning. As a whole, parents stated they "wish [they] had this experience when they were in high school," as many believed it would have helped them make decisions in their life prior to graduation. During the focus group it was evident the connection between what the parents experienced in high school and what they were witnessing their child experiencing made parents believe the internship was valuable. Parent six said, 
Um, I just think it's - it's just vital in helping these young people get a clue about what they want to do. Um, so many - I don't think they really, really know until they have some of these kinds of experiences, and it's not something that you want to go into college, and not having a clue about. We really need to prepare them better I think. And the internship does a great job at that.

The focus group brought up the idea that many of their children did not have realistic expectations for college and career plans. They explained this was because many have not been in the real world, nor have they had experiences that allowed them to think or explore these options.

I think it's the real deal, it's not the classroom setting, it is actually real. You think that you like engineering, or you think you like event planning, well, here's what it is. I often think they have unrealistic expectations, they have to have time to be in it. (Parent four)

Parent one explained,

I think it has taught my child confidence in their decision on what they will do after high school, and - it's just been invaluable in helping her to experience those kinds of things they just don't get in the regular classroom setting.

Parent two relayed this subtheme in this way: "Well, I think she would be continuing her education, probably in the same field, um, maybe with less assurance that this is what she might want to do.”

Parents believed the internship was experiential learning, where students were able to put what they were learning in the classroom into a real world context. This experiential learning allowed student participants clearer perceptions and helped them make decisions about their college and career path. Parent three validated this concept.

She has so much more schema, so much more background knowledge to tie what she hears in a classroom or what she reads in a book, to what she observed and is doing. She is experiencing it. No teacher could have given her that in a traditional classroom. 
The idea that student participants were gleaning skills that a traditional classroom could not offer, leading to better further decision making, surfaced numerous times throughout the focus group. Student participants, parents, and administrators believed classroom learning was essential and coupled with an internship experience made a drastic difference in the student participants' readiness to enter the next phase of their life upon graduation. Administrator one stated,

I'm going to use that term I used earlier, they know how to do school in the public school, they understand the process because that's all they have done. And frankly, we've taught them how to do school and color inside the lines. But, when you go to post-secondary, it looks completely different. No one is there to tell you what to do. This experience is invaluable in helping these students plan for postsecondary.

Administrator three added,

Sometimes I think we push them through school and then say good luck as you go forward, but really, we're trying to help bridge that with these programs. There is a gap, um around what happens after post-secondary. After graduation, they don't always know how to make that jump, this is exactly what they need for that planning.

We lecture them, we provide the homework, we do all these things. This is their opportunity to take ownership, and their own agency of their learning. They can see this is what I've done in the classroom, this is what I think I want to do, and now I can experience it - they can then make better post-secondary plans. (Administrator two)

As student participants, parents, and administrators talked about how the internships provided insight to post-secondary planning, two subthemes emerged; career exploration and planning for a college major.

Subtheme: Career exploration. Student participants described internships as providing direct exposure to his/her career choice. This exposure, coupled with the inclassroom reflections and lessons, provided the student participants with time to 
thoroughly explore a career path prior to graduation. This exploration allowed students to engage in conversations centered on post-secondary planning. All the student participants believed this was the most important or valuable part of the internship experience. Many of the student participants talked about how this experience validated their thinking and solidified future plans. "Um, it definitely, um, solidified that I wanted to stay in business and that I want to eventually try to work with a non-profit organization” (Participant eight). Participant seven said,

In my internship, I got to be with a diabetic educator, which is what I thought I wanted to do. I was able to learn I can go one step further and go into endocrinology. And being a diabetic educator, it made me $100 \%$ know that is what I want to do.

Participant six explained the experience:

I would highly, highly, highly recommend it to any student, um, especially those who aren't really sure what they want to go into, because this opportunity allows them to branch out, and see what they would be interested in before they go to college, and pick a career path.

They really drove me to try things, um, start thinking about my job and college, where I'm going. So, this helped me, um, get better at understanding who I am and answer the question of who you are and what you are going to do with your life. (Participant one)

Others found this experience just as important as it confirmed their chosen career path was not what they had hoped. The internship experience for these students allowed further career exploration and provided clarity for changing their future plans.

Yes, I 100\% I thought I knew what I wanted to do. I was thinking about being a baby nurse, I knew I wanted to work in the medical field and with kids. This really helped me figure out that is not what I want to do. It wasn't what I thought. So, I know - I was not on the right path and it really helped me out. (Participant ten)

Participant four said, 
If you are iffy about what you want to do, or don't know, or maybe think you know, um, but unsure, you should do this. For me it solidified it, showed me the first thing I picked wasn't the path for me.

Participant one shared,

I think it is important that when you go into a career path, that you know what this is for you, because it's such a hard career, and you have to give it everything. This helped me know I picked the wrong thing and that was a good thing. And I think it's better to learn it at this age before you go to college, and you waste years on it, and then realizing it then.

Participant nine conveyed, “I would still want to teach if I hadn’t done this and I’d probably be in college and wouldn't know until after college that this wasn't for me. I am so glad I know now, super glad.” According to Participant two, “Um, it did help change my career path, in essence, from psychology to business. I was back and forth on this, I know it is business.” Overall, student participants voiced the internship provided a authentic way for them to explore their career path.

Parents and administrators articulated similar responses. The parent focus group described the internship as specifically helping their children explore a career. Parents explained this immersion into a real world experience allowed their child clarity in making a career decision prior to work or college. "The experiences they get exploring and learning about a career is amazing. The professionalism they gain, and the experiences in the actual job they think they want, cannot be learned in a classroom” (Parent three). "I think it - the experiences she ended up with from the internship - will help her with everything from interviews, from, um, understanding what she wants to do in the work field" (Parent four). Parent seven expanded on how the internship provided career exploration. 
I think the pros is being out in the field, getting to actually see what that career looks like. Um, the good, the bad, and the ugly, it really is a broader perspective to be in the trenches day by day, and they say is this really what I want to do for the rest of my life? Nothing is better than having this opportunity.

It almost scared me to think about him not having this. Because he really hadn’t locked in on a career, and I think this has really helped him realize, "Oh, this is what I'm good at, and this is what I love, and this is what motivates me. (Parent eight)

Parents were clear in expressing the internship provided student participants with a structured experience in a career field where the student participants could decide if that career was a match for them long-term. Administrators brought additional insight about how the internship connected students with what they learned in school and how to apply that knowledge to choosing a career.

Administrators communicated the importance of connecting internship programs to what is being taught in the classroom. The administrators did not see these two experiences existing separately; instead, these experiences joined together, building a bridge for each other. Administrators believed without classroom content, students would not be academically ready for their future. The administrators thought internships provided the opportunity for students to use what they learned in the classroom while cultivating their professional skills. "I think the internships for our students actually are that wonderful connection between the classroom and their world, and the career choices they explore" (Administrator one). Administrator two expanded these thoughts:

As our students decide what they want to do in the future, in the areas of interest, what a great opportunity for them to experience the career in the field. They get experiences to determine if this is their passion or not their passion. The internship helps them look towards the future with confidence in what career they are choosing. 
“Our current system doesn’t provide enough time for our students to explore their careers in a hands-on way. This um, gives them that time, gives them the opportunity to see it firsthand” (Administrator three). Student participants, parents, and administrators clearly communicated internships provide students with time to explore their career. Adding to these thoughts, each of the student participants, parents, and administrators expressed that the career exploration helped student participants make decisions about college planning.

Subtheme: Planning for a college/major. This subtheme emerged as students began talking about their experiences in the internship. Student participants stated the experience helped them validate their career path and in turn provided them insight into college planning. Many student participants talked about the lack of knowledge gleaned in high school about understanding different college majors and how those connect to a career path.

Um so, this class was awesome, it made me like realize that - and I got to start my college classes soon, and now I know what I want to do. And so that just help me like relax for graduation, and help me in getting enrolled in college and understanding my classes and what major I needed - just really help me figure out what I want to do with life. (Participant three)

Other student participants shared in the same thoughts.

I feel like if you are thinking about going to college in any way, shape, or form, you should do this program. It was very helpful to me, because I got the experience before I went to college and spent all this money on a degree I didn't want to do. It's really good experience for a high school student, helps you plan for college and your degree.

Participant five stated, “It helped me make sure I was taking the right major, or minor, um, it helped me think about that.”

Um, it allowed me to, um, just look at all the degree programs available, and figure out from like the descriptions, or talking to some of the academic advisors, 
um what would be the best path for me, because obviously not everyone is the same. (Participant six).

Participant ten shared the same sentiments: "I was able to narrow down exactly what I wanted and get exactly how I wanted it, so I would have a degree that would interest me and be applicable to life.”

Without this class, um, honestly, I think I wouldn't have a degree, I'd be working towards the degree that I ultimately did not like. I probably would be stuck somewhere in a general degree, wrong path, trying to figure out what I wanted to do, and, um, that would suck honestly. (Participant eight)

The parent focus group and the administrators highlighted similar views about how internships provided insight into future post-secondary planning for college.

The parent focus group conveyed how important the internship was in providing time for students to engage in discussions and activities about college planning. Several parents said their child had lessons in the internship curriculum that helped their child explore colleges, plan their major (based on career and academics) and make a financial plan to pay for college. Parents believed these types of activities were not embedded into regular classroom curriculum, which limited the authentic learning experiences with real life application in the classroom.

My daughter knew where she wanted to go to college, however, had no basis for that knowledge. I think most kids go where their parents go or where their parent wants them to go or where they think they can afford to go. We wanted our child to kind of keep her choices a little broader. So, she landed on marketing. So, this, um, internship has helped her kind of land on a spot that I think she can make a college choice with some real information and experience. (Parent five)

Parent two made this point about how the internships helped college planning: "She really has a lot of experiences to pull from, um, this helped her make her plans for college. The internship helped her tie those two together.” 
Parent four stated,

I was very happy she had that opportunity prior to going to college. This helped her know what she wanted to major in, um, helped her to connect her passion to her work. Making these connections to college as a high school student is just an amazing opportunity.

Similar to the parent focus group, administrators believed post-secondary planning should be included in the internship class and was invaluable in helping students be successful in the post-secondary decision making process.

Administrators expressed pride in the internship program as they described the importance of student participants connecting their career exploration to making a good decision about where to attend college. Administrator two explained,

I think it is an important thing that I see each of them with a plan for what they will do in college and in a career. I want to see each of them having selfconfidence that they made a good choice for college and what they will study there. It is this confidence they have within themselves, uh, that says they can do this and college is attainable. It tells them they can make a difference in this field that they want to go into.

Administrator three explained,

There is another piece to this around the career path that we need to talk about we need to make sure our students have a plan for college. A plan that is solid and they know they can afford it. If they have a plan and can make a financial plan to get there, then they have a fulfilling, satisfying, and rewarding experience. They can spend their life doing the things they really care about.

I really do feel like this class is a kind of validation process. For students it answers, is this the right field, um, the right career plan. They decide if college is for them or if they want to go into the workforce. They have a general term or a general idea of something they've heard about, but they don't always understand all of it. Through this, we give them time to understand. (Administrator one) 
Because of their internship experiences, student participants felt more confident to make post-secondary decisions including career exploration and planning for college and their major (see Figure 11).

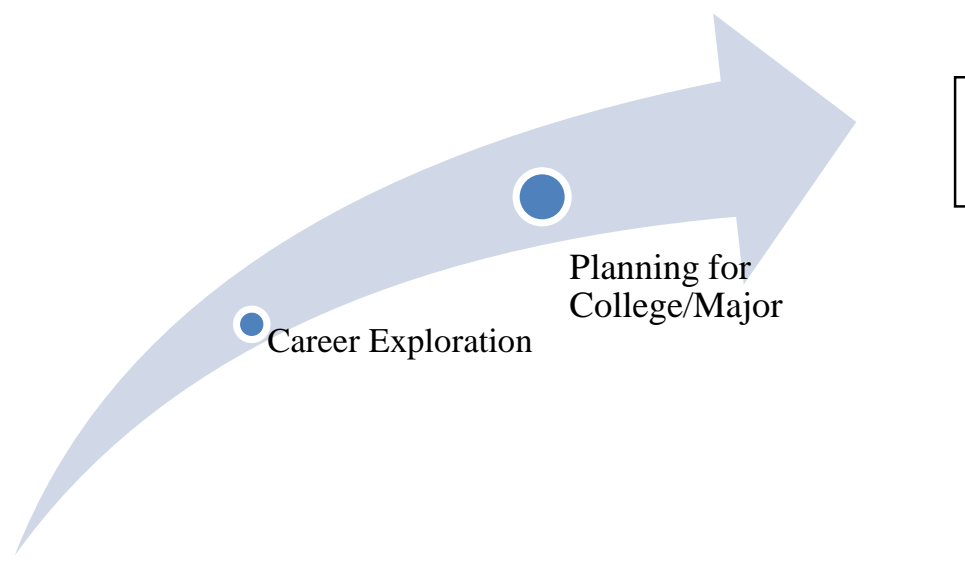

Post-secondary Planning

Figure 11. Post-secondary learning subthemes.

\section{Follow-up Questions}

Towards the end of the study, the researchers developed several follow-up questions based on the responses of the student participants during the interviews. The student participants were interviewed by phone (eight out of ten responded). The parent focus group members were interviewed via phone (all six parents responded), and all three administrators were reached and interviewed via phone.

The first follow-up question was, "What was the best part of this experience?” Three of the ten student participants said the best part of the internship as being a way of pursuing their career choices prior to going to college. "This was helpful for me to try new things before it was a life decision at stake" (Participant one). "The atmosphere, you actually get to feel what it's like being in the real world," said participant two. One participant responded by explaining how this experience provided him with a feeling of 
being an adult, in an adult world. He explained the level of trust he was given in this experience was the best part. "For me, I liked being trusted as an adult, in a real world job, um, with real responsibilities. This was like having an accomplishment before earning it” (Participant eight). Two student participants talked about the mentorship experience and that they were glad to have the connections with people where they have options to come back and work in this area. "I had the opportunity to network and get connected with great people, um, yea, I will be able to come back and will be able to know them when I am ready for a job” (Participant two). Three student participants talked about how this experience validated their future decisions and provided a sense of personal confidence moving forward from high school to college. "I would not have really known if this was for me. I thought it was, but I wasn't sure. So this validated what I was thinking and made me confident” (Participant seven). One participant believed the best part to be their ability to "see themselves in action" and know they are able to interact and be successful in an adult world (Participant six).

Parents in the focus group responded in two themes when answering this question. One theme the parents described was a sense of career exploration. They talked about how their child was able to pursue their career choice prior to college and how this exploration was beneficial in their child's personal planning past high school. Four of the six parents stated they wished a program like this had been around when they were in high school, as it would have benefited them as well.

This internship gave her the ability to interface with a lot of people doing what she says she wants to do. So, I think the internship is helping her find her direction and what she is going to do past high school. (Parent one) 
The second theme described by parents centered on professionalism. All six parents talked about how they saw their child learn professionalism while participating in the internship.

I think the internship helped her learn professionalism. Everything from interviews, from, um, understanding expectations out in the work field. She is using those experiences that she gained to help her with actual classes she will take in college. I um, think it's going to help her just be able to work with others in a more professional way, whether it is in college or with her bosses. (Parent three)

Administrators, when answering this question, had similar answers that focused on the importance of closing the gap between high school and planning or college or work experiences. Each of them believed these professional internships provided one more step to help students become college and career ready. The administrators articulated the importance of these off-campus experiences, as well as the importance of learning how to bring similar experiences into the classroom setting. All three administrators believed having the off-campus experience where students were immersed in real world circumstances was what made the most positive and transformational impact on student outcomes.

We have to do a better job of helping our students plan past high school. I think they need to know where they are heading after graduation, not just an idea, but a real plan. Plans they have been able to succeeded with or have failed. We have to help them bridge between high school and where they are heading in life. It's more than just a graduation and diploma. That is great, but they need more. (Administrator two)

"I believe these programs are helping to push back on our current models in education. We are able to see these experiences for our students and we need to bring more of this into the school setting” (Administrator one). 
The second follow-up question was, "What were the cons of the program?” This question had one similar answer throughout the interviews. Student participants identified the most difficult part of the program as transportation. Each participant had similar concerns regarding transportation. There was a two-pronged response regarding these concerns. One concern was from student participants who drove to and from the internship experience. Students stated they were responsible for their own fuel, thus creating an additional expense for the student and/or their family. Participant six stated,

Um, I definitely looked forward to it, because I knew I wasn't going to be stuck in a regular classroom, um for a while. Um, I think one of the cons though is that I had to drive, um and coming from somebody who had to pay for their own gas money every now and then, it would get, I would say expensive.

The second response was from those who did not drive. One of the internship programs provided cab transportation for those who did not drive. The other program did not. Student participants said the cab service provided additional stress, as they were responsible for helping to keep the cab service informed of changes in their changing schedules; often the cab rides were longer than if they were driving; and in some cases students described embarrassment for having to ride in a cab instead of drive. "Being in a cab can be stressful. You are responsible for letting them know of the schedule change and remembering everything, that part wasn't fun” (Participant one).

Sometimes people would ask why I didn't have my own car, like I was poor or something, um, I can't even drive yet, yea. I don't know if everyone else did that, but I was embarrassed to get in a cab at first. (Participant ten)

Overall, student participants described the off-campus experience as being a barrier for some students who were unable to juggle the sometimes weekly schedule 
changes, and get back to school for additional classes, sports, or after-school activities.

Participant seven explained,

Um some people didn't have cars. And so, there were a lot of people that would ask me for a ride, and I'd have to take them home, and stuff like that. And on some days, when school has a different schedule, like assembly days, it threw off our whole thing. Or on Wednesdays, we only had like 10 minutes to get there, and so, everybody drove like crazy, and drove really fast, and didn't have time to get back.

These concerns were coupled with the amount of time students participated in the internships. Several students stated they wished the time spent off-campus could be extended to a half-day experience, and two student participants mentioned they wished the program offered a full-day experience.

I know it's not possible, but more time in the classroom. I know we have internships, and those mean everything, and I learned so much from the internship. But, there's so much of the curriculum that we had to rush through just because we didn't have enough class time. I wish it could have been longer, more time during our school day. (Participant nine)

Parent interviews produced a common concern with student participants driving to and from the internship. Concerns varied from the lack of experience some students might have driving, additional expenses for fuel incurred by student participants/families while driving, and the multiple back and forth driving between school and the internship due to after-school activities. Parent three said,

The only con is the parking situation when she came back to school. She couldn't always find a parking spot. If it was bad weather, she would have to drive around and around to find a spot. I worried about her in the weather and where she would park if she didn’t find a spot.

An additional concern parents had was about the lack of communication about the program. Several parents stated they heard about the program from another parent and 
not from the school. Parents stated they believed the programs needed to do a better job at communicating this opportunity to both parents and students. Parents recommended letting students know they were able to do an internship and participate in school activities at the same time. "The program needs to let students know they can do an internship and still be a traditional student, in clubs and after school activities” (Parent five).

I don't think a lot of people know about this program or the expectations of the program. Now that the school is into this a few years, I think that we need to spend more time educating the staff, the counseling staff and the parents. (Parent two)

Administrator responses to this question were widely different. One administrator focused on the transportation piece, stating although she was proud they offered transportation to their students, she was unsure how long the district could sustain the cab cost.

The disadvantage and I think the challenge is being able to offer cabs or other transportation to all students who are interested in this program. I know this comes at a cost, but it's an invaluable cost. How do we sustain this without funding help as we move forward? (Administrator one)

Another administrator was concerned their program did not offer transportation and talked about this barrier for students. "We have built a program that some of our students to do not have access to. This is concerning. We must look at removing these barriers providing access and opportunity for all of our students” (Administrator two). The third administrator believed the internships were invaluable; however, he was disappointed that the educational system had not been challenged to add more of these authentic learning experiences in the classroom. "And so, I think we take these 
experiences and push them back into the current model that we're in; to provide these experiences for students, uh, within the school setting” (Administrator three).

\section{Summary}

This chapter provided an overview of high school professional internships and how these internships can be used to try to meet the expectations of college and career readiness in public education. The parameters of this study were described in depth and included the setting for the case study, the relationship of the researcher to the research, a description of the participants, and the methodology used in the study. Findings from the research questions were revealed. Perceptions about how high school professional internships impact college and career readiness were presented through the feedback from the internship student participants, parents of student participants, and administrators in several school districts. Finally, follow-up questions were presented to continue to clarify the perceptions of the research participants. Online and written artifacts were used to understand the context of the experience; in the interviews, student participants validated or invalidated the content of that experience. All research participants shared thoughts about how high school professional studies internships impacted a student's ability to be college and career ready. The responses were generally favorable that the high school professional internship experiences provided students with opportunities that aided in being college and career ready. 


\section{CHAPTER FIVE \\ DISCUSSION AND IMPLICATIONS}

At the time of this study, the school districts providing professional high school internships were considered to be a frontrunner in forging this type of off-campus programming (personal communication, Administrator one, August 11, 2017). These programs began in August of 2013 and can be attributed to forward thinking leadership in each of these programs. Administrators interviewed in this study collaborate on a monthly basis to discuss the logistics of these programs and how the districts can bring more of these authentic experiences into the individual grades K-12 classrooms. These administrators voiced the need to provide students with more nontraditional opportunities to provide insight into the students' choices upon graduation from high school.

All participants in this study believed in the appropriateness and importance of providing students with high school professional internships. Administrators interviewed voiced benefits for all students and articulated that each district had goals within their districts' strategic planning to support and expand these programs. These plans ranged from offering professional development for teacher externships with community partners to integrating professional skills into grades K-12 classroom curriculum Each administrator provided marketing materials for these internship programs, demonstrating a commitment to communicate with parents and students about these opportunities.

As a director of a program that facilitates professional internships for students, this researcher had great interest in understanding whether internship opportunities are realistic and sustainable in other districts. As the interviews progressed with the 
administrators, they too shared the same interest in how other districts were providing internship opportunities. This dialogue between the researcher and the administrators provided to be insightful for both parties (personal communication, Administrator three, August 17, 2017).

This qualitative case study was conducted to examine the impact of high school professional internships on college and career readiness. This study was framed by five research questions:

1. What experiences do internships provide in fulfilling graduation requirements and how have they helped you grow personally?

2. What soft skills (professional skills) do internships provide that cannot be provided in the traditional high school?

3. How do internships provide professional skills (soft skills) that can be used in post-secondary opportunities?

4. Did your internship provide you with experiences that helped you decide on college or career plans or change your thoughts on what you wanted to do? If so, how?

5. What was the best part of your internship and would you recommend this experience to other students and why?

Three qualitative data sources were used. First, a random sample of student participants and district administrators were interviewed, and then a focus group of parents was held. The five research questions were explored by asking participants, parents, and administrators their perceptions of how the internships impacted students' 
ability to be college and career ready after high school. These interviews and focus groups were recorded and transcribed. As the interviews progressed, the researcher began to include specific questions that emerged from the responses of the participants. This enabled the researcher to probe more deeply into the phenomena in the context of the internships (Onwuegbuzie \& Leech, 2007). Data was triangulated using the focus group, interviews, and collected artifacts. There were no changes to the transcripts, which allowed verification of trustworthiness and accuracy of the interview process. This allowed the researcher to begin the process of open and axial coding of the data (Creswell, 2009). The previous chapter ended summarizing the findings related to the research questions. This chapter discusses the case study findings as they relate to the literature through the lens of change theory, implications for future practice, and research and conclusions.

\section{Discussion of Findings}

The findings revealed four themes in this study using axial coding: (a) Transformational Learning; (b) Professional Experiences; (c) Professional (Soft) Skills; (d) Post Secondary Planning. Table 2 shows the four themes and subthemes derived from this coding process. 
Table 2

Themes and Subthemes

\begin{tabular}{llll}
\hline Theme 1 & \multicolumn{1}{c}{ Theme 2} & \multicolumn{1}{c}{ Theme 3 } & \multicolumn{1}{c}{ Theme 4 } \\
\hline $\begin{array}{l}\text { Transformational } \\
\text { Learning }\end{array}$ & $\begin{array}{l}\text { Professional } \\
\text { Experiences }\end{array}$ & $\begin{array}{l}\text { Professional (Soft) } \\
\text { Skills }\end{array}$ & $\begin{array}{l}\text { Post Secondary } \\
\text { Planning }\end{array}$ \\
Personal Reflections & $\begin{array}{l}\text { Personal Attributes } \\
\text { and Values }\end{array}$ & $\begin{array}{l}\text { Real World } \\
\text { Experiences }\end{array}$ & Career Exploration \\
Personal Validation & $\begin{array}{l}\text { Professional } \\
\text { Communication }\end{array}$ & $\begin{array}{l}\text { Hands-On } \\
\text { Experiences }\end{array}$ & $\begin{array}{l}\text { Planning for } \\
\text { College/Major }\end{array}$ \\
Self-Confidence & $\begin{array}{l}\text { Professional } \\
\text { Demeanor }\end{array}$ & Mentorship & \\
\hline
\end{tabular}

\section{Michael Fullan's Change Theory}

Michael Fullan's work in Change Theory referred to change as a constant journey, not a blueprint. Within change are uncertainties coupled with positive and negative forces of change. Leaders learn to maneuver within these uncertainties, carrying the core of the change forward. Fullan's book entitled The Six Secrets of Change (2011) described essential lessons for leaders to survive and thrive when implementing change in today’s complex educational systems. Leaders provoking change must master the concept of Change Theory and possess Change Theory skills to successfully apply large-scale reform. Without these skills, leaders are lost to rigid, chaotic systems, unable to navigate a road map to sustainable change. Fullan’s work creates a mental model for leaders capturing the conceptualization and multidimensional parts of educational change. Within this model, leaders learn the phases of change as a tool to implementing educational initiatives. Fullan's six secrets of change are summarized in this way: 
1. Love your employees. Fullan (2011) believes successful change happens when there is employee contribution in the strategic planning of change. Within this concept, employees have ownership and work diligently to uphold change goals during pinnacle times when the change becomes difficult to sustain.

2. Connect employees with purpose. Fullan (2011) believes employees who feel valued and are connected to the organization have purpose within the organization. This value promotes employees working towards a common goal rather that serving the individual goals or needs of the employee.

3. Capacity building prevails. Fullan (2011) believes organizations should strive to have processes that hire the right people coupled with providing the employees with opportunities to improve. Hiring talented employees with the opportunity to learn and grow provides capacity within the organization to promote, drive, and sustain organizational change.

This theory can be applied to the study's outcomes in relation to organizational or educational change. Historically, education has failed to embrace change systemically without state or federal mandates. Educational systems are bound to accountability measures that are often fraught with lack of equity, resources, and in some cases, community support. Due to limited resources and funding, public schools are forced to prioritize programs according to academic outcomes. Often programs, such as internships, are cut from comprehensive high school curricula due to lack of evidence that they enhance or improve academic achievement. This study provided insight from 
participants, parents, and administrators who validated positive outcomes for students participating in high school internships.

These summaries surfaced throughout the case study: Participants articulated internships provided purpose and value to their high school course work. Through the internships, students were provided experiences to learn professional skills while building a sense of self-confidence. This confidence provided students with the ability to make more informed choices upon graduating from high school. Students shared their experiences with other students, teachers, and administrators, thus sparking the spirit of change. Parents witnessed their children's personal and professional growth, awareness, and confidence throughout the internships. Parents articulated the importance of these internships in student's planning for postsecondary experiences. All parents believed their child was better equipped to enter a postsecondary experience upon graduation after completing the high school internship. These parent beliefs were relayed to teachers, other parents, and school administrators, thus sparking the validation for change. Administrators received feedback from students, parents, and teachers regarding the impact of internships on students’ postsecondary planning. Each administrator interviewed articulated that the impact of high school professional internships on students was transformational. In all accounts, case study participants described their internship as a way of changing their thoughts, ideas, values, and life decisions. This type of change is transformational. Transformational change is sustainable (Mezirow, 1991). Fullan’s Change Theory would reinforce the positive synergy of these programs and emphasize the need to include students, teachers, parents, and community members in a 
collaborative effort to improve, enhance, and sustain these types of programs within the public school setting.

\section{Transformational Learning}

Transformational learning was described by Mezirow (1991) as a constructive way of learning. The learner makes meaning from their "sense of the experience.” This "sense of the experience” is where the learning happens. Participants in this case study identified with key components of transformational learning such as personal growth and insight, personal connectiveness to career goals and passions, professional (soft) skill building, one-on-one mentorship, and long-term college and career planning opportunities. The internship experiences provided participants the opportunity to form cognitive and emotional perceptions through the experiential nature of these internships. These perceptions were shaped as the participants gleaned experience in critical thinking, problem-solving, decision making, recovering from failures and/or disappointments, selfreflection and internalizing positive/critical feedback. Each professional experience served as a building block to validate or change the participants' previous biases or perceptions. This validation, exploration, and "real world” hands-on experience proved to be the catalyst in sparking this transformational learning experience for the participants.

Internships provided participants the opportunity to feel confident in making plans for college and/or career opportunities beyond high school. A common theme was expressed: Participants believed this experience provided needed insight into post secondary planning that would not have been possible in the traditional comprehensive high school experience. This experience was described as a key component in aiding high 
school students in being college and career ready. These participants described having less anxiety and feeling better prepared to make decisions about their future based on what they had experienced.

\section{Professional (Soft) Skills}

Professional skills, more commonly known as soft skills, were the second theme that emerged in this study. All participants, parents, and administrators articulated that the internships provided the development and mastery of soft skills, including the ability to have people skills (interacting with others), personal attributes (characteristics), and social skills (communication). Harvard University conducted a study noting $80 \%$ of achievements in a career are determined by soft skills and only 20\% by hard skills (Studer, 2017). Soft skills are prioritized differently within each industry; however, this broad term is used when describing a set of skills needed by employees to successfully navigate their work environment. Internships provided participants with four weeks or 40 hours of professional skill building and a minimum of 100 hours of internship within a 16-week period. All the programs studied focused on helping students identify their personal values and attributes (such as honesty, integrity, compassion, and motivation), how to fit into the workplace through effective communication skills (such as professional writing, responding to positive and/or critical feedback, and communication and presentation skills) and portraying oneself in a professional manner (such as making eye contact, confident handshakes, and developing a 30-second elevator speech).

Participants described these skills as a fundamental part of their success. Each participant commented on how their professional skills led to successful communication with adults. 
These skills provided participants the opportunity to show initiative, be reliable, and seek out feedback. Participants believed these skills would help them be successful in both college and in a job. They voiced concern that these skills were not routinely taught in a traditional classroom and believed they may not have been as successful in a job without learning them.

Current research suggests soft skills or a lack of professionalism is seriously lacking from candidates entering into the workforce. Studer (2017) said this lack of professionalism is a key contributor as to why individuals fail in jobs. All the participants used the term "professionalism” in their interviews. It was clear the participants had an understanding of what professionalism meant and how it is demonstrated on a job. Participants viewed learning these skills as a way of building their confidence, allowing the interns the ability to integrate into their internship smoothly. Participants, parents, and administrators believed professional skills should be taught throughout school. This type of integration from grades preK-12 would support the development of students being college and career ready. The mastery of soft skills within the professional internship provided another positive building block to prepare students for college experiences and aided in their ability to enter the world of work successfully.

\section{Implications for Practice}

The following recommendations have stemmed from an in-depth investigation of the literature and a comprehensive understanding of the perceptions of the participants in this case study. These recommendations are offered to assist schools in their efforts to improve college and career readiness through high school professional internships. Many 
of these implications could be applied to traditional classrooms within a comprehensive high school in order to afford more authentic learning experiences.

1. Communicate the vision, mission and values. Often new programs go unnoticed and have little impact on the larger system when the vision is not clearly communicated to the workforce within an organization. Vision gives meaning and purpose to the implementation and work done within the initiative. In some cases, lack of communication can sabotage the initiative's progress and its integration into the larger system. Internships serve as one component in the overall goal of college and career readiness (Fullan, 2011). For most of these programs, it seemed as though they were competing with other courses and programs. This competition seemed to break down the effectiveness in marketing and recruiting students into internships. Students often relayed that classroom teachers lacked understanding and vision about what these internship courses offered and how internships complemented and reinforced classroom learning.

2. Build in measurement. Although participants in this case study articulated the importance and value of internships, a clear measurement to capture this success in numbers or words was not present. Administrators believed the programs were doing a good job and providing valuable experiences for their students; however, they were unable to share data to reinforce these opinions.

3. Collaborate with customers and stakeholders. Internships provided multiple opportunities for continued growth and improvement. Parents, students, staff, 
administration, and community partners should be part of assessing the program and providing feedback for improvement. This type of continuous improvement would build ownership from customers and stakeholders, thus providing multiple levels of communication and commitment to the continued implementation of the internship program.

4. Provide multiple opportunities for feedback loops. Perceptions surveys should be given to all customer and stakeholder groups as a means to gather perceptions of the program. These surveys would encompass questions that would help determine how effective internships are in improving college and career readiness. Surveys should also include opportunities for customers and stakeholders to offer input in identifying strengths of the program and improvements that can be made.

5. Allot funding to hire fulltime staff to plan, cultivate, and improve programming. The internship programs that allotted funds to hire fulltime staff (teachers working only in the internship program) seemed more successful in moving these courses forward than those that shared part-time staff from high school buildings. Part-time staff were unable to provide adequate time to mentor and observe students in the internships, cultivate meaningful relationships with community partners, and actively pursue new partners for internships.

6. Provide thoughtful marketing. Provide clear and purposeful messaging when communicating on websites and marketing materials. Artifacts were taken 
from websites and marketing materials were collected for each of the programs. Although the messages were clear in outlining program information, they lacked connection to the overall vision of the comprehensive high school and school district. None of the programs articulated how these experiences provided insight into post secondary planning or provided opportunities to improve college and career readiness. This disconnectiveness seemed sabotaging to the overall implementation of high school internship programs. Providing the connection (in the marketing materials) between what students are doing in their content work in the classroom (their academic pathway to college and career readiness) with what they will learn in an internship seems valuable. Relaying a message that internships are enhancing classroom learning seems important and may decrease the competiveness between the high schools and the internship courses.

7. Hire the right fit. Participants in the study talked a lot about the teachers in these courses/programs. The difference between those who were "assigned" to teach an internship course and those who wanted to teach the course was obvious. Nothing sabotages an initiative more quickly than a negative workforce. Participants were aware of disgruntled or disconnected staff members and articulated the negative impact these teachers had on the internship experience. Interestingly, the students in this study still valued the experience despite having negative opinions about the teachers. 
8. Communicate the vision to the community. Successful internship programs spent time meeting with local chambers and economic development councils to provide information to community businesses about the internships. These local organizations also provided marketing materials to help recruit community partners for internships.

9. Partner with parents to find internship opportunities. One out of the three programs targeted parents as key partners for internship recruitment. This type of recruitment makes sense. Parents are invested in their child’s learning. Soliciting parents as a way to build referrals for internships seemed to provide this program with a quicker start-up time in acquiring internships for students. Partnering with parents seemed to reduce cold calls to businesses and provided a natural networking resource throughout the community.

10. Develop a clear framework for program goals and outcome expectations. Each of the programs researched in this case study had a framework for day-to-day operations. This framework was unclear about how program goals were set and evaluated. This seemed confusing to parents, who articulated they were hesitant at first to send their child out into an internship. Parents also articulated they were confused about the benefits of this course and had difficulty helping their child decide between an internship and an AP (advanced placement) course. Internship courses should clearing post outcome goals showing how they provide career exploration and improve post secondary decision making for students. 
11. Develop curriculum. When introducing new learning models, developing curriculum is essential. Two of the three programs had a written curriculum for the internship course. One program seemed unclear, vague, and disorganized in their curriculum expectations. Clear articulation of the curriculum helps parents and students know what they will learn. A lack of curriculum seems to detract from the credibility of the course or program. Public education accountability outcomes are based on a guaranteed, viable, and rigorous curriculum. This is essential when competing with traditional learning models. Parents, students, and even staff members can be unclear about how authentic experiential learning is engaging, motivating, and providing opportunities for personal reflection and growth.

12. Provide face-to-face meetings with students. Internship courses must provide weekly check-ins with teachers. Courses providing only online connections with teachers didn’t appear adequate. Programs lacking weekly check-ins seemed to have less meaningful relationships and mentorship opportunities between the teacher and student. This face-to-face contact served as the catalyst in the transformational learning process. Students who were given time to talk about their experiences, voice concerns, and glean insight and encouragement from their teacher reported having a deeper level of personal/professional growth.

13. Provide students with service learning or project time. Each program provided opportunities for students to work together on a project throughout the 
semester. Project time was provided once a week for students during the faceto-face check-in times. These projects ended each semester with a culminating event in the community. Projects were reported as a valuable experience by students. Students said project time provided them with the opportunity to work collaboratively with students from numerous career paths. Students believed they acquired insight into other careers through hearing the experiences of other students in their group.

14. Provide opportunities for students to learn professional skills (soft skills). Professional skill building (soft skills) was a key component in the internship courses. Each of these programs provided students with time to learn professional skills (soft skills) prior to going out into the internships. Participants stated they did not have opportunities in traditional classrooms to learn the soft skills needed to enter the workforce. Programs that offered a minimum of three to four weeks of skill training prior to students entering the internship seemed adequate. Participants in this study relayed students who had three to four weeks of skill training entered the workforce with more confidence than those with online training or one-day camps.

15. Provide students with personalized internship opportunities. Students need to be matched with internships that connect as closely as possible to their career choice. Programs that recruit partners and place students with partners are different than programs who find partners based on student interest. Matching students with partners is more time consuming and requires ongoing 
recruitment of partnerships; however, this type of programming seems to provide a deeper level of engagement on the part of the student.

16. Provide mentorship time with teachers and partners. Participants named mentorship as a key component to transformational learning and post secondary planning. Participants in programs providing weekly mentorship reported more validation of career choices, more reflection opportunities, and increased personal/professional growth.

17. Provide mentorship training for partners. None of the programs provided training to partners on mentorship. Some participants complained they did not get constructive feedback in their internships. Basic mentorship training to community partners may improve and strengthen mentorship feedback within internships.

18. Provide ongoing communication and support for partners. Programs in this study provided two to three onsite internship visits by teachers. Visits provided time for partners and students to do evaluative midterms and finals, highlight accomplishments, ask questions, and provide feedback. All of the programs provided support to partners when the student was not a fit for the business or organization. In some cases, program staff members assumed responsibility for coordinating necessary paperwork for the partner's human resource department (gathering paperwork from students). 
19. Provide time for reflection. Reflection time built into the program's curriculum provide students structured opportunities to think about what they had learned and apply that understanding to themselves.

20. Provide time for post secondary planning. Program curriculum should have purposeful learning activities that help students plan for after high school. This should include exploration of personal values, financial planning, college exploration/planning, and career exploration/planning. This type of programming was reported by participants as improving confidence in student decision-making for plans past high school.

21. Provide time for parents to be involved in the programming/course. Involving parents in professional skill building activities improves parent communication and engagement. Several programs enlisted parents to be guest speakers, recruit business partners, and provide help with mock interviews and resume building.

22. Provide transportation. Participants reported that not all programs provided transportation to and from internships. Students stated lack of transportation was a barrier for some of their friends, thereby eliminating them from enrolling in an internship experience. One program raised money to provide cab services for students who could not access transportation.

23. Provide access to technology. Make sure district level technology departments (those providing one-to-one hardware) can support students with necessary rights or privileges when in an internship. For example, students need access 
to g-mail accounts, laptops that can access $\mathrm{Wi}-\mathrm{Fi}$ at businesses, the ability to download programs from business, and so forth. Lack of these resources can cause barriers for students in meeting expectations and completing onsite projects.

24. Provide resources for professional dress. All of the programs set expectations for students to have professional dress when in the classroom and onsite at internships. Expectations for professional dress may be a struggle for some students. One program provided students with resources to purchase clothes if this was a barrier to dressing professionally on a daily basis.

25. Provide activities that showcase student work. Two of the three programs provided an event where students displayed their work from the internship. Community members, media, board members, parents and families, school staff, and other students were invited to tour the event. This type of event provides accountability for students and demonstrates the mastery of skills learned within the internships.

26. Provide teachers in traditional classrooms to observe. One of the two programs provided opportunities for teachers to come and observe the classroom activities and hear from students about their experiences; it also offered teachers summer externship opportunities with business partners. This type of professional development provides teachers with strategies for integrating authentic learning experiences within traditional classrooms. 
27. Be prepared to strategically respond to disruption. This type of programming can serve as a disruption to traditional educational pedagogy. Being prepared to respond to the reaction to this disruption is essential to the progress of the initiative. Districts using this model as a catalyst to improve authentic experiences in classroom learning should be strategic in articulating how this type of learning can be integrated within the traditional classroom setting.

Transformational learning was a common theme described by this study's student participants. High school professional internships not only provided opportunities for students to master professional skills (soft skills), it also provided a natural bridge between high school and post-secondary planning. Upon completion of these programs, student participants believed they had more confidence to transition into the world of work and were more capable of making informed decisions about college and career pathways.

\section{Implications for Future Research}

The following implications emerged in this case study. These implications are presented in hopes of inspiring future research in the area of how professional high school internships impact student college and career readiness. First, a case study similar to this one, with a large sample size, could be compared to the findings in this study. Secondly, longitudinal data (of students who have done internships) could add validity to this study. Looking at perceptions of students one, two, and five years after high school and measuring their perceptions of how internships impacted their college and career readiness could be compared to this study's outcomes. Finally, future studies could 
measure integrating these type of authentic learning experiences in traditional classrooms and the impact those strategies have on college and career readiness.

\section{Conclusion}

This study showed professional high school internships to be beneficial to students in the areas of validating their career choices, building confidence in decisionmaking during post-secondary planning, and increasing professional/personal growth. Student participants in this study clearly articulated their connection to personal growth and a new sense of confidence for postsecondary planning. “I don’t know where I’d be without this experience. I feel more confident that I can make good decisions about my future, my life” (Participant three).

Districts providing these experiences appeared forward thinking in wanting to provide students with transformational learning experiences. Student participants reported they were given opportunities to engage in real world, personally relevant experiences. These experiences, coupled with professional mentorship, allowed students to feel assured in their decision making as they transitioned between high school and the world of work. “Without this experience, I don’t know where I’d be. I guess others would be making decisions for me rather than with me” (Participant three).

As schools are faced with programming decisions and budget constraints, it is this researcher's hope that this study will provide new insight into how high school internships impact students' ability to be college and career ready, thus validating the importance of internship experiences in comprehensive high schools. "I would definitely recommend this to other students. Everyone needs the opportunity to experience this 
program, they need to be given time to make sure they know what they want to do after high school” (Participant three). 


\section{APPENDIX 1}

\section{PARK HILL APPROVAL LETTER}

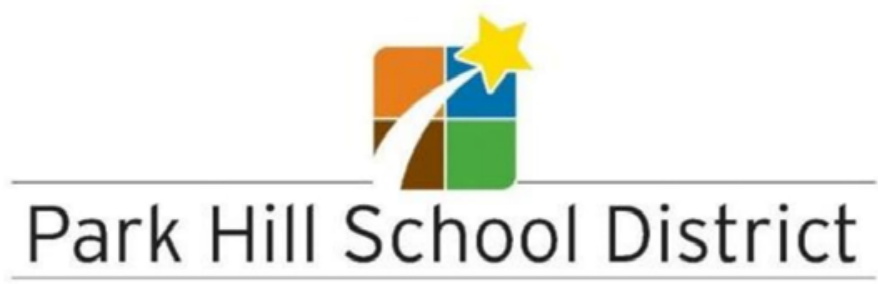

Building Successful Futures. Each Student . Every Day

April 9, 2017

Dear Ms. Amaya:

Per Park Hill School District Board Policy, external agencies or individuals desiring to conduct research studies involving either students or staff members during the school day must submit a written prospectus to the Superintendent, or designee, for approval prior to initiation of the study. To be approved, all such research proposals must demonstrate that the projected findings will have value to either the District as a whole or to a unit within the District, and not be unduly disruptive or time consuming to the normal educational process.

The Park Hill School District recognizes the importance of research as a means of improving the instructional program for the District's students and also recognizes the need to monitor and control the amount of time and energy expended by both staff and students on research projects.

I have had the opportunity to review the prospectus for the research project entitled $A$ CASE STUDY OF THE IMPACTOF PROFESSIONAL INTERNSHIPS ON COLLEGE AND CAREER READINESS. It is my pleasure to approve the project A CASE STUDY OF THE IMPACTOF PROFESSIONAL INTERNSHIPS ON COLLEGE AND CAREER READINESS and the use of relevant Park Hill School District data, classrooms and students within the project. I find the project to have value to the district, support the goals of the district, and not be unduly disruptive or time consuming to the educational process.

Please contact me if you have any questions.

Cordially,

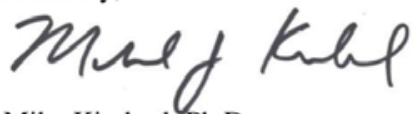

Mike Kimbrel, Ph.D.

Executive Director for Quality and Evaluation

Park Hill School District 


\section{APPENDIX 2}

\section{IRB APPROVAL LETTER}

May 23, 2017

Principal Investigator: Stephanie L Amaya, Ed D- ELPA

Department: Educational Leadership and Policy Analysis

Your Exempt Application to project entitled A CASE STUDY OF THE IMPACTOF PROFESSIONAL INTERNSHIPS ON COLLEGE AND CAREER READINESS $w$ as reviewed and approved by the MU Institutional Review Board according to the terms and conditions described below:

$\begin{array}{ll}\text { IRB Project Number } & 2008112 \\ \text { IRB Review Number } & 224715 \\ \text { Initial Application Approval Date } & \text { May 23, 2017 } \\ \text { IRB Expiration Date } & \text { May 23, } 2018 \\ \text { Level of Review } & \text { Exempt } \\ \text { Project Status } & \text { Active - Open to Enrollment } \\ \text { Exempt Categories } & 45 \text { CFR 46.101b(1) } \\ \text { Risk Level } & 45 \text { CFR 46.101b(2) } \\ \text { Internal Funding } & \text { Minimal Risk }\end{array}$

The principal investigator (PI) is responsible for all aspects and conduct of this study. The PI must comply with the following conditions of the approval:

1. No subjects may be involved in any study procedure prior to the IRB approval date or after the expiration date.

2. All unanticipated problems and deviations must be reported to the IRB within 5 business days.

3. All changes must be IRB approved prior to implementation unless they are intended to reduce immediate risk.

4. All recruitment materials and methods must be approved by the IRB prior to being used.

5. The Annual Exempt Form must be submitted to the IRB for review and approval at least 30 days prior to the project expiration date. If the study is complete, the Completion/Withdrawal Form may be submitted in lieu of the Annual Exempt Form

6. Maintain all research records for a period of seven years from the project completion date.

7. Utilize all approved research documents located within the attached files section of eCompliance. These documents are highlighted green.

If you are offering subject payments and would like more information about research participant 
payments, please click here to view the MU Business Policy and Procedure: http://bppm.missouri.edu/chapter $2 / 2 \quad 250 . \mathrm{html}$

If you have any questions, please contact the IRB at 573-882-3181 or irb@missouri.edu.

Thank you,

MU Institutional Review Board 


\title{
APPENDIX 3
}

\section{LETTER FROM THE EXECUTIVE DIRECTOR OF QUALITY AND EVALUATION}

Dear

I am writing you on behalf of Stephanie L. Amaya, the director of professional studies in the Park Hill School District. She has been a staff member in Park Hill for the past seven year and working in public education for the past 21 years. She has served as a social worker, teacher, counselor and administrator during her 21 year tenure. She is currently completing her dissertation at the University of Missouri and will be conducting a study in our district. Her dissertation is titled, "A Case Study of The Impact of Professional High School Internships on College and Career Readiness”. This study focuses on student's perceptions of how his/her internship impacts skills needed to be successful beyond high school. This study will help our school district in providing recommendations for future Professional Studies program development.

I believe it is important for our district to understand how these internships impact or students. It is import to study students', parents' and administrators' opinions and beliefs regarding these professional studies experiences. Voices from each of these levels will be invited to be heard. This study is confidential; no identifying information of any of the participants will be disclosed.

Soon, Mrs. Amaya will contact you by email to ask you to be part of the study, which will take approximately one hour of your time. I encourage you to volunteer to be one of the participants. Please feel free to reach out to me with any questions.

\author{
Sincerely, \\ Dr. Mike Kimbrel \\ Executive Director for Quality and Evaluation \\ Park Hill School District
}




\section{APPENDIX 4}

\section{INITIAL CONTACT VIA PHONE}

Good day,

I am a doctoral student at the University of Missouri working on my doctoral degree in Educational Leadership and Policy Analysis and am working with your district to gather information about internships in the Northland School District. This information will be used to improve the overall Professional Studies programming. Your input is extremely valuable in this project.

Your participation as either an interviewee or a focus group member (parent) is entirely voluntary; there will be no compensation for participating. I'd like to assure you that all participants will be protected by confidentiality from any negative repercussions from participation. The interviews and focus group will be held in a quiet and secure setting at a time convenient for you, and you will have the opportunity to review a transcript of the interview or focus group for corrections. I would like to begin accumulating data within three weeks, so please respond soon if you are interested.

There are no known risks or discomforts associated with this research study. If you have concerns you may contact my research advisor, Dr. Carole Edmonds, at cake@nwmissouri.edu or 660.562.1258. If you would have any further questions, please feel free to contact me, the researcher, at stephanieforsure@gmail.com.

I'd like you to read over my Informed Consent Statement. Would you feel comfortable with me obtaining your email address to send this to you? Thank you for your willingness to participate in this case study. I will send you via email to become familiar with your rights. If you consent to be interviewed in a one-on-one situation, please contact me at the following email or phone numbers (Numbers were deleted to be faithful to anonymity of the district):

stephanieforsure@gmail.com

Thank you for your time,

Stephanie L. Amaya 


\section{APPENDIX 5}

\section{INFORMED LETTER OF CONSENT}

\section{STUDY TITLE: A CASE STUDY OF THE IMPACT OF PROFESSIONAL INTERNSHIPS ON COLLEGE AND}

\section{CAREER READINESS}

1. I would like to ask you to participate in a study that involves research.

2. Participation is voluntary and your decision not to participate will not involve any penalty or loss of benefits.

3. For this study, informal semi-structured interviews and focus groups will be used for gathering data. Students, teachers and administrators will participate in the informal semistructured interviews and parents will participate in the focus groups. The data collection in both the interviews and focus groups will answer the main research question, "What is the impact of high school internships on college and career readiness?" A semi-structured interview method will be followed during the interview sessions and the focus groups. Questions will follow an open-ended format in order to gain a deeper understanding of the participants experiences, allowing each participant their own scope and pace of reporting. Finally, each interview and the focus group will be audio-recorded and the researcher will take notes as a cross reference for accuracy when working with transcriptions. The researcher will provide all semi-structured interview participants and focus group participants with a half hour follow-up (done within 10-15 days of the original interview) to assure trustworthiness within the interview process. At this time, participants will be provided an opportunity to check for accuracy in the researcher's reflected transcript and artifacts. Furthermore, during the follow up interview, participants will be provided additional follow-up questions relating to themes emerging from initial data coding and analysis to ensure interviews have reached proper saturation in answering the research question.

4. The purpose of our study is to explore the impact high school internships have on college and career readiness. As school districts continue to search for ways to improve postsecondary preparedness, this study aims to determine whether internships serve as a valuable part of the high school experience that directly impacts college and career readiness.

5. We are asking approximately $10-15$ subjects to participate in this study.

6. The researcher may withdraw you from the study at any time after explaining to you the reason for withdrawal.

7. While participating in the study, you are at risk for discussing experiences that might have been uncomfortable or provoke emotions from the experience. You should discuss these with the investigator.

8. If you agree to take part in this study, you may expect to benefit from taking part in this research to the extent that you are contributing to the body of research knowledge.

9. If you choose to participate, confidentiality is ensured throughout the study. All information collected by the researcher is considered confidential information and will not be shared. The researcher will increase participant confidentiality by providing the use of pseudonyms and by archiving data by type (interview, survey, and artifact) and not by participant.

10. There is no compensation given to you for participation in this study. 
11. If you have any questions regarding your rights as a participant in this research and/or concerns about the study, or if you feel under any pressure to enroll or to continue to participate in this study, you may contact the MU Campus IRB at (573) 882-9585.

12. If you have any problems or questions, you may contact Stephanie L. Amaya, Principal Investigator at 816.547.2303.

13. I would be happy to answer any questions that you may have.

\section{Researcher Contact Information:}

Stephanie L. Amaya

Principal Investigator

3109 S. Redtail Drive

Blue Springs, MO 64015

816.547.2303

stephanieforsure@gmail.com
Carole Edmonds, Ed.D.

Faculty Advisor

Educational Leadership and Policy Studies

Northwest Missouri State University

Maryville, MO

660.562.1258

cake@nwmissouri.edu 
APPENDIX 6

SEMI-STRUCTURED INDIVIDUAL INTERVIEW QUESTIONS

Pseudonym:

1) What experiences do internships provide in fulfilling graduation requirements and how have they help you grow personally?

2) What soft skills (professional skills) do internships provide that cannot be provided in the traditional high school?

3) How do internships provide professional skills (soft skills) that can be used in postsecondary opportunities?

4) Did your internship provide you with experiences that helped you decide on college or career plans or change your thoughts on what you wanted to do? If so, how?

5) What was the best part of your internship and would you recommend this experience to other students and why? 


\section{APPENDIX 7}

FOCUS GROUP INTERVIEW QUESTIONS

Pseudonym:

1) What experiences do internships provide in fulfilling graduation requirements and how have they help you grow personally?

2) What soft skills (professional skills) do internships provide that cannot be provided in the traditional high school?

3) How do internships provide professional skills (soft skills) that can be used in postsecondary opportunities?

4) Did your internship provide you with experiences that helped you decide on college or career plans or change your thoughts on what you wanted to do? If so, how?

5) What was the best part of your internship and would you recommend this experience to other students and why? 


\section{APPENDIX 8}

\section{FOLLOW-UP PHONE CALL PROTOCOL}

\section{Project: Impact of Professional High School Internships on College and Career Readiness}

Researcher: "Hello, this is Stephanie Amaya and I am a doctoral student at the University of Missouri who recently interviewed you for my case study. I would like to take this time to go over your transcripted responses to assure I have collected your thoughts accurately.”

\section{Participant: Response}

Researcher: "Secondly, I'd like to ask you some additional clarifying questions. These questions were created to continue to clarify your responses and understand your perceptions of the case study."

Researcher engages in questions.

Researcher: "Thank you for agreeing to meet with me via phone. Is there anything else you would like to add?"

Researcher: "Thank you for your willingness to participate in this case study. Your time is greatly appreciated.” 


\section{REFERENCES}

A guide to career readiness \& employability skills lesson plans. (2015). Applied Educational Systems. Retrieved from http://www.aeseducation.com/careercenter21/employability-skills-lesson-plans/

Achieve. (2016). The college and career readiness of U.S. high school graduates. Retrieved from http://www.achieve.org/state-profiles

Alfeld, C., Charner, I., Johnson, L., \& Watts, E. (2013, February). Work-based learning opportunities for high school students. The National Research Center for Career and Technical Education. Retrieved from http://www.nrccte.org/resources/publications/work-based-learning-opportunitieshigh-school-students

Asher, H. B. (1984). Theory-building and data analysis in the social sciences. Knoxville, TN: University of Tennessee Press.

Bentley University. (2014, January 29). The prepared U project: An in-depth look at millennial preparedness for today’s workforce. Retrieved from Bentley.edu

Berkeley: University of California Career Center. (2016). Career exploration. Retrieved from https://career.berkeley.edu/Info/CareerExp

Bohrnstedt, G., Birman, B., Phillips, G., Osher, D., \& O’Day, J. (2013). Three decades of education reform: Are we still “A Nation at Risk”? (2013). Retrieved from http://www.air.org/resource/three-decades-education-reform-are-we-still-nationrisk 
Brand, B. (2009, November). High school career academies: A 40-year proven model for improving college and career readiness. Retrieved from http://casn.berkeley.edu/resource_files/career-academies-policy-paper-10-1509.pdf

Bridgeland, J. M., Dilulio, J. J., \& Morison, K. B. (2006, March). The silent epidemic: Perspectives of high school dropouts. Washington, DC: Civic Enterprises with Peter D. Hart Research Associates.

Carnevale, A. P., Rose, S. J., \& Cheah, B. (2011). The college payoff: Education, occupations, lifetime earnings. Georgetown University Center for Education and the Workforce. Retrieved from https://cew.georgetown.edu/cew-reports/thecollege-payoff/

Casner-Lotto, J., \& Barrington, L. (2006). Are they really ready to work? Employers' perspectives on the basic knowledge and applied skills of new entrants to the 21st century U.S. workforce. USA: The Conference Board, Inc., the Partnership for 21st Century Skills, Corporate Voices for Working Families, and the Society for Human Resource Management.

Cawelti, G. (2006, November). The side effects of NCLB. Educational Leadership, 64(3), 64-68.

Common Core State Standards Initiative. (2016). Frequently asked questions. Retrieved from http://www.corestandards.org/about-the-standards/frequently-askedquestions/ 
Commonwealth Association for Public Administration and Management. (2010).

Overview of case study models and methodology. Retrieved from https://www.scribd.com/document/91619866/Report-on-Case-StudyMethodologies

Conley, D. T. (2011). Redefining college readiness. Eugene, OR: Educational Policy Improvement Center.

Conley, D. T. (2012, May 2). A complete definition of college and career readiness. Retrieved from http://bostonbeyond.org/wp-content/uploads/2016/06/Conleycollege-readiness-definition-2012.pdf

Conley, D. T., Drummond, K. V., de Gonzalez, A., Rooseboom, J., \& Stout, O. (2011). Reaching the goal: The applicability and importance of the common core state standards to college and career readiness. (ERIC Document Reproduction Service No. ED 537 872)

Conley, D. T., \& McGaughy, C. (2012, April). College and career readiness: Same or different? Educational Leadership, 69(7), 28-34.

ConnectEd: California Center for College and Career. (2012, April 12). College and career readiness: What do we mean? A proposed framework. Berkeley, CA: Author.

Connell, J. I., Kubisch, A. C., Schorr, L. B., \& Weiss, C. H. (1995). New approaches to evaluating community initiatives: Concepts, methods, and contexts. Washington, DC: The Aspen Institute. 
Connolly, M., \& Seymour, E. (2010, January). Why theories of change matter. Mobilizing STEM Education for a Sustainable Future. Retrieved from http://mobilizingstem.wceruw.org/documents/jan09meet.html

Copa, G. H., \& Pease, V. H. (1992). The comprehensive high school: An historical perspective. Washington, DC: National Center for Research in Vocational Education.

Corbin, J., \& Strauss, A. (2006). Grounded theory research: Procedures, canons, and evaluative criteria. Thousand Oaks, CA: Sage.

Creswell, J. W. (2009). Research design: Qualitative, quantitative, and mixed methods approaches (3rd ed.). Thousand Oaks, CA: Sage.

Dewey, J. (2015). Democracy and education. Brooklyn, NY: Sheba Blake Publishing. (Original work published 1916).

Ellsworth, J. B. (2001). A survey of educational change models. (ERIC Document Reproduction Service No. ED 444 597).

Fitzpatrick, S. (n.d.). Fullan's educational change. [Images]. Retrieved from http://www.personal.psu.edu/wxh139/Fullan.htm

Fullan, M. G. (1991). The meaning of educational change. In M. G. Fullan (Ed.), The new meaning of educational change (pp. 30-46). New York, NY: Teachers College Press.

Fullan, M. G. (1993, March). Why teachers must become change agents. Educational Leadership, 50(6), 12-17.

Fullan, M. G. (1999). Change forces: The sequel. New York, NY: Routledge. 
Fullan, M. G. (2010). All systems go: The change imperative for whole system reform. Thousand Oaks, CA: Corwin.

Fullan, M. G. (2011). The six secrets of change. Hoboken, NJ: Jossey-Bass.

Fullan, M. G. (2012). Lead the change series: Q\&A with Michael Fullan. Retrieved from http://www.aera.net/Educational_Change_SIG.htm

Fullan, M., \& Boyle, A. (2013, April). Reflections on the change leadership landscape. National College for Teaching and Leadership. Retrieved from https://nationalcollege.org.uk/cm-mc-lci12-tp.pdf

Fullan, M., \& Langworthy, M. (2014). A rich seam: How new pedagogies find deep learning. London: Pearson.

Fullan, M., \& Smith, G. (1999, December). Technology and the problem of change. Retrieved from http://michaelfullan.ca/wpcontent/uploads/2016/06/13396041050.pdf

Fullan, M., \& Stiegelbauer, S. (1991). The new meaning of educational change. School Effectiveness and School Improvement, 2(4), 2-24.

Fusch, P. I., \& Ness, L. R. (2015). Are we there yet? Data saturation in qualitative research. The Qualitative Report, 20(9), 1408-1416. Retrieved from http://nsuworks.nova.edu/tqr/vol20/iss9/3

Given, L. M. (2008). The Sage encyclopedia of qualitative research methods. Thousand Oaks, CA: Sage. 
Grandin, T. (2014). The importance of hands-on learning. Retrieved from https://www.huffingtonpost.com/temple-grandin/the-importance-ofhandson_b_4086423.html

Guilfoyle, C. (2006, November). NCLB: Is there life beyond testing? Educational Leadership, 64(3), 8-13.

Hammack, F. M. (Ed.). (2004). The comprehensive high school today. New York, NY: Teachers College Press.

Haslam, S. A., Reicher, S. D., \& Reynold, K. J. (2012, March). Identity, influence, and change: Rediscovering John Turner’s vision for social psychology. British Journal of Social Psychology, 51(2), 201-218.

Hatch, J. A. (2002). Doing qualitative research in education settings. Albany, NY: State University of New York Press.

Hughes, K. L., Moore, D. T., \& Bailey, T. R. (1999, September). Work-based learning and academic skills. IEE Working Paper No. 15.

Hyland, T. (1993). Competence, knowledge, and education. Journal of Philosophy of Education, 27(1), 57-68.

Hyslop-Margison, E. J. (2000). An assessment of the historical arguments in vocational educational reform. Journal of Career and Technical Education, 17(1), 23-30.

ICF International. (2012). College and career readiness. Icfi.com. Retrieved from http://files.eric.ed.gov/fulltext/ED532588.pdf

Junior Achievement. (2010). The role of common core standards in college and careerreadiness education. Retrieved from juniorachievement.org 
Junior Achievement. (2016). The role of common core standards in college and careerreadiness education. Retrieved from https://www.juniorachievement.org/documents/20009/36541/The+Roll+of+Com mon+Core+Standards.pdf/274c78bd-2dd4-407f-9050-78243ef836e9

Keller, F. J. (1955). The comprehensive high school. The School Review, 63(9), 494-495.

Klink Thomas, M. J. (2008). Re-designing the high school library for the forgotten half. Westport, CT: Greenwood Publishing.

Koliba, C. (2000). Democracy and education schools and communities initiative conceptual framework and preliminary findings. Retrieved from http://www.uvm.edu/ dewey/articles/Democonc.html

Krueger, R. A., \& Casey, M. A. (2015). Focus groups: A practical guide for applied research. Thousand Oaks, CA: Sage.

Linked Learning. (2012, November). Work-based learning in linked learning: Definitions, outcomes, and quality criteria. Retrieved from http://casn.berkeley.edu/resource_files/WBL_Definitions_Outcomes_Criteria_pg _120512_v2.pdf

Lukas, I. (2013). The importance of mentorship. Huffington Post. Retrieved from http://www.achieve.org/publications/making-career-readiness-count Making career readiness count. (2014, May 28). Achieve. Retrieved from http://www.achieve.org/publications/making-career-readiness-count Maphosa, A. (2014). Work-based learning public seminar. CEIA National Congress \& Annual General Meeting Education for Purpose. 
Martin, R. L. (2007, June). How successful leaders think. Harvard Business Review. Retrieved from hbr.org/2007/06/how-successful-leaders-think

Mattern, K., Burrus, J., Camara, W., O’Connor, R., Hanson, M. A., Gambrell, J., ... \& Bobek, B. (2014). Broadening the definition of college and career readiness: A holistic approach. ACT Research Report Series 2014.

McLachlan, J. (2015, February 23). How a high school internship can help you save on college tuition. Retrieved from https://www.noodle.com/articles/how-a-highschool-internship-can-help-you-save-on-college-tuition

Meister, J. C., \& Willyerd, K. (2010, May). Mentoring millennials. Harvard Business Review. Retrieved from https://hbr.org/2010/05/mentoring-millennials

Merriam, S. B. (1998). Qualitative research and case study applications in education. San Francisco, CA: Jossey-Bass.

Mezirow, J. (1991). Transformative dimensions of adult learning. San Francisco, CA: Jossey-Bass.

Mondal, P. (2016). Educational system: The meaning, aspects and social functions of education. Retrieved from http://www.yourarticlelibrary.com/education/educational-system-the-meaningaspects-and-social-functions-of-education/8582/

Mourshed, M., Farrell, D., \& Barton, D. (2013). Education to employment: Designing a system that works. McKinsey Center for Government. Retrieved from http://www.mckinsey.com/industries/social-sector/our-insights/education-toemployment-designing-a-system-that-works 
Mueller, D., \& Gozali-Lee, E. (2013, April). College and career readiness: A review and analysis conducted for Generation Next. Retrieved from https://www.wilder.org/WilderResearch/Publications/Studies/Generation\%20Next/College\%20and\%20Career\% 20Readiness\%20\%20A\%20Review\%20and\%20Analysis\%20Conducted\%20for\%20Generation\%2 0Next.pdf

Myers, C. Mentorship is key to career success for young professionals. Retrieved from https://www.forbes.com/sites/chrismyers/2016/02/21/mentorship-is-key-to-careersuccess-for-young-professionals/\#b0db51921b8d

National Commission on Excellence in Education. (1983). A nation at risk: The imperative for educational reform. Washington, DC: Author. Retrieved from http://www2.ed.gov/pubs/NatAtRisk/index.html

Noddings, N. (2013). Education and democracy in the 21st century. New York, NY: Teacher College Press.

Northland Center for Advanced Professional Studies. Program overview. Retrieved from http://www.northlandcaps.org/s/1625/index.aspx?sid=1625\&gid=1\&pgid=383

OECD. (2013). Education at a glance 2013: OECD indicators. OECD Publishing. doi: http://dx.doi.org/10.1787/eag-2013-en

Onwuegbuzie, A. J., \& Leech, N. L. (2007). Sampling designs in qualitative research: Making the sampling process more public . The Qualitative Report, 12(2), 238254. Retrieved from http://nsuworks.nova.edu/tqr/vol12/iss2/7 
Owens, D. N. (2013, April 4). Technology in education: Key to college and career readiness. Classworks, Curriculum Advantage. Retrieved from http://www.classworks.com/uploads/research/Technology2013_KeytoCCR.pdf

Patton, M. Q. (2002). Qualitative research and evaluation methods. Thousand Oaks, CA: Sage.

Proefriedt, W. A. (2005, May 18). Revisiting James Bryant Conant: Realism, then and now. Education Week, 24(37), 30, 32.

Raelin, J. A. (2008, January). Work-based learning: Bridging knowledge and action in the workplace. San Francisco, CA: Jossey-Bass.

Reference: An IAC Publishing, LLC Company. (2016a). What does post-secondary education mean? Retrieved from https:/www.reference.com/education/postsecondary-education-mean-9f3ac9b397af04cd

Reference: An IAC Publishing, LLC Company. (2016b). What is the definition of “academic achievement?” Retrieved from https://www.reference.com/education/definition-academic-achievementd765166a90871dcd

Reforming No Child Left Behind. (2013). Retrieved from https://www.whitehouse.gov/issues/education/k-12/reforming-no-child-leftbehind

Robert Wood Johnson Foundation. (2008). Lincoln and Guba's evaluative criteria. Retrieved from http://www.qualres.org/HomeLinc-3684.html Rogers, E. (1962). Diffusion of innovation. New York, NY: Simon and Schuster. 
Rosenbaum, J. E., Miller, S. R., \& Scott Krei, M. (1996). Gatekeeping in an era of more open gates: High school counselors' views of their influence on students' college plans. American Journal of Education, 104(4), 257-279.

Samboldt, M., \& Balestreri, K. (2013, December). Considerations for collaborations to support college and career readiness: A facilitator's guide. Washington, DC: American Institutes for Research.

Scherer, M. (2015). The cardinal principles of secondary education. Retrieved from https://www3.nd.edu/ rbarger/www7/cardprin.html

Scott, J. L., \& Sarkees-Wircenski, M. (2004). Overview of career and technical education (3rd ed.). Homewood, IL: American Technical. Retrieved from http://cte.unt.edu/about

Seidman, I. (2006). Interviewing as qualitative research (3rd ed.). Teachers College Press. Available from Researchgate.net

Shenton, A. K. (2004). Strategies for ensuring trustworthiness in qualitative research projects. Education for Information 22, 63-75.

Sherington, G., \& Campbell, C. (2006). The comprehensive public high school. Retrieved from palgraveconnect.com

Smith, J. A., Flowers, P., \& Larkin, M. (2009). Interpretive phenomenological analysis: Theory, method, and research. London: Sage.

Soft skills. (2016). In Investopedia.com. Retrieved from http://www.investopedia.com/terms/s/soft-skills.asp 
Stake, R. E. (2005). Qualitative case studies. In N. K. Denzin \& Y. S. Lincoln (Eds.), The Sage handbook of qualitative research (3rd ed.) (pp. 443-466). Thousand Oaks, CA: Sage.

Stern, D., Dayton, C., \& Raby, M. (2010). Career academies: A proven strategy to prepare high school students for college and careers. Retrieved from http://files.eric.ed.gov/fulltext/ED524061.pdf

Studer, Q. (2017). Studer: Soft skills underrated in business culture. Special to The News Journal. Retrieved from http://www.pnj.com/story/money/2017/06/03/studercolumn-soft-skills-underrated-business-cultur/355049001/

Sturges, J. W., \& Rogers, R. W. (1996). Preventive health psychology from a developmental perspective: An extension of protection motivation theory. Health Psychology, 15(3), 158-166.

Sullivan, S., \& Baruch, Y. (2009). Advances in career theory and research: A critical review and agenda for future exploration. Journal of Management. doi: $10.1177 / 0149206309350082$

Tanner, D. (1982, May). The comprehensive high school in American education. Educational Leadership, 39(8), 606-613.

Tanner, D., \& Tanner, L. N. (1980). Curriculum development: Theory into practice. New York, NY: Macmillan.

ten Brummelhuis, A. C. A. (1995). Models of educational change: The introduction of computers in Dutch secondary education. Delden, NL: ten Brummelhuis. 
U.S. Department of Education. (n.d.). Every Student Succeeds Act. Retrieved from http://www.ed.gov/esea

U.S. Department of Education. (2009a). The condition of education 2009. Retrieved from http://nces.ed.gov/pubs2009/2009081.pdf

U.S. Department of Education. (2009b, November). Race to the top program executive summary. Retrieved from https://www.whitehouse.gov/the-press-office/factsheet-race-top

U.S. Department of Education. (2010, May). The condition of education 2010. Washington, DC: National Center for Education Statistics.

U.S. Department of Education. (2016). Career and technical education. Retrieved from http://www2.ed.gov/about/offices/list/ovae/pi/cte/index.html?exp=7

Wenger, D., \& Owens, L. C. (2013). An examination of job skills required by top U.S. broadcast news companies and potential impact on journalism curricula. Electronic News, 7(1) 22-35. doi: 10.1177/1931243113484314

Wimberly, G. L., \& Noeth, R. J. (2005). College readiness begins in middle school. Retrieved from www.act.org/research/policy/index.html

Wraga, W. G. (1994). Democracy's high school: The comprehensive high school and educational reform in the United States. Lanham, MD: University Press of America. 
Stephanie L. Moczygemba-Amaya was born February 13, 1968, in San Antonio, Texas. She graduated from Tom C. Clark High School in San Antonio in 1985. She then pursued undergraduate studies and was awarded a Bachelor of Social Work from the University of Central Missouri in 1996. She continued her academic pursuit, earning a Master in Social Work from the University of Kansas in 1998. Mrs. Amaya worked as a school social worker and therapist for five years. In 2002, she became a school counselor while earning an Education Specialist Degree in School Counseling from the University of Central Missouri in 2003. Mrs. Amaya worked as a school counselor in the public education setting for six years. She became a teacher/administrator for two years in 2008 while earning a Master of Science in Education. In 2010, Mrs. Amaya became a school principal, where she worked for the next four years. Since 2014, Mrs. Amaya works at the district level as the Director of Professional Studies in the Park Hill School District. Mrs. Amaya has spent more than 26 years in public education serving in multiple roles as a social worker, teacher, counselor and administrator.

Mrs. Amaya entered the University of Missouri at Columbia Educational Leadership and Policy Analysis Ed.D. Program with a passion for disrupting public education's current status quo. Upon completion of the doctoral program, Mrs. Amaya plans to continue working in public education and pursuing a superintendent position. 